LUIZ OCTÁVIO MASSATO KOBAYASHI

\title{
ABORDAGEM CRIPTOGRÁFICA PARA INTEGRIDADE E AUTENTICIDADE EM IMAGENS MÉDICAS
}

Tese apresentada à Escola Politécnica da Universidade de São Paulo para obtenção do Título de Doutor em Engenharia.

São Paulo 2007 

LUIZ OCTÁVIO MASSATO KOBAYASHI

\section{ABORDAGEM CRIPTOGRÁFICA PARA INTEGRIDADE E AUTENTICIDADE EM IMAGENS MÉDICAS}

Tese apresentada à Escola Politécnica da Universidade de São Paulo para obtenção do Título de Doutor em Engenharia.

São Paulo

2007 



\section{ABORDAGEM CRIPTOGRÁFICA PARA INTEGRIDADE E AUTENTICIDADE EM IMAGENS MÉDICAS}

Tese apresentada à Escola Politécnica da Universidade de São Paulo para obtenção do Título de Doutor em Engenharia.

Área de Concentração:

Sistemas Eletrônicos

Orientador:

Sergio Shiguemi Furuie

São Paulo

2007 
Este exemplar foi revisado e alterado em relação à versão original, sob responsabilidade única do autor e com a anuência de seu orientador.

São Paulo, 23 de novembro de 2007.

Luiz Octávio Massato Kobayashi

Sérgio Shiguemi Furuie

\section{FICHA CATALOGRÁFICA}

Kobayashi, Luiz Octavio Massato

Abordagem criptográfica para integridade e autenticidade em imagens médicas (Edição revisada) / L.O.M. Kobayashi. -- São Paulo, 2007. p.

Tese (Doutorado) - Escola Politécnica da Universidade de São Paulo. Departamento de Engenharia de Telecomunicações e Controle.

1. Diagnóstico por imagens 2. Imageamento (Bioengenharia) 3. Criptologia I. Universidade de São Paulo. Escola Politécnica. Departamento de Engenharia de Telecomunicações e Controle II. t. 


\section{AGRADECIMENTOS}

Primeiramente, Àquele que não possui Nome, mas é chamado por muitos nomes, por tudo o que tenho e o que sou.

Aos meus pais, por todo o amor, carinho e dedicação infinitos com que me criaram.

Ao amigo, orientador e diretor, Prof. Dr. Sérgio S. Furuie, pela confiança, paciência, apoio, incentivo e motivação constantes, bem como conselhos e sugestões inestimáveis dentro da vida acadêmica.

Ao Prof. Dr. Marco A. Gutierrez, por ter me aceito como aluno de iniciação científica sob sua orientação, conduzindo-me de forma magistral nos primeiros passos da minha formação acadêmica no InCor.

A todos os diretores, funcionários e estudantes do Serviço de Informática do Instituto do Coração. Em particular, a todos os funcionários e estudantes da Unidade de Pesquisa e Desenvolvimento, tanto atuais quanto passados: Cecil C. Robilotta, Julio C.B. Figueiredo, Marina F. S. Rebelo, Nivaldo Bertozzo Jr., Paulo E. Pilon, Gustavo H. B. M. Motta, Ramon A. Moreno, Marcelo dos Santos, Fabiane B. Nardon, Keith Takizawa, Keyla S. Urtiga, Pedro P. M. Oliveira Jr., Alice S. Bacic, Alexandre Murakami, Ângela V. Dias, Vivian Fiales, Fabio H. Palladino, Carlos S. Santos, Danilo M. Lage, Fernando J. S. Sales, João E. M. M. Silva, Juan L. P. Soto, Leandro A. Silva, Mauricio Higa, Mônica M. S. Matsumoto e Shridhar Jayanthi.

Ao Prof. Dr. Paulo S. L. M. Barreto, pela cortesia e generosidade em ter fornecido bibliotecas essenciais para a etapa de avaliação deste trabalho.

A todos os professores da Escola Politécnica da USP por terem contribuído para a minha formação.

Às secretárias e funcionários da Escola Politécnica da USP pela atenção e presteza no atendimento às minhas necessidades. 
Ao $\mathrm{CNPq}$ e à FINEP pelo auxílio financeiro que permitiu a realização deste trabalho de pesquisa.

Por fim, a todos os que colaboraram, direta ou indiretamente, para o bom desenvolvimento deste trabalho. 

"A jornada mais longa inicia-se com um simples passo." -- Lao Tzu, “Tao Te Ching” 



\section{SUMÁRIO}

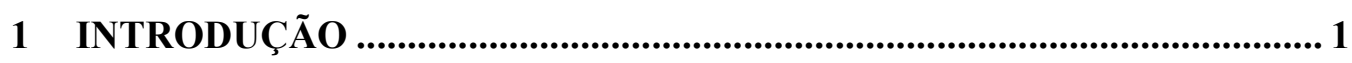

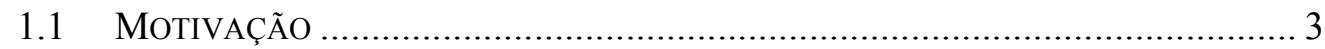

1.1.1 Aspectos ético-legais da segurança em imagens médicas ..................... 4

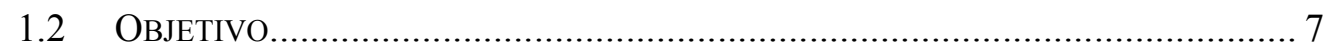

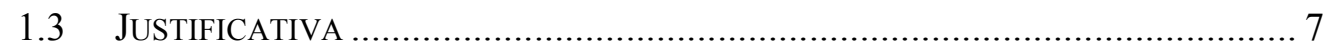

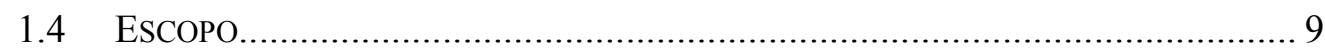

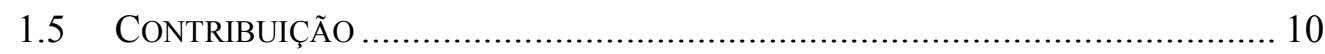

1.5.1 Acadêmica .................................................................................. 10

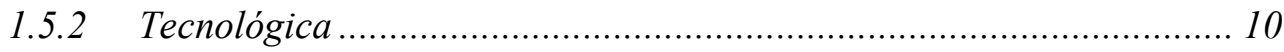

1.6 ORGANIZAÇÃO DO TRABALHO ………………………............................ 10

2 CONCEITOS E MÉTODOS ................................................................. 12

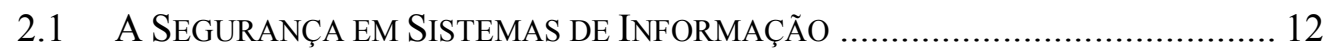

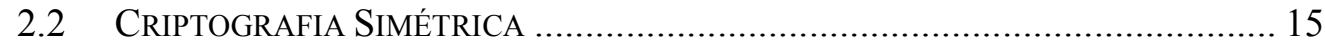

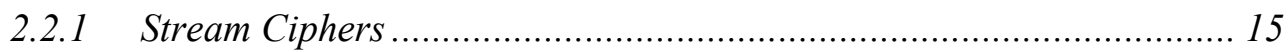

2.2.2 Block Ciphers (Cifras de Bloco) ....................................................... 15

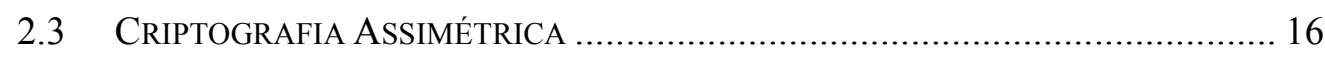

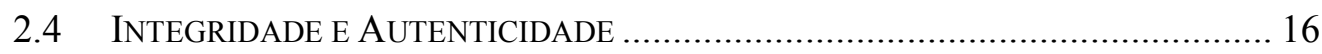

2.4.1 Resumos Criptográficos ou Message Digests .................................... 16

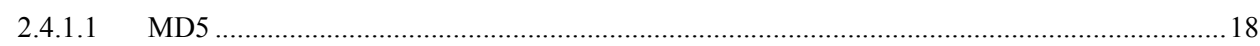

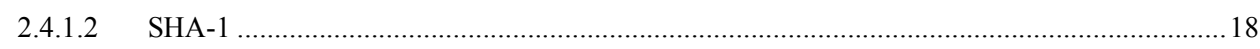

2.4.1.3 Whirlpool .............................................................................................................18

2.4.2 Assinatura Digital....................................................................... 19

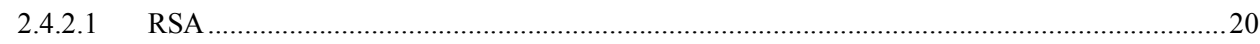

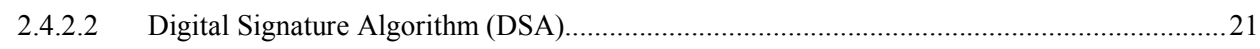

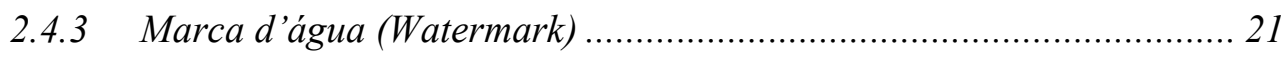

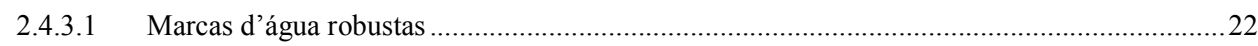

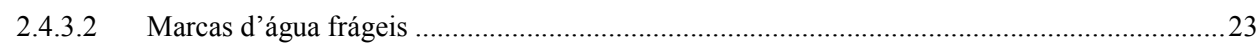

2.4.4 Classificação de técnicas de integridade e autenticidade de imagens médicas 23

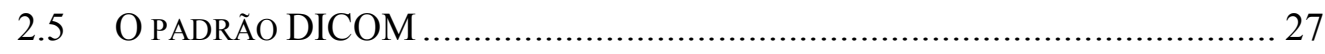

2.5.1 Parte 15 - Perfis de Segurança ....................................................... 27

2.6 CONSIDERAÇÕES SOBRE AS ABORDAGENS EXISTENTES ................................. 29 


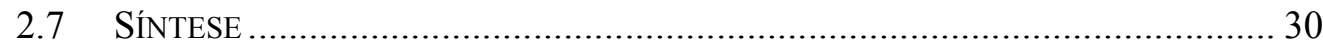

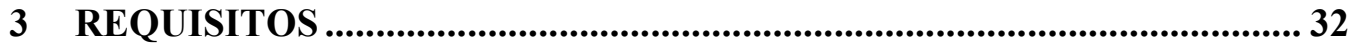

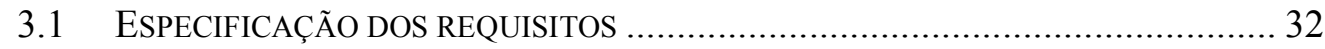

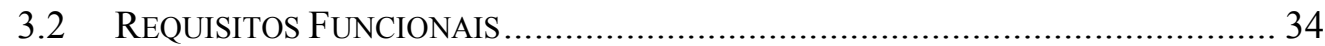

4 METODOLOGIA E IMPLEMENTAÇÃO_............................................ 36

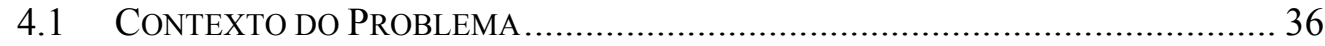

4.2 ModELAGEM DA INTEGRIDAdE E AUTENTICIDADE...................................... 39

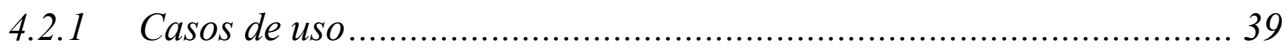

4.2.2 Diagramas IDEF0 nivel 1 ........................................................... 40

4.2.3 Diagramas de Classe e Seqüência.................................................. 41

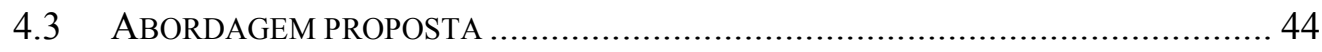

4.3.1 Atribuição de segurança ............................................................... 44

4.3.2 Verificação de segurança.............................................................. 45

4.3.3 Geração dos Dados de Segurança .................................................. 46

4.4 ALGORITMO PROPOSTO ..................................................................... 46

4.4.1 Atribuição de segurança ............................................................. 47

4.4.2 Verificação de segurança.............................................................. 47

4.4.3 Extensão para imagens multiframe ................................................ 48

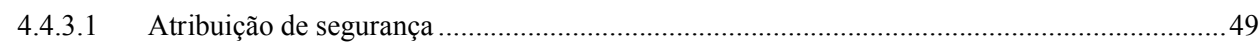

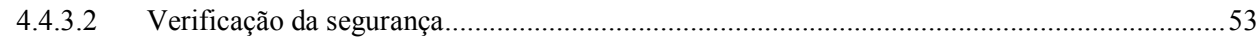

4.4.4 Considerações sobre a construção do algoritmo .............................. 55

4.4.4.1 Simplificações que introduzem potenciais vulnerabilidades no algoritmo ...............................58

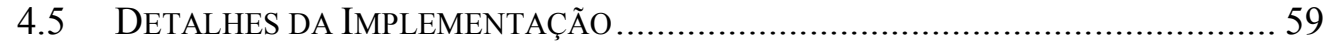

4.5.1 Pacote de segurança do Java ...................................................... 60

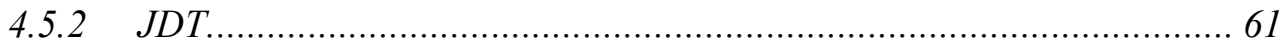

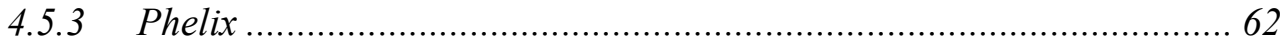

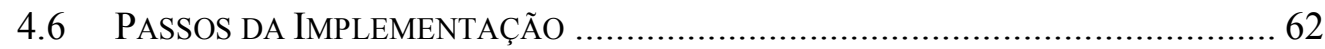

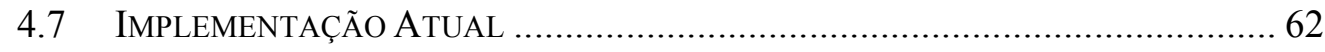

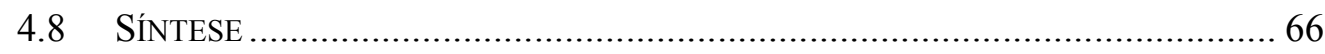

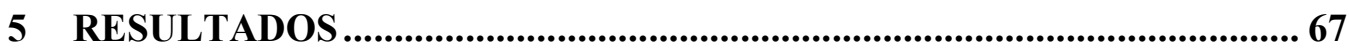

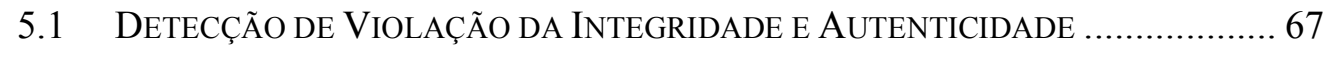

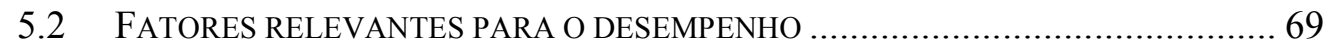


5.3 AVALIAÇÃO COMPARATIVA DE DESEMPENHO ............................................. 72

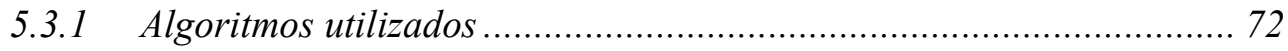

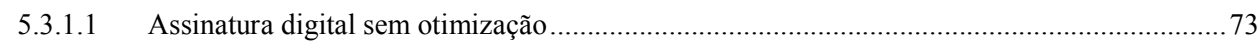

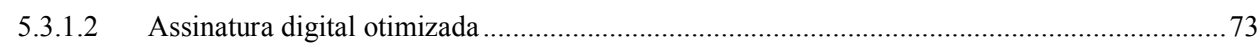

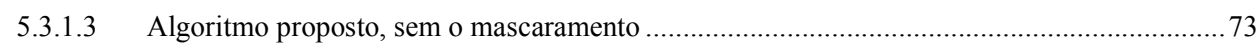

5.3.1.4 Algoritmo utilizando AES em Galois Counter Mode (GCM) .............................................. 73

5.3.1.5 Algoritmo de marca d'água com substituição no bit menos significativo (LSB) ....................75

5.3.1.6 Algoritmo de marca d'água utilizando wavelets de Haar ......................................................75

5.3.2 Resultados .............................................................................. 76

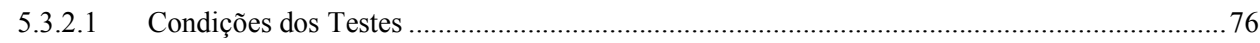

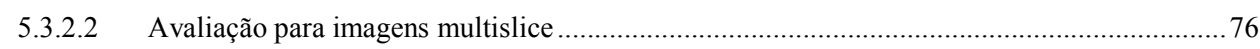

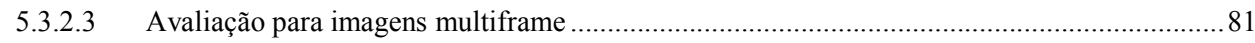

5.3.3 Considerações sobre o desempenho dos algoritmos ........................... 84

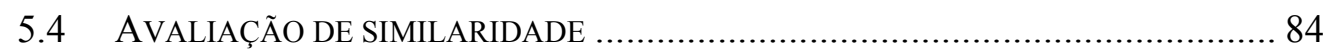

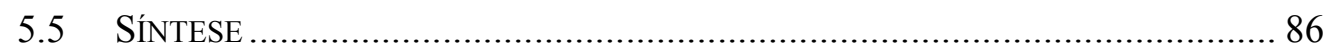

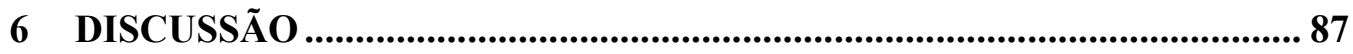

6.1 CONSIDERAÇÕES ACERCA DO ALGORITMO........................................... 88

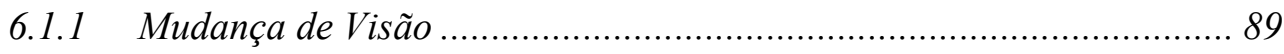

6.1.2 A Abordagem Proposta e o Padrão DICOM ..................................... 90

6.2 DiSCUSSÃO ACERCA DA IMPLEMENTAÇÃO ................................................... 90

6.3 CONCLUSÕES SUGERIDAS PELAS AVALIAÇÕES REALIZADAS ......................... 91

6.4 PossíVEIS EXTENSÕES E DeSAFIOS Futuros ............................................. 92

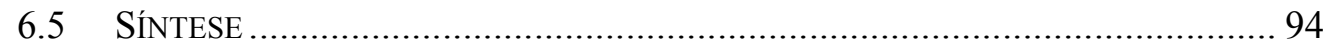

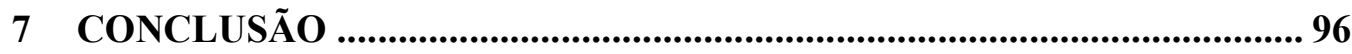

8 REFERÊNCIAS BIBLIOGRÁFICAS...................................................98

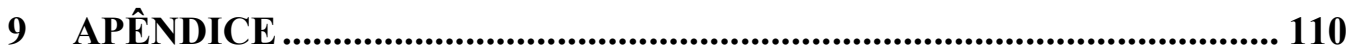

9.1 LISTA DE PUBLICAÇÕES DO DOUTORANDO............................................. 110

9.2 GlosSÁRIO DE TERMOS RELATIVOS À SEGURANÇA ................................. 112 


\section{LISTA DE FIGURAS}

Figura 1 - O esquema básico da criptografia assimétrica................................. 16

Figura 2 - A estrutura lógica típica para a geração de um resumo criptográfico...... 17

Figura 3 - Os processos de geração e verificação da assinatura digital................... 20

Figura 4 - O processo de adição de assinatura digital para o DICOM..................... 28

Figura 5 - O processo de verificação de assinatura digital para o DICOM............... 28

Figura 6 - O cálculo da assinatura digital das imagens no padrão DICOM. ............ 29

Figura 7 - Diagramas IDEF0 nível 0 para o sistema proposto.............................. 35

Figura 8 - O Registro Eletrônico de Saúde (RES) concentra várias informações

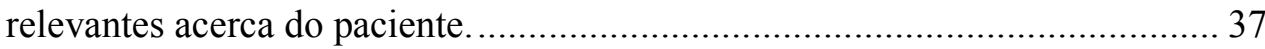

Figura 9 - Fluxo de aquisição, armazenamento e recuperação de imagens médicas em um típico estabelecimento de saúde....................................................... 38

Figura 10 - As possíveis entidades envolvidas no fluxo para a atribuição da

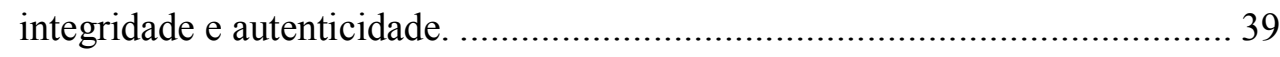

Figura 11 - As possíveis entidades envolvidas no fluxo para a verificação da

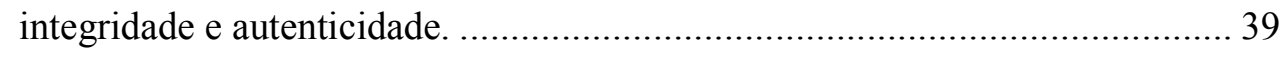

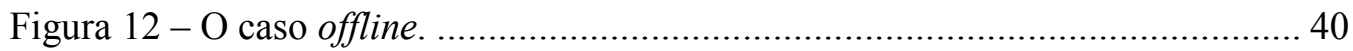

Figura 13 - O diagrama IDEF0 nível 1 para a atribuição de integridade e autenticidade.

Figura 14 - O diagrama IDEF0 nível 1 para a verificação de integridade e autenticidade.

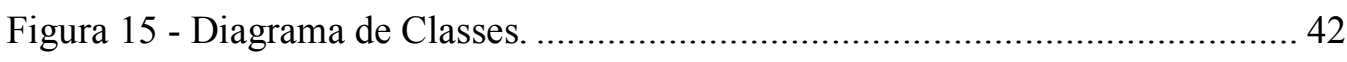

Figura 16 - Diagrama de Seqüência - Atribuição de Integridade............................ 43

Figura 17 - Diagrama de Seqüência - Verificação de Integridade........................... 43

Figura 18 - Abordagem proposta para atribuição de segurança............................. 44

Figura 19 - Abordagem proposta para verificação de segurança............................. 45

Figura 20 - Fluxo de adição de segurança. ......................................................... 47

Figura 21 - Fluxo de verificação de segurança. .................................................... 48

Figura 22 - Fluxo de adição de segurança. ........................................................ 49

Figura 23 - Fluxo detalhado da adição de segurança para imagens multiframe...... 50

Figura 24 - Detalhe do fluxo de adição de segurança. .......................................... 51

Figura 25 - Fluxo de verificação de segurança. ................................................... 53 
Figura 26 - Fluxo detalhado de verificação de segurança para imagens multiframe. 54

Figura 27 - Verificação propriamente dita da assinatura digital............................. 55

Figura 28 - A aplicação da segurança para a versão simplificada do algoritmo....... 57

Figura 29 - A verificação da segurança para a versão simplificada do algoritmo. ... 58

Figura 30 - Exemplo de uma imagem DICOM (acima) e os dados da assinatura digital em seu cabeçalho (abaixo).

Figura 31 - Exemplo de imagem multiframe (à esquerda) com os respectivos frames criptografados (à direita).

Figura 32 - O resultado da adulteração da imagem cifrada em um bit no segundo

frame. Da esquerda para a direita: a imagem original, sua versão cifrada, a adulteração em um bit e a imagem recuperada (decifrada).

Figura 33 - O resultado da adulteração da imagem cifrada em um bit no último

frame. Da esquerda para a direita: a imagem original, sua versão cifrada, a adulteração em um bit e a imagem recuperada (decifrada).

Figura 34 - Fatores atuantes na cifração. ...................................................... 70

Figura 35 - Fatores atuantes na decifração. .................................................. 71

Figura 36 - Gráfico ilustrativo mostrando o perfil de algumas modalidades em termos de armazenamento a cada estudo realizado. 72

Figura 37 - Obtenção da chave e do vetor de inicialização para AES em modo GCM.

75

Figura 38 - Tempo gasto para aplicação dos mecanismos de segurança em imagens multislice. 78

Figura 39 - Tempo gasto para aplicação dos mecanismos de segurança em imagens multislice para os quatro algoritmos de melhor desempenho. 78

Figura 40 - Tempo gasto para verificação dos mecanismos de segurança em imagens multislice. 80

Figura 41 - Tempo gasto para verificação dos mecanismos de segurança em imagens multislice para os quatro algoritmos de melhor desempenho. 80

Figura 42 - Tempo gasto para aplicação dos mecanismos de segurança em imagens multiframe. 82

Figura 43 - Tempo gasto para aplicação dos mecanismos de segurança em imagens multiframe para os cinco algoritmos de melhor desempenho. 
Figura 44 - Tempo gasto para verificação dos mecanismos de segurança em imagens

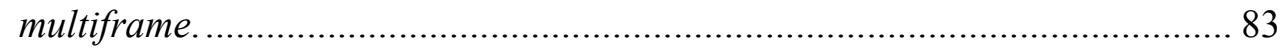

Figura 45 - Tempo gasto para verificação dos mecanismos de segurança em imagens multiframe para os cinco algoritmos de melhor desempenho..

Figura 46 - Figura que compara o resultado da cifração. À esquerda, a imagem original. Ao centro, a imagem cifrada de acordo com o algoritmo completo e à direita, cifrada sem o mascaramento. ............................................................ 92 


\section{LISTA DE TABELAS}

Tabela 1 - Média da correlação para as imagens sem criptografia. ....................... 85

Tabela 2 - Média da correlação para as imagens criptografadas. .......................... 85

Tabela 3 - Média da correlação entre as imagens originais e as imagens

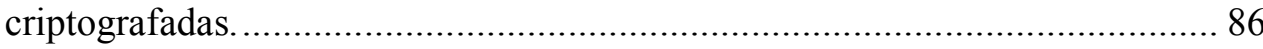

Tabela 4 - Comparação da abordagem proposta com as alternativas existentes....... 87 


\section{LISTA DE SÍMBOLOS E ABREVIATURAS}

$24 \times 7 \quad 24$ horas por dia, 7 dias por semana

ACR American College of Radiology

AES Advanced Encryption Standard

ANSI American National Standards Institute

API Application Programming Interface

CA Certificate Authority

CT Computed Tomography

DES Data Encryption Standard

DICOM Digital Imaging and COmmunications in Medicine

DSA Digital Signature Algorithm

DSS Digital Signature Standard

ECDSA Ellyptic Curve Digital Signature Algorithm

FIPS Federal Information Processing Standards

GCM Galois Counter Mode

HIPAA Health Insurance Portability and Accountability Act

IETF Internet Engineering Task Force

IMIA International Medical Informatics Association

ICP Infra-Estrutura de Chaves Públicas

IEC International Electrotechnical Committee

InCor Instituto do Coração

ISO Internation Organization for Standardization

IVUS IntraVascular UltraSound

J2EE Java2 Enterprise Edition

JCA Java Cryptographic Architecture

JCE Java Cryptographic Extension

JDK Java Development Kit

JDT Java DICOM Tools

JPEG Joint Photographic Experts Group

LKB Algoritmo proposto neste trabalho

LKB Light Versão simplificada do algoritmo proposto neste trabalho 


$\begin{array}{ll}\text { LSB } & \text { Least Significant Bit } \\ \text { MAC } & \text { Message Authentication Code } \\ \text { MB } & \text { Megabytes } \\ \text { MD5 } & \text { Message Digest 5 } \\ \text { MMAC } & \text { Master Message Authentication Code } \\ \text { MR } & \text { Magnetic Resonance } \\ \text { NBR } & \text { Norma Brasileira } \\ \text { NEMA } & \text { National Electrical Manufacturers Association } \\ \text { NIST } & \text { National Institute of Standards and Technology } \\ \text { NM } & \text { Nuclear Medicine } \\ \text { NSA } & \text { National Securiy Agency } \\ \text { PACS } & \text { Picture Archiving and Communication System } \\ \text { PEP } & \text { Prontuário Eletrônico do Paciente } \\ \text { PKI } & \text { Public Key Infrastructure } \\ \text { RES } & \text { Registro Eletrônico do Paciente } \\ \text { RIU } & \text { Ratio Image Uniformity } \\ \text { ROI } & \text { Region Of Interest } \\ \text { RLE } & \text { Run Length Encoding } \\ \text { S } & \text { Segundo(s) } \\ \text { SDK } & \text { Standard Development Kit } \\ \text { SHA } & \text { Secure Hash Algorithm } \\ \text { S/MIME } & \text { Secure Multipurpose Internet Mail Extensions } \\ \text { SOP } & \text { Service-Object Pair } \\ \text { SSL } & \text { Secure Sockets Layer } \\ \text { TTP } & \text { Trusted Third Party } \\ \text { UID } & \text { Unique IDentifier } \\ \text { UML } & \text { Unified Modeling Language } \\ \text { US } & \text { UltraSound } \\ \text { X-ray Angiography } \\ \text { XXclusive OR (OU exclusivo) } \\ \text { XAR }\end{array}$




\section{RESUMO}

KOBAYASHI, L. O. M. Abordagem criptográfica para autenticidade e integridade em imagens médicas. 2007. Tese (Doutorado) - Escola Politécnica, Universidade de São Paulo, São Paulo, 2007.

Cada vez mais, a infra-estrutura de segurança está assumindo um lugar de destaque na área de saúde, para garantir fatores críticos como confidencialidade, autenticidade, integridade, irretratabilidade e auditoria. Em particular, a integridade e a autenticidade de imagens médicas são fatores bastante críticos, na medida em que fornecem mecanismos para evitar e minimizar a adulteração de informações acerca do paciente, auxiliando a prevenir erros que podem causar prejuízos de ordem física e moral ao paciente. Entretanto, os trabalhos apresentados até agora nesta área apresentam limitações que devem ser solucionadas. Este trabalho tem por objetivo propor uma solução baseada em métodos criptográficos para prover autenticidade e integridade de imagens médicas, visando o uso em um ambiente real de Saúde. A partir da solução conceitual criada, foi proposto e codificado um algoritmo para atribuição e verificação da segurança nas imagens, para atender aos requisitos especificados. A implementação foi feita com sucesso, e testes comparativos de desempenho revelaram que o algoritmo possui uma boa relação custo-benefício, oferecendo um grau adicional de segurança à assinatura digital sem acarretar uma perda de performance significativa. É importante ressaltar que a abordagem proposta neste trabalho abre uma outra alternativa em termos de segurança, onde um usuário só poderá visualizar imagens que estejam íntegras e autênticas. Contudo, isso traz consigo uma vulnerabilidade, onde há uma facilidade maior para a destruição de dados, bastando introduzir uma adulteração mínima. Esse aspecto certamente deve ser levado em conta para implementações em ambiente de produção. A solução proposta é compatível com a arquitetura do padrão DICOM, podendo ser incorporado facilmente como extensão do padrão sem gerar dados adicionais a serem armazenados. Como passos futuros, deve-se otimizar o desempenho, bem como realizar avaliações quantitativas e qualitativas dentro de um ambiente de produção.

Palavras-chave: Segurança, Autenticidade, Integridade, Imagens médicas. 


\begin{abstract}
KOBAYASHI, L. O. M. A cryptographic approach to achieve authenticity and integrity in medical images. 2007. Doctorate Thesis - Escola Politécnica, Universidade de São Paulo, São Paulo, 2007.

The importance of the security infrastructure in the healthcare field is increasingly growing, in order to provide critical features like confidentiality, authenticity, integrity, non-repudiation and auditing. Among them, authenticity and integrity are critical factors regarding the medical images, since they provide mechanisms to avoid and minimize modifications in the patient information, helping to prevent mistaken diagnosis that could potentially cause physical and moral damage to the patient. However, the works so far available present several limitations that must be addressed. The purpose of this work is to propose a cryptographic solution to provide authenticity and integrity of medical images, envisioning its use in a real healthcare environment. Based on the conceptual solution, an algorithm was devised and implemented to add and verify the two aforementioned security services. The implementation was done in a successful fashion and comparative performance tests showed that the proposed algorithm offers a good cost-benefit ratio, offering an addicional layer of security without compromising performance in a significative degree. It's important to emphasize the fact that the approach devised in this work opens a new paradigm, where a user will only see images that haven't been tampered with. On the other hand, this brings along a potential vulnerability, making it easier to destroy patient data by introducing the slightest adulteration. This issue must be taken into account when deploying this solution in a real environment. Also, the proposed solution is based on the DICOM architecture, making it easier for deployment as an extension, without any storage overhead. For the next steps, performance must be optimized and evaluation, both quantitative and qualitative, must be done in a production environment.
\end{abstract}

Keywords: Security, Authenticiy, Integrity, Medical images. 


\section{Introdução}

"A long time ago, in a galaxy far, far away..."

STAR WARS - A NEW HOPE

\section{Resumo deste Capítulo}

- breve descrição do panorama de sistemas de informação na área da saúde

- motivação deste trabalho

- objetivo, justificativa e escopo

- contribuições deste trabalho

- organização desta obra

A saúde é uma das necessidades mais fundamentais da sociedade e, portanto, está intimamente presente na sociedade moderna, como atesta o Artigo XXV da Declaração Universal dos Direitos Humanos (ORGANIZAÇÃO DAS NAÇÕES UNIDAS, 1948), que contempla o direito do ser humano de ter acesso à saúde e aos cuidados médicos.

No século XIX, surgiu o conceito de prontuário médico. Na época, basicamente era um conjunto altamente personalizado de anotações em papel que os clínicos usavam para registrar as suas observações e planos para que pudessem se lembrar dos detalhes mais importantes quando o paciente voltasse para uma nova consulta. Não havia requisitos de ordem burocrática, não havia a intenção de usar tais registros para o intercâmbio de informações entre vários provedores de saúde e os registros eram bastante simples, com poucos dados e testes.

Entretanto, esse prontuário primitivo, que atendia às necessidades do corpo clínico cem anos atrás, teve que evoluir para atender a novos requisitos com a mudança ocorrida na Medicina e na área da Saúde como um todo. 
Com a introdução das modernas tecnologias de informação e comunicação no campo médico, houve a gradual evolução de prontuários em papel para Registros Eletrônicos de Saúde (RES) do paciente. Shortliffe (1998) aponta a crescente percepção das ineficiências e frustrações associadas com o uso de registros médicos baseados em papel, especialmente quando o acesso inadequado a informações clínicas é uma das principais barreiras que os clínicos encontram quando tentam aumentar sua eficiência para atender a metas de produtividade.

Hoje, a tecnologia de informação permeia todos os sistemas de um hospital. Mesmo em um centro de tamanho médio, os visitantes travam contato com o sistema de admissão, que rastreia não somente a admissão de pacientes e dos tratamentos dispensados, mas também monitora a disponibilidade de leitos e infra-estrutura.

Em determinados setores, existe um conjunto de terminais para a equipe de enfermagem, visando a monitoração de sinais vitais usando dados coletados por equipamentos presentes em cada quarto. Os farmacêuticos liberam prescrições, verificam interações de drogas e mantém um controle de inventário usando sistemas on-line para farmácia. Em alguns centros, médicos utilizam-se da telemedicina para diagnosticar e tratar pacientes em locais remotos.

E, entre os centros, os registros de saúde e o sistema de cobrança rastreiam a evolução do paciente e provêem os dados necessários para seguradoras de saúde. Dwivedi et al (2003) apontam até mesmo para uma disseminação transnacional dos registros médicos do paciente através do acesso Web.

Entretanto, essa grande quantidade de informações a ser adquirida, armazenada, processada e gerenciada levanta uma questão bastante delicada, que é a questão da segurança dos dados e da privacidade do paciente, que remonta desde a Antigüidade com o Juramento de Hipócrates (JURAMENTO DE HIPÓCRATES, 2004). Raghupathi e Tan (2002) lembram que o prospecto de armazenar informações de saúde na forma eletrônica suscita discussões acerca de padrões, ética, privacidade, confidencialidade e segurança.

A falta de controles apropriados, procedimentos e políticas pode levar tais sistemas a tentarem usuários não autorizados a acessar e até mesmo utilizar de forma inadequada as informações associadas com usuários legítimos. Se tais preocupações não forem discutidas, a indústria da saúde pode ser desencorajada a usar as ferramentas de tecnologia da informação e os consumidores de saúde irão hesitar em 
compartilhar as suas informações médicas pessoais. Assim sendo, cada vez mais a segurança está assumindo um lugar de destaque na área de saúde, para garantir fatores críticos como autenticidade, integridade, confidencialidade, irretratabilidade e auditoria das informações.

Em particular, as imagens médicas merecem especial atenção, na medida em que podem ser informações de grande complexidade e importância para diagnóstico, tratamento e pequisa médica. Desta forma, torna-se necessário criar mecanismos de segurança apropriados para que as imagens não possam ser armazenadas, processadas e visualizadas de maneira incorreta.

\subsection{Motivação}

O serviço mais importante de segurança no tocante ao armazenamento, processamento e transmissão de imagens médicas é a integridade, isto é, a garantia de que os dados não foram adulterados e de que não houve nenhuma perda de informação. A integridade das imagens médicas é de importância crucial em um sistema médico na medida em que um erro, seja culposo ou doloso, pode dificultar um diagnóstico preciso.

Hamilton (1992) aponta que este aspecto da integridade se torna mais importante à medida que as tarefas são automatizadas, pois uma menor participação do ser humano no processo irá reduzir a chance de que se descubram erros no processamento e gerenciamento de dados antes que seja tarde demais. E tais erros podem levar a um diagnóstico errado, que pode afetar seriamente a saúde, o convívio social e a empregabilidade do paciente.

A integridade das imagens médicas está intimamente relacionada com a sua autenticidade, ou seja, a correta determinação da autoria das imagens. Rector, Nolan e Kay (1991) ressaltam a importância da fidelidade das informações contidas em um registro médico, exigindo naturalmente a imputabilidade das observações contidas no registro ao seu respectivo agente.

Nos sistemas de hoje em dia, a assinatura do médico é um método eficaz de verificar que eles entraram com a informação, requisitaram procedimentos ou concordaram com a informação que os outros entraram. Mesmo se as notas forem 
ditadas e cadastradas por um membro da equipe em nome do médico, uma assinatura escrita pode verificar que o médico leu e concordou com a informação.

Desta forma, as assinaturas oferecem um mecanismo para prover autenticidade, indicando reponsabilidade, e mostrando permissão e compreensão (e.g., permissão pelo médico para a dispensa de medicamentos ou autorização de um procedimento, permissão do paciente para permitir um procedimento).

Para que um sistema médico envolvendo assinaturas seja computadorizado, deve haver um mecanismo para prover uma funcionalidade idêntica e com a mesma facilidade encontrada no uso de assinaturas em papel. Este mecanismo deve ser confiável e verificável, além de ser aplicável tanto para o armazenamento quanto para a transmissão de dados. Caso contrário, as leis irão proibir o seu uso, assim como alguns estados norte-americanos não aceitam o uso de carimbos de assinatura como sendo válidos. Aplicações futuras em telemedicina, como a observação médica dos pacientes em suas casas para reduzir o período de internação (BLEUMER, 1994), podem aumentar ainda mais a importância deste aspecto.

Um pré-requisito essencial é a existência de uma ligação forte entre a assinatura e a informação. Para documentos de papel, não é simples remover ou adulterar a assinatura sem deixar nenhum vestígio. Esta propriedade deve ser transportada para o ambiente eletrônico, configurando-se na ligação forte citada. Em outras palavras, mesmo em um ambiente digital, não deve ser trivial remover e/ou adulterar a assinatura digital sem deixar algum tipo de vestígio. Esse é um desafio bastante grande, considerando-se a facilidade e a precisão com que as informações digitais podem ser manipuladas.

\subsubsection{Aspectos ético-legais da segurança em imagens médicas}

As características ético-legais da prática médica são de suma importância dentro da segurança em saúde, incluindo-se os sistemas digitais de saúde, pois possuem peculiaridades próprias da área, recebendo uma ênfase bastante pronunciada pelos profissionais da saúde.

O segredo médico, no qual estão contidas a integridade e a autenticidade das informações médicas, é bastante antigo e vem desde o Juramento de Hipócrates, datado do século V a.C., que diz claramente: "àquilo que no exercício ou fora do exercício da profissão e no convívio da sociedade, eu tiver visto ou ouvido, que não 
seja preciso divulgar, eu conservarei inteiramente secreto" (JURAMENTO DE HIPÓCRATES, 2004).

A Associação Médica Mundial adotou várias declarações no tocante ao segredo médico, a começar pela Declaração de Lisboa (ASSOCIAÇÃO MÉDICA MUNDIAL, 1981), que define os direitos do paciente, incluindo o direito à confidencialidade sobre qualquer informação sobre o estado de saúde do paciente, explicitando a necessidade de proteção de todos os dados identificáveis do paciente de acordo com seu arquivamento apropriado.

Mas os primeiros esforços nesse sentido surgem já em 1973, com a Declaração de Munique (ASSOCIAÇÃO MÉDICA MUNDIAL, 1973), que versa sobre o uso de computador na medicina, propondo esforços conjuntos para assegurar a privacidade, a segurança e a confidencialidade de informação dos seus pacientes. Esta declaração foi posteriormente complementada pela Declaração de Tel Aviv (ASSOCIAÇÃO MÉDICA MUNDIAL, 1999), que definiu a posição da comunidade médica internacional com relação à telemedicina, estabelecendo que as regras do consentimento esclarecido e da confidencialidade do paciente também devem ser aplicadas para o exercício da medicina à distância.

Ao mesmo tempo, em 1999 o Conselho da Europa aprovou a Convenção para a Proteção dos Direitos do Homem e da Dignidade do Ser Humano face às Aplicações da Biologia e da Medicina (CONSELHO DA EUROPA, 1999), cujo capítulo III, artigo 10, estabelece claramente o direito à privacidade de qualquer pessoa sobre as informações sobre sua saúde. E, nos Estados Unidos, foi aprovado em 1996 o Health Insurance Portability and Accountability Act (HIPAA), que estabelece uma série de diretrizes para o âmbito da saúde, incluindo-se a integridade e autenticidade das informações.

No âmbito nacional, o segredo das informações do paciente é um direito assegurado pelo artigo 5, inciso X, da Constituição Federal de 1988 (BRASIL, 2001), que garante a inviolabilidade da intimidade, da vida privada, da imagem e da honra das pessoas. Diretrizes mais específicas foram estabelecidas pela Portaria do Ministério da Saúde nº1286, de 1993, (BRASIL, 1993) definindo mais claramente o direito do paciente acerca da manutenção dos seus segredos. Mais recentemente, foi proposto também o Projeto de Lei PL-20/2003 (BRASIL, 2003) que versa sobre o mesmo assunto, com uma menção explícita ao prontuário eletrônico, que pode ser 
considerado como instrumento de evidência legal de acordo com o artigo 225 do novo Código Civil (BRASIL, 2001).

Deve-se lembrar também que existem esforços sobre a proteção de dados pessoais de um modo geral, nos quais se incluem os dados sobre a saúde. Por exemplo, estão em trâmite os Projetos de Lei PL-3494/2000 (BRASIL, 2000), que obriga a tomada de medidas de segurança adequadas contra o acesso não autorizado, modificação, revelação ou destruição de tais dados, e o Projeto PL-6981/2002 (BRASIL, 2002), que estipula a exatidão no tratamento dos dados pessoais.

Dentro da comunidade médica nacional, o Conselho Regional de Medicina do Estado de São Paulo publicou em 2001 (CONSELHO REGIONAL DE MEDICINA DO ESTADO DE SÃO PAULO, 2001) a Resolução CREMESP nº 97, tratando sobre a privacidade na rede. E o Conselho Federal de Medicina baixou em 2002 (CONSELHO FEDERAL DE MEDICINA, 2002) a Resolução CFM nº 1639/2002, que estabelece normas técnicas para o uso de sistemas informatizados para a guarda e manuseio do prontuário médico, incluindo-se aí a necessidade de manter a integridade da informação e da autenticação.

Em termos de ética, o Código de Ética Médica (CONSELHO FEDERAL DE MEDICINA, 1988) afirma no Art. 11 sobre o sigilo do médico quanto às informações confidenciais de que tiver conhecimento no desempenho de suas funções, estabelecendo outras diretrizes sobre o mesmo tema também no Capítulo IX.

Paralelamente ao Código de Ética Médica, a International Medical Informatics Association (IMIA) definiu um Código de Ética para Profissionais de Informática em Saúde que engloba dois princípios, sobre privacidade e sobre segurança. Neste Código, há diretrizes para que os profissionais de informática em saúde assegurem que os registros eletrônicos, incluindo imagens médicas, sejam armazenados, acessados, utilizados, manipulados ou transmitidos somente para fins legítimos. Tais profissionais devem assegurar também a existência de protocolos e mecanismos para monitorar a manipulação de dados contidos nos prontuários, incluindo-se um controle rigoroso sobre a integridade e a autenticidade dos dados. (IMIA, 2004).

Em termos jurídicos, cabe ressaltar que existem ainda muitos outros aspectos que devem ser considerados no contexto da saúde, tais como a responsabilidade civil 
relativa a instituições e profissionais da área de saúde, como é discutido por Moreira Filho (2002), Souza (2002a, 2002b) e Cintra (2004).

\subsection{Objetivo}

O objetivo principal deste trabalho é propor uma nova abordagem, utilizando mecanismos de criptografia da imagem, para conferir integridade e autenticidade fortes para imagens médicas.

O objetivo acima pode ser expandido em vários objetivos mais detalhados, quais sejam:

1) fornecer mecanismos fortes para garantir a segurança de informações clínicas, por meio de:

- Integridade de Conteúdo

- Autenticidade (Controle de autoria)

2) desenvolver a partir de algoritmos criptográficos um novo algoritmo, simples e robusto, para a adição dos serviços de segurança almejados;

3) mostrar a viabilidade da implementação, visando uma utilização eficaz em um ambiente hospitalar, utilizando-se da arquitetura proposta no padrão DICOM (Digital Imaging and Communications in Medicine);

4) propor métodos de avaliação da implementação, com ênfase no desempenho.

\subsection{Justificativa}

Apesar da importância que a integridade e a autenticidade de imagens médicas possuem, existe um número surpreendentemente baixo de trabalhos publicados sobre o tema. Além disso, as abordagens existentes atualmente possuem limitações, o que suscita a necessidade de pesquisas e desenvolvimento de alternativas para solucioná-las.

Talvez o trabalho pioneiro na área seja de Wong (1995), mas existe um intervalo de tempo considerável até que mais trabalhos sobre o tema fossem publicados. Somente a partir de 1999, com Macq e Dewey (1999), que propõem a inserção de informações de integridade do cabeçalho da imagem embutidas dentro da própria imagem, é que começaram a surgir mais trabalhos de interesse na área. 
Existem atualmente duas formas de garantir a integridade e autenticidade: a primeira se baseia em marcas d'água embutidas na própria imagem e a segunda se baseia em metadados anexos à imagem original.

Observa-se uma tendência maior em utilizar marcas d'água para assegurar a integridade de imagens médicas, que é uma abordagem proposta por Coatrieux et al. (2000, 2001) para conferir um grau adicional de segurança em imagens. Zhou e Huang (2001) apresentam um método utilizando envelopes digitais, que consistem de assinaturas digitais criptografadas, para conferir autenticidade e integridade para imagens de mamografia.

Este método foi aperfeiçoado em Cao, Huang e Zhou (2003), com o armazenamento do envelope digital em partes não importantes da imagem, adicionando-se também a compatibilidade com o padrão DICOM e o uso para imagens de diferentes modalidades. Por outro lado, Trichili et al. (2002) optaram por criar uma borda virtual para guardar a marca d'água em imagens DICOM ao invés de embutir os dados na própria imagem.

Abordagens similares de marca d'água também são apresentadas por U.R.A et al. (2003) e Miaou et al. (2000), onde dados do paciente são codificados adequadamente e a marca d'água é utilizada para esconder tais dados no bit menos significativo da imagem. Um método mais sofisticado é proposto por Wakatani (2002), com o uso de wavelets para assinar a região de interesse (ROI) da imagem com uma outra imagem, armazenando-a na região próxima à ROI.

Por outro lado, a abordagem utilizando metadados é explorada por Bernarding, Thiel e Grzesik (2001), confiando-se no cabeçalho DICOM para a criptografia dos dados. Similarmente, Kroll et al. (2003) apresentam um sistema que implementa a integridade e a autenticidade na imagem médica através de assinatura digital, de acordo com a parte 15 do padrão DICOM, com uma "caixa preta" que recebe as imagens da modalidade, assina-as e envia-as ao servidor.

Tanto a marca d'água quanto o uso de metadados possuem limitações. Embora permita uma ligação forte entre a imagem e a assinatura digital, a marca d'água é uma abordagem que, por definição, implica em uma adulteração na imagem, o que pode trazer dúvidas sobre o seu aproveitamento em um ambiente de saúde (LYNCH, 2000). 
Por outro lado, o uso de metadados não adultera as informações, mas não provê uma ligação forte como a marca d'água. Desta forma, é bastante interessante desenvolver soluções que ofereçam todas as vantagens dos dois métodos supracitados, ao mesmo tempo em que resolvam as limitações descritas.

Um aspecto importante a ser observado é de que as duas abordagens acima adotam a integridade e autenticidade como serviços opcionais de segurança. Em outras palavras, sem um mecanismo específico que contemple os dois serviços, um usuário poderia muito bem basear as suas decisões em imagens incorretas. É interessante que exista um meio mais forte de garantir que a imagem visualizada não tenha sido adulterada.

Um outro aspecto a ser ressaltado é a falta de preocupação das soluções com relação ao desempenho. Hamilton (1992) lembra que a implementação de algoritmos de autenticidade e integridade tem um custo em termos de desempenho e a demora no processamento pode piorar a percepção da facilidade de uso do sistema por parte do usuário final.

Desta forma, pode-se concluir que existem desafios a serem superados para uma implementação eficaz de integridade e autenticidade de imagens médicas.

\subsection{Escopo}

Existe uma vastidão de aspectos de segurança a serem considerados sobre aplicações médicas. Dentro deste trabalho, limitou-se o escopo a preocupações sobre segurança em nível de aplicação, em particular sobre os aspectos de integridade e autenticidade. Alguns aspectos bastante importantes de segurança não são discutidos neste trabalho, mas não há a intenção de se diminuir a sua importância. Exemplos dos aspectos importantes, mas não discutidos, são confidencialidade, controle de acesso, políticas e procedimentos de segurança, treinamento, segurança física, garantia de qualidade de serviço e facilidade de uso. Um panorama bastante interessante dos aspectos de proteção de dados em informática médica pode ser encontrado em Pfitzmann e Pfitzmann (1992). 


\subsection{Contribuição}

\subsubsection{Acadêmica}

Sob o aspecto acadêmico, as possíveis contribuições derivadas deste trabalho são:

- Proposta de um novo algoritmo para incorporar segurança em termos de integridade e autenticidade para imagens médicas no formato DICOM;

- Demonstração da viabilidade da implementação do algoritmo;

- Proposta de métodos de avaliação para a abordagem proposta.

\subsubsection{Tecnológica}

Com relação ao aspecto tecnológico, este trabalho deve gerar:

- Implementação do algoritmo, com geração do software correspondente para integridade e autenticidade para imagens no formato DICOM;

- Métodos para avaliação da eficácia da solução.

\subsection{Organização do trabalho}

Este trabalho está organizado da seguinte forma:

- Capítulo 2: delineia os aspectos gerais de segurança de informação e oferece uma visão geral dos principais mecanismos dos dois serviços de segurança e uma classificação dos métodos. Além disso, apresenta o contexto DICOM para a área de segurança.

- Capítulo 3: define os requisitos necessários para a solução almejada.

- Capítulo 4: apresenta a solução proposta e os principais detalhes da implementação, discorrendo também sobre as ferramentas utilizadas.

- Capítulo 5: mostra os principais resultados obtidos, oferecendo os subsídios necessários para a discussão levada a cabo no capítulo seguinte.

- Capítulo 6: realiza uma discussão sobre a metodologia deste trabalho, com base nos resultados obtidos, e propõe extensões futuras ao trabalho.

- Capítulo 7: apresenta as principais conclusões derivadas desta pesquisa.

Existem dois itens adicionais que complementam o trabalho, quais sejam: 
- Item 8: lista as referências bibliográficas utilizadas nesta tese.

- Item 9: mostra as publicações do doutorando. O item também contém um glossário com alguns dos termos mais comumente empregados na área de segurança da informação. 


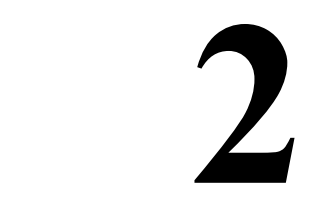

\section{Conceitos e} Métodos

"Art and science have their meeting point in method."

EDWARD BULWER-LYTTON

\section{Resumo deste Capítulo}

- aspectos importantes da segurança em sistemas de informação

- principais técnicas de criptografia simétrica

- resumos criptográficos e assinatura digital

- marca d'água e sua classificação

- integridade e autenticidade de informações no padrão DICOM

\subsection{A Segurança em Sistemas de Informação}

A segurança de um sistema de informação pode ser definida como a capacidade de evitar que atacantes atinjam os seus objetivos através de acesso não autorizado ou uso ilegítimo de um sistema através dos seus computadores ou de suas redes de comunicação, como afirma Howard (1997).

A segurança é um conceito intuitivo, mas ao mesmo tempo extremamente vago por causa da vastidão de aspectos que ela compreende. Neumann (NEUMANN, 2005) cita alguns casos reais de riscos em termos de segurança na área médica em diferentes aspectos, incluindo aspectos físicos, que prejudicaram em maior ou menor grau o atendimento aos pacientes. Uma análise em termos de segurança deve ser bastante ampla, levando-se em consideração o contexto no qual a segurança é mencionada. 
Para que tal análise seja apropriada, primeiramente devem-se ressaltar três pontos essenciais sobre a segurança:

\section{1) A segurança não é uma questão meramente tecnológica.}

As ferramentas tecnológicas são apenas instrumentos que podem, ou não, ser aplicados de forma eficaz. São necessários meios para definição e adoção de boas práticas, bem como meios para detectar e punir eventuais transgressões. Isso implica em abordar a segurança em âmbito organizacional, com a definição, implantação e manutenção de políticas, procedimentos e mecanismos, e em âmbito pessoal, com treinamentos e ética.

Como referência, Anderson (1996) propõe uma especificação formal de política de segurança para sistemas de informações clínicas. Tais políticas serão representadas por modelos de segurança, que poderão ser implementados em sua parte ou totalidade através de meios tecnológicos.

Em última análise, pode-se dizer que a segurança é um problema em termos de pessoas, não em termos de tecnologias (NIINIMAKI et al, 1998).

\section{2) Não existe segurança total.}

Por melhor que seja a segurança implantada, sempre é possível burlá-la, tendo-se os recursos necessários e suficientes. A máxima "não existe corrente mais forte do que o seu elo mais frágil" se aplica de forma perfeita à segurança. Apenas a título de exemplo, por melhor que as políticas, procedimentos, mecanismos e treinamentos sejam, um usuário legítimo, mas desonesto, pode perfeitamente tomar posse de informações que não lhe pertencem.

É bom lembrar que o nível de segurança atingido depende do nível de confiança que se assume acerca das medidas nos níveis organizacional, pessoal e tecnológico (PFITZMANN e PFITZMANN, 2001).

\section{3) A segurança é um processo evolutivo e não um projeto rígido e fechado.}

É ingenuidade acreditar que a implantação da segurança terá um término bem definido. As mudanças nas regras de negócio e as evoluções tecnológicas pedem por um acompanhamento e uma atualização contínuos dos projetos de segurança, para 
evitar que esta se torne inócua ou, ainda pior, um fardo que impede que as tarefas sejam executadas a contento.

Margi (2002) aponta que a implantação de segurança não deve ser vista como um projeto fechado, mas sim um processo cíclico e permanentemente em aberto, incluindo, mas não se limitando a: planejamento das necessidades de segurança, análise de risco, análise de custo-benefício, estabelecimento de políticas de segurança, implementação, auditoria e resposta a incidentes. Isso é explicitado em normas como ISO 27001 e NBR 17799.

Em termos tecnológicos, a menção à segurança traz à mente conceitos como criptografia, controle de acesso e integridade dos dados. Entretanto, cabe lembrar que é necessário ter uma infra-estrutura tecnológica, que compreenda não apenas os mecanismos, mas também uma arquitetura que forneça o contexto no qual serão utilizados, bem como as diretrizes de planejamento que irão definir tal arquitetura. As exigências legais também devem ser devidamente contempladas durante o planejamento.

No caso da área da saúde, existem várias diretrizes e padrões que norteiam as visões acerca da segurança, como o DICOM, proposto originalmente pelo ACRNEMA (American College of Radiology - National Electrical Manufacturers Association). Nos Estados Unidos, existe uma legislação específica (HIPAA Health Insurance Portability and Accountability Act), aprovado em 1996 pelo Congresso Norte-Americano, cujas implicações são analisadas por Jepsen (2003), que ressalta a necessidade das imagens médicas atenderem às determinações do HIPAA quando do seu armazenamento e do seu transporte.

Entretanto, há muitas formas de se implementar cada item de segurança em ambientes relativos à saúde, e em geral existe uma deficiência dos sistemas hospitalares com relação a esse aspecto. Em particular, a integridade e a autenticidade de informações médicas é um fator bastante crítico, na medida em que fornece mecanismos para evitar ou minimizar a adulteração de informações acerca do paciente.

Ao mesmo tempo, documentos como laudos, prescrições e imagens médicas, quando armazenados apenas na forma eletrônica, necessitam do mesmo status legal 
do que os documentos escritos e assinados. Assim, são necessários mecanismos que garantam que um documento consolidado não seja mais alterado.

\subsection{Criptografia Simétrica}

A criptografia simétrica é uma forma de ocultação da informação, cifrando-a através do uso de uma chave. A mesma chave (ou duas chaves facilmente correlacionáveis) é utilizada tanto para a cifração quanto para a decifração.

Os algoritmos de criptografia simétrica são mais eficientes do que os de criptografia assimétrica, mas possuem uma vulnerabilidade muito maior em termos de distribuição e gerenciamento das chaves.

Existem duas grandes classes de algoritmos, quais sejam: as block ciphers (cifras de bloco) e as stream ciphers.

\subsubsection{Stream Ciphers}

As stream ciphers são cifras que criptografam dígito a dígito os dados. Para que não sejam facilmente quebradas, tais cifras possuem estados internos, de forma que há uma maior variabilidade nos dados de saída.

Existem vários algoritmos propostos, mas muitos foram quebrados. Atualmente, há um projeto (ESTREAM, 2006) objetivando avaliar a robustez dos mais recentes stream ciphers propostos.

\subsubsection{Block Ciphers (Cifras de Bloco)}

As block ciphers são cifras que criptografam blocos de dados. Estes blocos possuem um tamanho fixo, que é dependente do algoritmo. Para dados maiores do que o tamanho do bloco, as cifras são utilizadas de acordo com um modo de operação, permitindo codificar dados de comprimento arbitrário.

O algoritmo mais famoso é o DES (Data Encryption Standard) e a sua variante, o 3DES (Triple DES). Recentemente, um novo algoritmo foi proposto, recebendo o nome de AES (Advanced Encryption Standard). O AES é a cifra mais utilizada atualmente e foi descrita pelo NIST dentro da publicação FIPS 197.

Existem também outros algoritmos, como o Camellia (AOKI et al, 2000) e o Blowfish (SCHNEIER, 1993). 


\subsection{Criptografia Assimétrica}

A criptografia assimétrica é uma outra forma de ocultação da informação, desenvolvida para solucionar a vulnerabilidade da distribuição e gerenciamento das chaves presente na criptografia simétrica.

Nesta modalidade de criptografia, existem duas chaves, uma pública e uma privada, sendo que os dados cifrados por uma chave só podem ser recuperados com o uso da outra chave.

Utilizando-se a chave pública para cifração e a privada para decifração, como mostrada pela Figura 1, permite que apenas o destinatário possa recuperar a informação original, supondo-se que as chaves são armazenadas de forma segura..

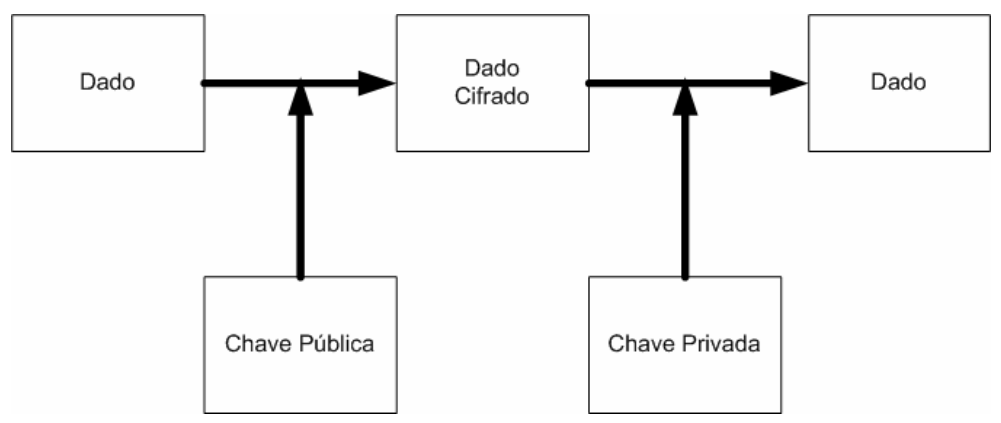

Figura 1 - O esquema básico da criptografia assimétrica.

Por outro lado, utilizando-se a chave privada para cifração e a pública para decifração permite uma forma robusta de autenticação da mensagem, sendo denominada de assinatura digital, cuja explicação será dada mais adiante.

\subsection{Integridade e Autenticidade}

\subsubsection{Resumos Criptográficos ou Message Digests}

A integridade dos dados é comumente assegurada através do uso de resumos criptográficos, gerada a partir de funções de espalhamento (hash functions). Uma função de espalhamento aceita uma entrada de dados de tamanho variável e gera uma representação de tamanho fixo dos dados de entrada. Esta representação é dita como sendo o resumo criptográfico, também chamado de hash ou o digest dos dados de 
entrada. A Figura 2 mostra uma estrutura lógica típica utilizada para a geração de resumos criptográficos.

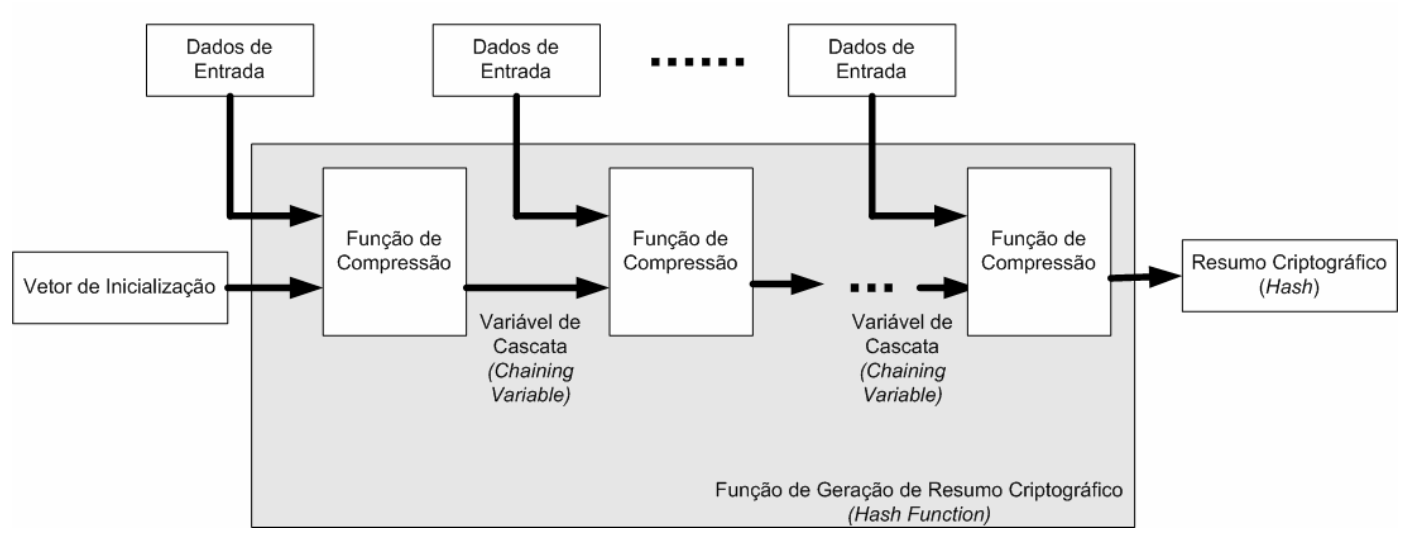

Figura 2 - A estrutura lógica típica para a geração de um resumo criptográfico.

Uma função de espalhamento possui as seguintes propriedades:

1) Não é factível determinar a entrada a partir da saída. Por isso, as funções de espalhamento são também chamadas de funções unidirecionais (one-way functions);

2) A menor mudança nos dados de entrada deve gerar uma significativa mudança nos dados de saída, uma propriedade chamada de espalhamento. Ao mesmo tempo, as saídas geradas devem ser suficientemente pequenas para serem gerenciadas e grandes o suficiente para evitar ataques;

3) Não é factível descobrir duas entradas com a mesma saída. Esta propriedade é chamada de resistência à colisão (collision resistance). Cabe lembrar que, por causa do tamanho fixo da saída, o Princípio da Casa dos Pombos permite afirmar que certamente existem duas entradas que geram o mesmo hash. Mas a função deve ser construída de forma a impossibilitar a obtenção determinística de tais entradas.

É importante enfatizar que as funções de geração de hash devem ser totalmente previsíveis, sem nenhum componente de aleatoriedade. Em outras palavras, um mesmo dado sempre deve gerar uma mesma saída. 
Um aspecto que deve ser notado é que as funções não provêem confidencialidade, nem precisam de uma chave secreta para gerar a saída, fazendo com que sejam apropriadas para verificar a integridade dos dados.

Os dois algoritmos mais comuns usados hoje são o MD5 e o SHA-1. Mais recentemente, surgiram novos algoritmos, dentre os quais merece destaque o Whirlpool.

Deve-se ter em mente que ainda não foi desenvolvido um método de construção de funções de hash que seja comprovadamente forte, sendo um campo bastante intenso de pesquisas na área da criptografia (BARRETO, 2005).

\subsubsection{MD5}

O algoritmo MD5, especificado no RFC 1321 (IETF, 1992), é um aperfeiçoamento do algoritmo MD4, desenvolvido por Ronald Rivest em 1990, cujas falhas, que permitiam alguns tipos de ataque de colisão, foram a motivação para o surgimento do seu sucessor, o MD5, que foi lançado em 1991.

Deve-se ressaltar que este algoritmo não resolveu algumas das vulnerabilidades vindas desde o MD4 e foi quebrado recentemente. Apesar de ainda ser usado em algumas aplicações, não deve ser escolhido para futuros projetos.

O MD5 produz uma saída de 128 bits.

\subsubsection{SHA-1}

O algoritmo SHA-1, especificado no FIPS 180-1, é baseado no algoritmo SHA (Secure Hash Algorithm), publicado pelo NIST em 1993 e adotado pela IETF em 2001 (IETF, 2001).

Deve-se ressaltar que este algoritmo já está bastante fragilizado. Futuras implementações devem utilizar algoritmos mais fortes. Uma alternativa é a família SHA-2, sucessora do SHA-1.

O SHA-1 produz uma saída (digest) de 160 bits (20 bytes).

\subsubsection{Whirlpool}

O Whirlpool é um algoritmo bastante recente, similar ao AES (Advanced Encryption System). Ele foi proposto como uma alternativa aos métodos tradicionais, em resposta ao projeto europeu NESSIE de segurança de dados (BARRETO e 
RIJMEN, 2004). É um dos algoritmos adotados pela ISO no padrão ISO/IEC 101183:2004 (ISO, 2003), juntamente com o SHA-228.

O Whirlpool produz uma saída de 512 bits.

\subsubsection{Assinatura Digital}

Para garantir a autenticidade dos dados, a solução mais comumente empregada é a assinatura digital. A assinatura digital é similar à assinatura física, mas não idêntica. Uma assinatura digital associa uma entidade a um dado como um contrato ou um e-mail. A assinatura física é similar, mas não contém nenhuma referência ao dado que está sendo assinado. Assim, a falsificação de uma assinatura física é mais fácil do que falsificar uma assinatura digital, bastando copiar a assinatura de um outro documento. As assinaturas digitais geralmente provêem um grau maior de segurança, já que estão associadas com o documento assinado e são muito difíceis de serem falsificadas sem ter o acesso à chave usada para criá-las.

As assinaturas digitais normalmente são usadas para associar uma entidade a um dado em particular. Por exemplo, uma pessoa pode assinar digitalmente o seu email, indicando ao destinatário que a mensagem foi realmente enviada pela pessoa. Um outro uso possível é a assinatura de documentos de caráter legal, um campo incipiente mas já contemplado dentro da legislação brasileira no âmbito da ICPBrasil.

Uma assinatura digital é, fundamentalmente, um resumo criptográfico que foi processado com a chave privada de uma entidade. $\mathrm{O}$ resumo gerado a partir dos dados é cifrado com a chave privada, gerando uma assinatura que atesta que os dados foram confirmados pela entidade que possui a chave.

$\mathrm{O}$ processo de validação consiste em processar a assinatura com a chave pública da entidade, comparando a saída resultante com o message digest dos dados. Se ambas as informações forem coincidentes, então isso significa que a chave privada foi usada para assinar os dados.

A assinatura digital (digital signature) é implementada da seguinte forma: 

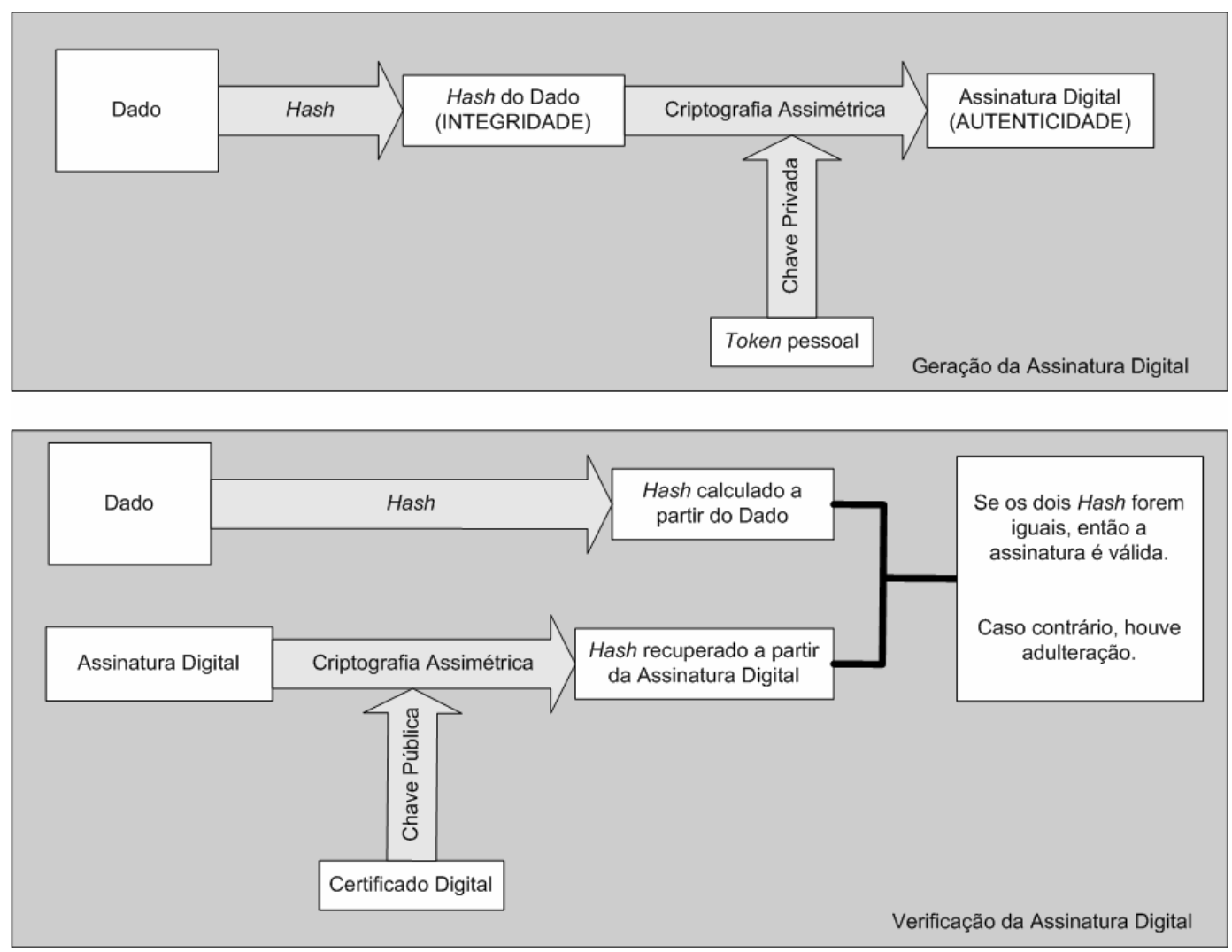

Figura 3 - Os processos de geração e verificação da assinatura digital.

Existem dois algoritmos que são os mais utilizados para a assinatura digital: RSA (SHA-1 com RSA) e DSA. Existem também algoritmos como o ECDSA, RSAPSS, CFS e BLS.

\subsubsection{RSA}

O RSA foi um algoritmo desenvolvido por Ron Rivest, Adi Shamir e Leonard Adleman em 1977, impulsionado pelo trabalho desenvolvido por Diffie e Hellman. Foi o primeiro algoritmo de criptografia de chaves públicas publicado e é considerado como o melhor algoritmo até agora, sendo usado em vários protocolos como SSL e S/MIME (ATREYA et al, 2002). O RSA utiliza criptografia assimétrica, utilizando duas chaves diferentes, uma pública e outra privada, em uma abordagem que permite tanto criptografar os dados quanto servir de assinatura digital.

O algoritmo se baseia na aritmética com grandes inteiros compostos positivos e sua fatoração, cuja dificuldade é a base para a robustez do algoritmo. Para a 
assinatura digital, o RSA é utilizado em conjunto com algoritmos de hash, sendo que a combinação mais tradicional é o SHA-1 com RSA.

\subsubsection{Digital Signature Algorithm (DSA)}

O DSA foi um algoritmo desenvolvido pela National Security Agency (NSA) dos Estados Unidos e publicado pelo NIST em 1991, com o anúncio de um novo padrão de assinatura digital (DSS - Digital Signature Standard).

O algoritmo, que é baseado na dificuldade de cálculo de funções de logaritmos discretos, está descrito em FIPS 186 e funciona de modo similar ao RSA no sentido de que os dados podem ser assinados e a assinatura pode ser verificada. Entretanto, o DSA não possui a capacidade de criptografar os dados, permitindo evitar algumas das restrições em termos de patente e de exportação que valiam para o RSA (GARMS e SOMERFIELD, 2001). Entretanto, com o fim da validade da patente do RSA e a maior facilidade de exportação deste tipo de tecnologia por parte dos Estados Unidos, esta questão está perdendo importância.

Outra característica importante é o seu desempenho: a verificação de assinaturas geradas por DSA é mais lenta que as geradas por RSA. Isso foi solucionado através do desenvolvimento de algoritmos de criptografia elíptica, que foram adotados para a assinatura digital, gerando o algoritmo ECDSA (Elliptic Curve DSA), descrito em FIPS 186-2.

\subsubsection{Marca d'água (Watermark)}

Uma marca d'água digital é um sinal portador de informação, visualmente imperceptível, embutido numa imagem digital. A imagem que contém a marca d'água é dita imagem marcada ou hospedeira. (BARRETO, 2003) A informação contida numa marca d'água é de natureza e quantidade variada, desde um dado simples até semânticas complexas como logotipos ou legendas.

Idealmente, uma marca d'água deve satisfazer as seguintes propriedades:

- Armazenada na própria imagem;

- Visualmente imperceptível quando inserida;

- Irreproduzível por terceiros não autorizados;

- Capaz de localizar alterações maliciosas na imagem hospedeira com resolução suficiente; 
- Publicamente verificável;

- Indelével por manipulação não autorizada;

- Resistente a certas operações de processamento de imagens (como mudar o nível de compressão);

- Aplicável a formatos com e sem perdas, e a imagens binárias, em níveis de cinza e coloridas;

- Eficiente em tempo de processamento e espaço de armazenamento.

$\mathrm{Na}$ prática, é quase inviável obter todas estas características em um mesmo algoritmo. A maioria dos algoritmos de marca d'água concentra-se apenas em atender a alguns destes requisitos, e portanto são aplicáveis numa gama restrita de circunstâncias. Além disso, os requisitos acima podem ser contraditórios, já que algumas operações em imagens podem atender a um requisito, ao mesmo tempo em que violam um outro.

Por exemplo, é desejável que se possa verificar uma marca d'água depois de uma operação de truncamento (cropping) em uma disputa judicial de autoria ou propriedade legal de uma imagem (i.e., deve-se ser capaz de mostrar que a marca d'água ainda está na imagem, e determinar inequivocamente o seu autor ou proprietário). Entretanto, uma verificação de marca d'água deve falhar (indicando adulteração no conteúdo da imagem) após o truncamento quando o problema em consideração é o de integridade exclusivamente (como em imagens legais ou médicas).

As marcas d'água podem ser classificadas em dois tipos: robustas e frágeis.

\subsubsection{Marcas d'água robustas}

Uma marca d'água é considerada como robusta se sua remoção de uma imagem marcada deteriorar a qualidade da imagem resultante a ponto de destruir seu conteúdo visual. Mais precisamente, a correlação entre uma imagem marcada e uma marca d'água robusta nela inserida permanecerá detectável mesmo após um processamento digital, enquanto a imagem resultante do processamento continuar visualmente reconhecível e identificável com a imagem original. Por esse motivo, marcas d'água robustas são normalmente utilizadas para a verificação de propriedade ou de copyright de imagens. 


\subsubsection{Marcas d'água frágeis}

Uma marca d'água é dita frágil se puder ser removida sem afetar substancialmente o aspecto visual da imagem resultante. Contudo, é possível construir marcas d'água frágeis cuja remoção sempre possa ser detectada. Esta propriedade torna tais marcas d'água úteis para fins de autenticação e verificação de integridade de imagens. Ou seja, uma marca d'água frágil é um mecanismo para detectar adulterações da imagem marcada, ao mesmo tempo em que verifica a sua procedência.

\subsubsection{Classificação de técnicas de integridade e autenticidade de imagens médicas}

As técnicas podem ser classificadas através de suas características estruturais, para agrupá-las em classes homogêneas que permitam comparações objetivas de desempenho e que permitam identificar quais são os principais pontos fortes e pontos fracos de cada abordagem (ALBANESI, 2001).

1) Nivel da verificação de integridade

Podem ser definidos três níveis de verificação de integridade para imagens:

- verificação completa da integridade, onde são detectadas até mesmo as menores modificações na imagem (FRIEDMAN, 1993; LIN e PODILCHUCK, 2000; WONG, 1997; COPPERSMITH et al., 1999; KUNDUR e HATZINAKOS, 1999 );

- verificação robusta da integridade, onde é permitido um certo grau de manipulação. A imagem é considerada autêntica desde que a manipulação seja praticamente imperceptível (e.g., compressão de alta qualidade) (LIN e CHANG, 2000; LIN, 2000; TEFAS e PITAS, 2000; FRIDRICH, 1998; QUELEZ e LAMY, 2000; LIN e CHANG, 1998a; LIN e CHANG, 1998b; LIN e CHANG, 1997);

- verificação da integridade do conteúdo, onde são permitidas manipulações perceptíveis ao olho humano, desde que o conteúdo semântico da imagem seja preservado. (KUNDUR e HATZINAKOS, 1999; MARVEL, HARTWIG e BONCELET, 2000).

2) Geração da autenticação 
Os métodos de autenticação de imagens também podem ser classificados com relação ao método utilizado para gerar os dados necessários para a verificação da integridade que deve ser feita pelo destinatário. Os algoritmos existentes podem ser divididos em duas grandes classes: a primeira, que engloba os algoritmos que utilizam a abordagem de Message Authentication Code (MAC) e a segunda, que compreende os algoritmos baseados em marcas d'água.

\section{- Algoritmos baseados em MAC}

Uma Message Authentication Code (MAC) é um dado extraído a partir da imagem e transmitido juntamente com os dados originais. A obtenção do MAC pode ser feita tanto através de funções de hash seguras, como através de algoritmos de extração de características, que são capazes de codificar em alguns bytes as principais características da imagem, como formas, bordas importantes, palheta de cores etc.

A extração desse código MAC pelo destinatário está intimamente relacionada com o seu gerenciamento quando da transmissão da imagem. Assim sendo, esses algoritmos podem ser divididos em duas subclasses dependendo do lugar onde o código é armazenado.

- O código é anexo à mensagem (labeling) (LIN e CHANG, 2000; MARVEL, HARTWIG e BONCELET, 2000; FRIDRICH, 1998; QUELEZ e LAMY, 2000)

Esta arquitetura é a arquitetura clássica baseada em assinatura digital. A facilidade de remoção do código MAC da imagem, impossibilitando que o destinatário verifique a autenticidade e integridade da imagem, é um ponto negativo desta abordagem. Por outro lado, ela possui as características positivas da arquitetura clássica, quais sejam: a verificação do remetente dos dados e a irretratabilidade da mensagem, além da possibilidade de criptografar o código MAC através de algoritmos de criptografia assimétrica (como o RSA).

- O código MAC é embutido na imagem fonte através de técnicas de esteganografia (LIN e CHANG, 1998a; LIN e CHANG, 1998b; LIN e CHANG, 1997)

Nesta abordagem, a remoção do código é uma tarefa muito mais difícil, pois ele está escondido de maneira segura através de modificações imperceptíveis na imagem. Este processo de inserção da mensagem secreta envolve geralmente uma 
chave secreta que o destinatário precisa conhecer, para que possa extrair o código MAC e verificar a integridade da mensagem. Caso contrário, sem o conhecimento da chave é impossível (ou não é factível computacionalmente) extrair o código MAC e/ou inserir um novo código MAC depois de manipular a imagem.

Esta abordagem gerencia de forma eficaz o dado de autenticação, mas não pode ser vista como uma solução completa, pois, como foi visto anteriormente, não implementa a verificação do remetente nem a irretratabilidade da mensagem. Como o MAC está embutido na imagem original, ele pode ser alterado através de manipulações legais na imagem e algoritmos de criptografia assimétrica não podem ser usados para o MAC.

- Algoritmos baseados em marcas d'água (LIN, 2000; TEFAS e PITAS, 2000; YEUNG e MINTZER, 1997; WONG, 1997; COPPERSMITH et al., 1999; KUNDUR e HATZINAKOS, 1999)

Uma marca d'água de autenticação (e.g., uma assinatura digital, um logotipo ou um sinal digital mais complexo com propriedades bem definidas no domínio do espaço e da freqüência) é gerada e então sobreposta à imagem de forma que nenhuma distorção perceptível seja introduzida. O destinatário da mensagem recebe o sinal embutido e compara-o com o sinal original, que deve estar disponível ao destinatário. Se as duas marcas d'água apresentarem um grau pré-definido de similaridade (no caso da assinatura digital, é feita a sua verificação), então se assume que a integridade foi verificada com sucesso. Caso contrário, assume-se que a imagem foi manipulada. Isso implica que uma métrica deve ser definida para medir a distância entre as marcas originais e as extraídas da imagem, assim como limiares devem ser definidos para se separar as manipulações aceitáveis das manipulações maliciosas.

O uso de marca d'água é uma abordagem conveniente para implementar algoritmos de verificação de integridade. Dependendo de como a marca é feita, é possível alcançar todos os três níveis de integridade. As marcas d'água ditas frágeis são usadas para uma verificação completa da integridade, pois são destruídas por qualquer modificação na imagem. Quando é necessária uma robustez maior com relação a manipulações, então são usadas marcas d'água semi-frágeis. 
A segurança desses algoritmos depende de uma informação secreta (que deve estar disponível tanto para o remetente quanto para o destinatário) para gerar, inserir e extrair a marca d'água. Este esquema é seguro na medida em que é impossível (ou inviável computacionalmente) modificar a imagem e inserir uma nova marca d'água sem ter o conhecimento da informação secreta. Por natureza, este é um esquema simétrico e por isso não pode garantir a verificação da fonte de dados e a irretratabilidade do gerador da mensagem.

\section{3) Capacidade de localização}

A capacidade de localização permite que um algoritmo de autenticação localize as áreas onde a manipulação ocorreu. Para este critério, os esquemas de autenticação podem ser divididos em três classes, em ordem decrescente de precisão.

- Nivel de pixel

Neste caso, o algoritmo de verificação de integridade gera um mapa binário que contém a localização dos pixels de valores diferentes dos pixels originais. Este tipo de localização é feito tipicamente por algoritmos de marca d'água frágeis.

- Nível de bloco

A imagem é dividida em blocos, geralmente de tamanho fixo. A verificação da integridade é feita bloco a bloco, ou seja, cada bloco é marcado como adulterado ou íntegro. Obviamente, a precisão da localização está intimamente relacionada com a dimensão do bloco.

- Sem localização

Neste caso, a verificação de integridade permite descobrir apenas se a imagem foi manipulada ou não. 


\subsection{O padrão DICOM}

\subsubsection{Parte 15 - Perfis de Segurança}

O DICOM (Digital Imaging and COmmunications in Medicine) é um padrão internacionalmente estabelecido para a transmissão e armazenamento de imagens médicas (NEMA, 2007).

Em 2001, o padrão lançou a parte 15, que trata especificamente da segurança no contexto DICOM. A parte 15 especifica perfis de segurança que as implementações podem seguir. Cabe notar que ela foca em prover uma infraestrutura para a transmissão, armazenamento e recuperação corretos das imagens, oferecendo flexibilidade para a implantação de diferentes políticas de segurança, estabelecidas de acordo com cada instituição.

Existem várias diretrizes estabelecidas para o padrão, tanto em termos de comunicação quanto em termos de armazenamento de imagens médicas, abordando serviços de segurança como confidencialidade, controle de acesso, integridade e autenticidade.

Em particular, sobre estes dois últimos serviços, o padrão define o conceito de Perfis de Uso Seguro (Secure Use Profiles) no anexo A da parte 15. Isto permite o rastreamento e a verificação do estado das imagens e de suas cópias. E, no anexo C, é definido especificamente o Perfil para Assinaturas Digitais (Digital Signature Profiles), onde há instruções de como as informações devem ser processadas e armazenadas. A estrutura de dados propriamente dita para o armazenamento é definida na parte 3 do padrão.

Em particular, o padrão permite a assinatura não apenas dos dados da imagem em si, mas também de metadados da imagem (e.g., dados pessoais do paciente) contidos em seu cabeçalho.

Deve-se manter em mente que a adoção ou não de um determinado perfil deverá estar registrado em um documento chamado de Conformance Statement, de forma que possa ser configurado para se comunicar adequadamente com as outras aplicações DICOM.

O padrão DICOM, na sua parte 15 , prevê o seguinte fluxo para assinaturas digitais: 
- para a adição da assinatura digital:

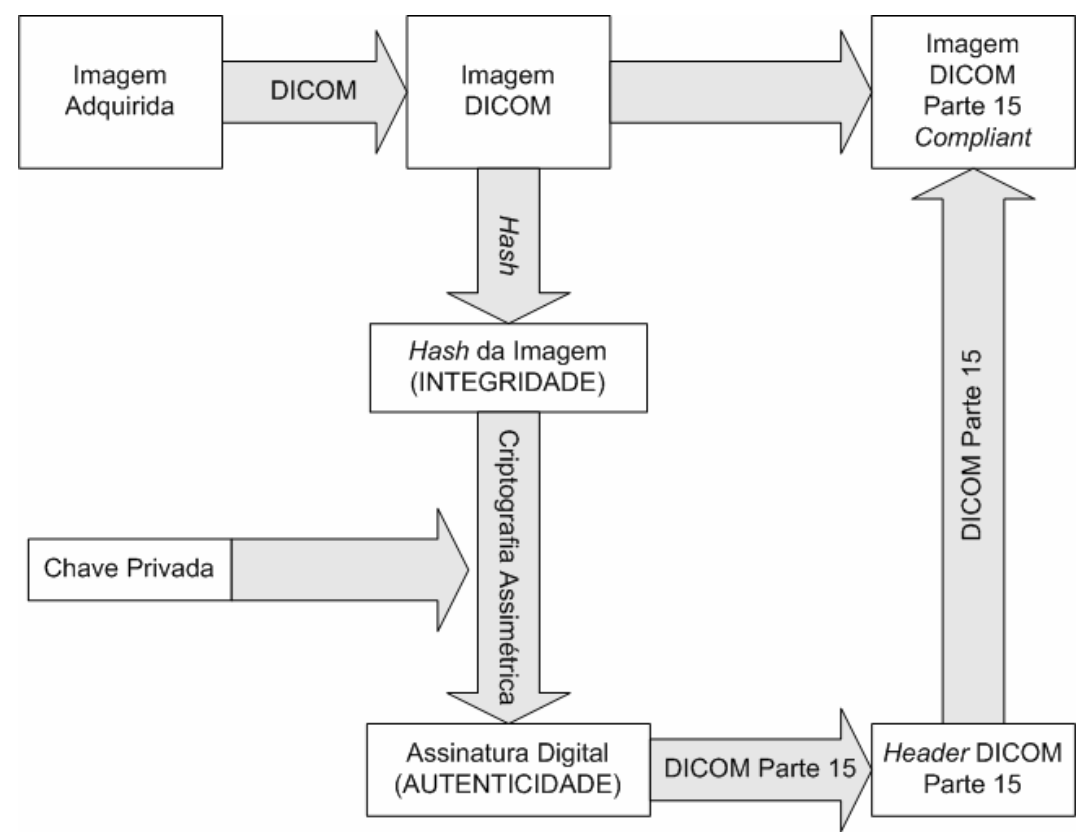

Figura 4 - O processo de adição de assinatura digital para o DICOM.

- para a verificação da assinatura digital:

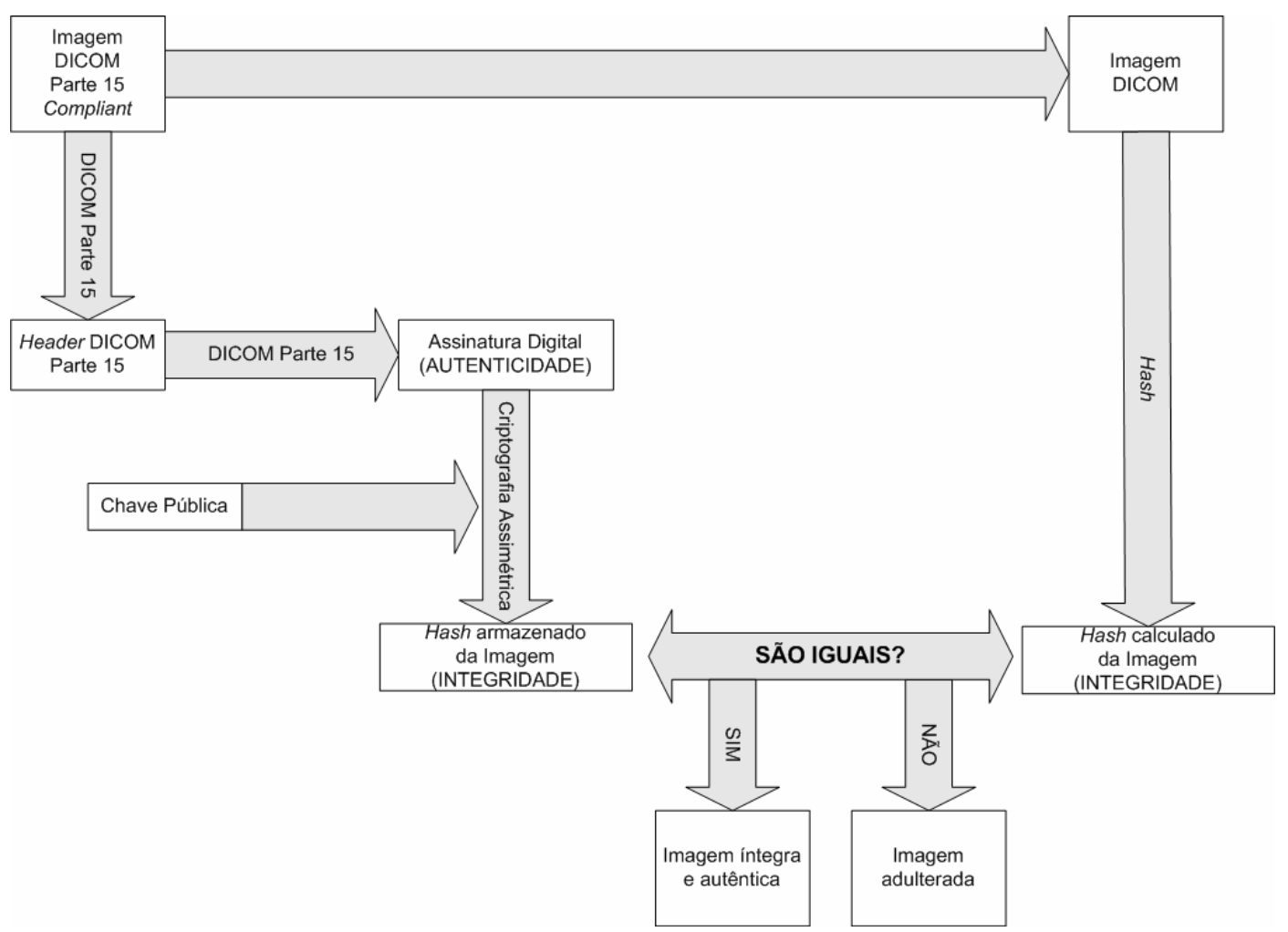

Figura 5 - O processo de verificação de assinatura digital para o DICOM. 
Além disso, no padrão DICOM, o cálculo da assinatura digital é feito da forma mais simples possível, assinando-se todos os dados relevantes. Para ilustrar, a assinatura das imagens, supondo-se que nenhum dado do cabeçalho é assinado, é feita da seguinte forma (Figura 6):

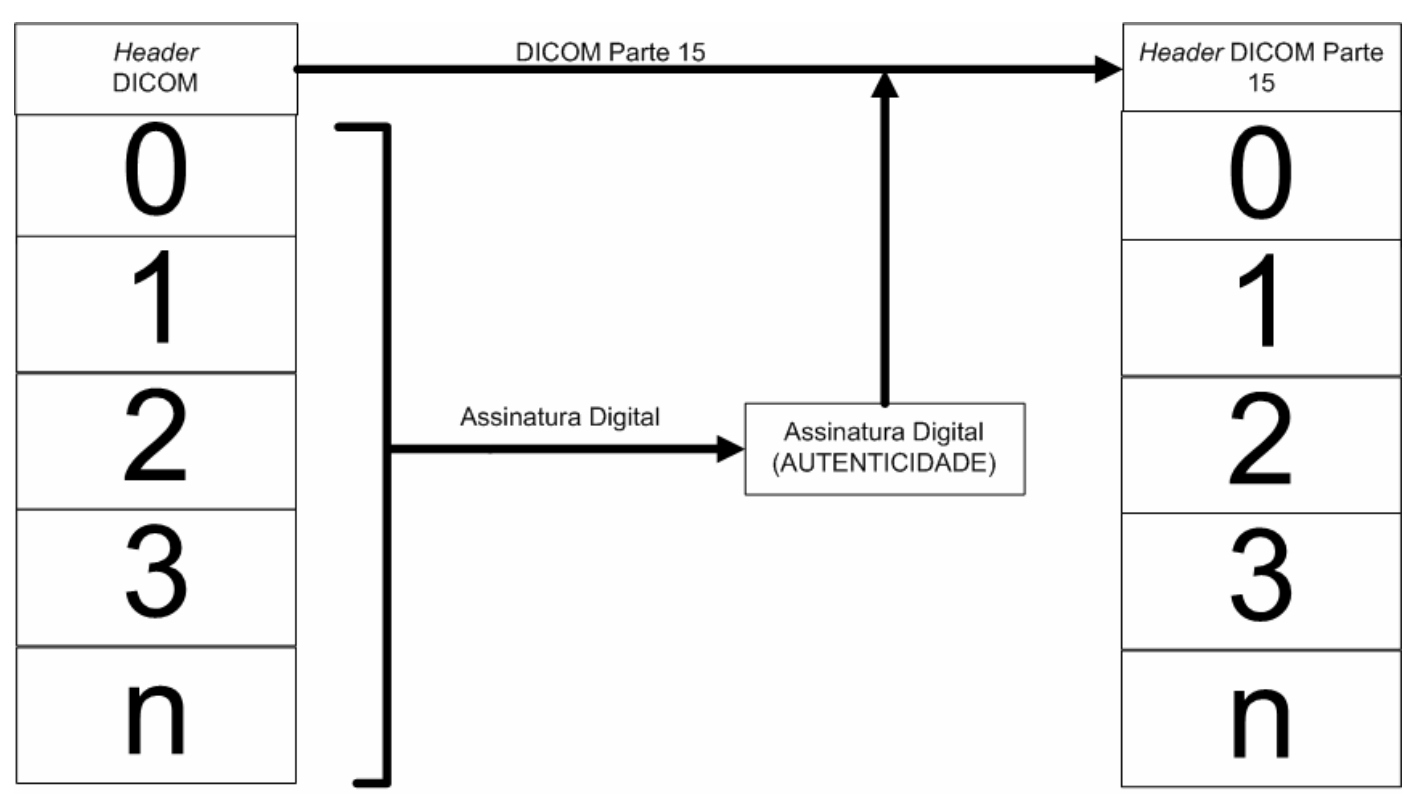

Figura 6 - O cálculo da assinatura digital das imagens no padrão DICOM.

\subsection{Considerações sobre as abordagens existentes}

Com relação aos métodos empregados para integridade e autenticidade, existem alguns autores que se posicionam contra o uso de marca d'água e métodos similares para integridade e autenticidade em imagens médicas. Em particular, Lynch (2000) apresenta um argumento bastante interessante contra o uso de marca d'água para fins de autenticidade e integridade, defendendo a posição de que a introdução da marca d'água já é um processo que degrada a imagem original, comprometendo a integridade da imagem, a não ser que a imagem com a marca seja considerada como a imagem original.

Existem algoritmos que reduzem a diferença perceptual de uma imagem sem e com a marca, mas isso implica em uma evidência mais fraca em termos de integridade. Mais recentemente, surgiram também algoritmos de marca d'água 
reversível, como a proposta feita por Pamboukian e Kim (2007), mas ainda necessitam de estudos mais aprofundados acerca da sua viabilidade para qualquer tipo de imagem.

Assim, para este trabalho, optou-se por utilizar o armazenamento dos dados de autenticidade e integridade anexos à imagem, ao invés da utilização de marcas d'água. Uma característica interessante com relação a este método é a aderência maior ao padrão DICOM, que é essencialmente baseado em metadados e estabelece macros para assinaturas digitais e perfis de implementação. Em uma primeira instância, decidiu-se implementar o perfil mais básico para este trabalho, assinandose meramente a imagem (Pixel Data) em si.

Um outro aspecto importante que não é discutido nas abordagens propostas até agora é a questão das imagens multiframe. Em modalidades como a angiografia ou ultra-som, são armazenados vários frames em um único arquivo. Assim sendo, são necessários métodos adequados para garantir a segurança desta categoria de imagens.

Por fim, a questão do desempenho também é de suma importância. Por melhor que sejam os algoritmos, se os tempos de processamento forem grandes, será muito difícil a sua adoção em um ambiente de produção. Avaliações de desempenho devem ser realizadas para que os métodos propostos não fiquem restritos à área acadêmica.

\subsection{Síntese}

Neste capítulo, foram tecidas algumas considerações relevantes acerca da segurança da informação. Foram também apresentados de uma forma geral os conceitos de criptografia simétrica, resumos criptográficos (hash) e assinatura digital, que são três conceitos essenciais dentro da segurança da informação.

Um foco mais detalhado foi dado à marca d'água, apresentando seu conceito e as possíveis classificações. A marca d'água é uma técnica que vem ganhando um destaque crescente em diversas áreas e é interessante conhecer as suas características.

Em seguida, foi apresentada a forma como o padrão DICOM lida com a integridade e autenticidade em imagens médicas, utilizando assinatura digital para autenticar a imagem e armazenando a assinatura no cabeçalho. Por fim, foi feita uma 
discussão sobre as abordagens existentes para a segurança em imagens médicas, levantando algumas questões não tratadas em trabalhos anteriores. 


\section{Requisitos}

"Let us watch well our beginnings, and results will manage themselves."

ALEXANDER CLARK

\section{Resumo deste Capítulo}

- principais requisitos a serem atendidos

- requisitos funcionais

\subsection{Especificação dos requisitos}

O Manual de Requisitos de Segurança, Conteúdo e Funcionalidades para Sistemas de Registro Eletrônico em Saúde (RES) (SOCIEDADE BRASILEIRA DE INFORMÁTICA EM SAÚDE, 2004), estabelece o controle de sigilo e integridade como um dos requisitos. Os Códigos de Ética citados anteriormente também incluem a autenticidade e integridade das informações como um dos pontos-chave para o gerenciamento das informações em saúde. Entretanto, não há determinações detalhadas sobre os requisitos e os métodos de implementação.

Assim sendo, faz-se necessário definir, em primeiro lugar, os requisitos básicos para a implementação. Cabe lembrar que o objetivo básico é a implementação da integridade e autenticidade fim-a-fim em imagens médicas, no contexto do fluxo de informações relativas a imagens médicas, primariamente relacionado com o sistema de armazenamento de imagens da instituição de saúde, 
conhecido como Picture Archiving and Communication System (PACS), e uma correlação secundária, mas ainda importante, com o RES/PEP e similares.

Deve-se também definir as entidades que irão interagir com o sistema, que podem ser separadas em duas grandes categorias: a primeira, que irá se utilizar das características introduzidas no sistema para verificar sobre a procedência e a veracidade dos dados. Nesta categoria se enquadram o corpo clínico de uma forma geral, os auditores e os agentes da Justiça. A segunda será o provedor das tais características, incluindo usuários e equipamentos.

Isto posto, pode-se estabelecer os principais requisitos. Estes devem ser elaborados de forma a serem consistentes, como defende Young (2001).

Os principais requisitos são:

\section{1) Segurança}

- deve estar de acordo com o Princípio de Kerckhoffs, ou seja, o algoritmo deve ser público e totalmente conhecido com exceção das chaves, mas mesmo assim seguro, no que é chamado de "segurança pela transparência”.

\section{2) Integridade e Autenticidade}

- deve existir um método de detectar e/ou lidar com quaisquer adulterações para imagens simples ou multiframe. Em particular, para imagens multiframe, o método também deve ser capaz de detectar a remoção de frames inteiros;

- deve existir uma ligação forte entre as informações de integridade e autenticidade e a imagem em si;

- os algoritmos implementados devem ser robustos;

- deve implementar também a irretratabilidade.

\section{2) Desempenho}

- deve existir um compromisso entre robustez de autenticidade e desempenho para que as imagens médicas tenham um nível aceitável de segurança ao mesmo tempo em que são de fácil acesso. Em particular, uma verificação de autenticidade não deve demorar mais de 30 s para imagens médicas da ordem de 100MB; 
- o processamento das informações deve consumir um tempo similar ao método proposto na parte 15 do padrão DICOM para assinatura digital;

- não deve gerar overhead de armazenamento exceto para atender a uma compatibilidade com o armazenamento proposto pelo padrão DICOM.

\section{3) Aderência a padrões internacionais}

- deve atender às exigências dos padrões e diretrizes existentes para a área. Em particular, deve-se manter uma compatibilidade mínima com o padrão DICOM.

\subsection{Requisitos Funcionais}

Para a solução, foram propostos os seguintes diagramas IDEF0 nível 0 para a atribuição e verificação dos atributos de segurança, mostrados pela Figura 7. O objetivo deste diagrama é mostrar o contexto mais amplo em que esta solução está inserida. Existem vários mecanismos e regras para auxiliar na implantação desta solução, que deve manipular os dados do usuário para conferir integridade e autenticidade.

É interessante notar que, por causa da abordagem criptográfica, é necessário introduzir as chaves e algoritmos de confidencialidade como recursos adicionais. 

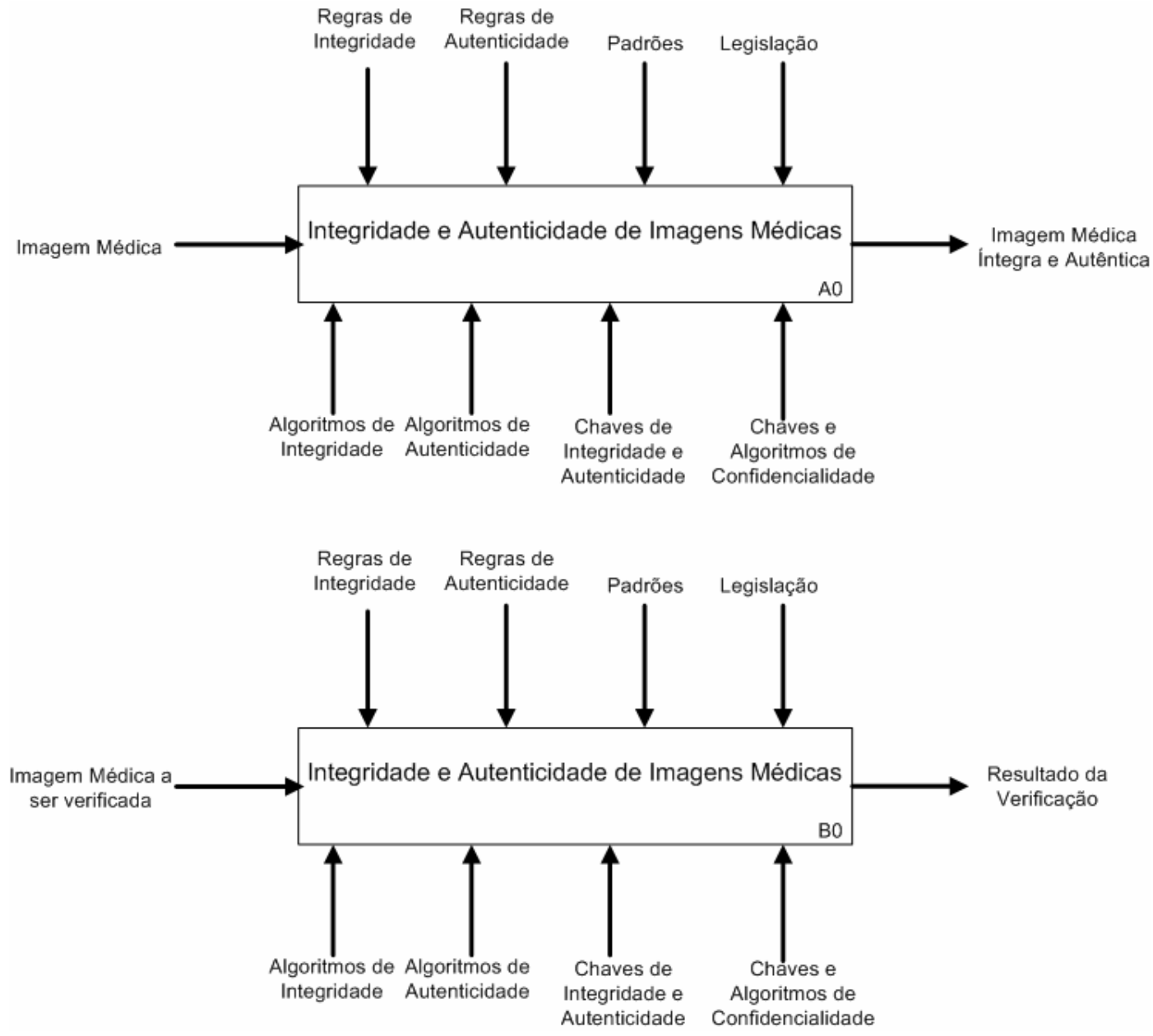

Figura 7 - Diagramas IDEF0 nível 0 para o sistema proposto. 


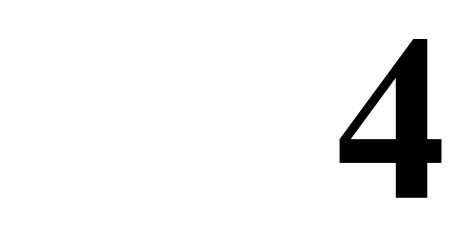

Metodologia e Implementação

"To achieve, you need thought.

You have to know what you are doing and that's real power."

AYN RAND

\section{Resumo deste Capítulo}

- descrição do contexto

- definição dos casos de uso

- diagramas IDEF0 nível 1, de classe e de seqüência

- apresentação da abordagem proposta neste trabalho

- apresentação do algoritmo proposto

- descrição das ferramentas utilizadas para a implementação

\subsection{Contexto do Problema}

Para correta compreensão dos aspectos relevantes de autenticidade e integridade de imagens médicas, é necessário compreender o ambiente em que tais informações são trafegadas, de modo a oferecer serviços de segurança consistentes.

Dentro de uma visão centrada nas informações do paciente, pode-se considerar o Registro Eletrônico de Saúde (RES) como sendo a entidade principal, aglutinando uma série de dados fornecidos por diferentes entidades, como exemplifica a Figura 8. 


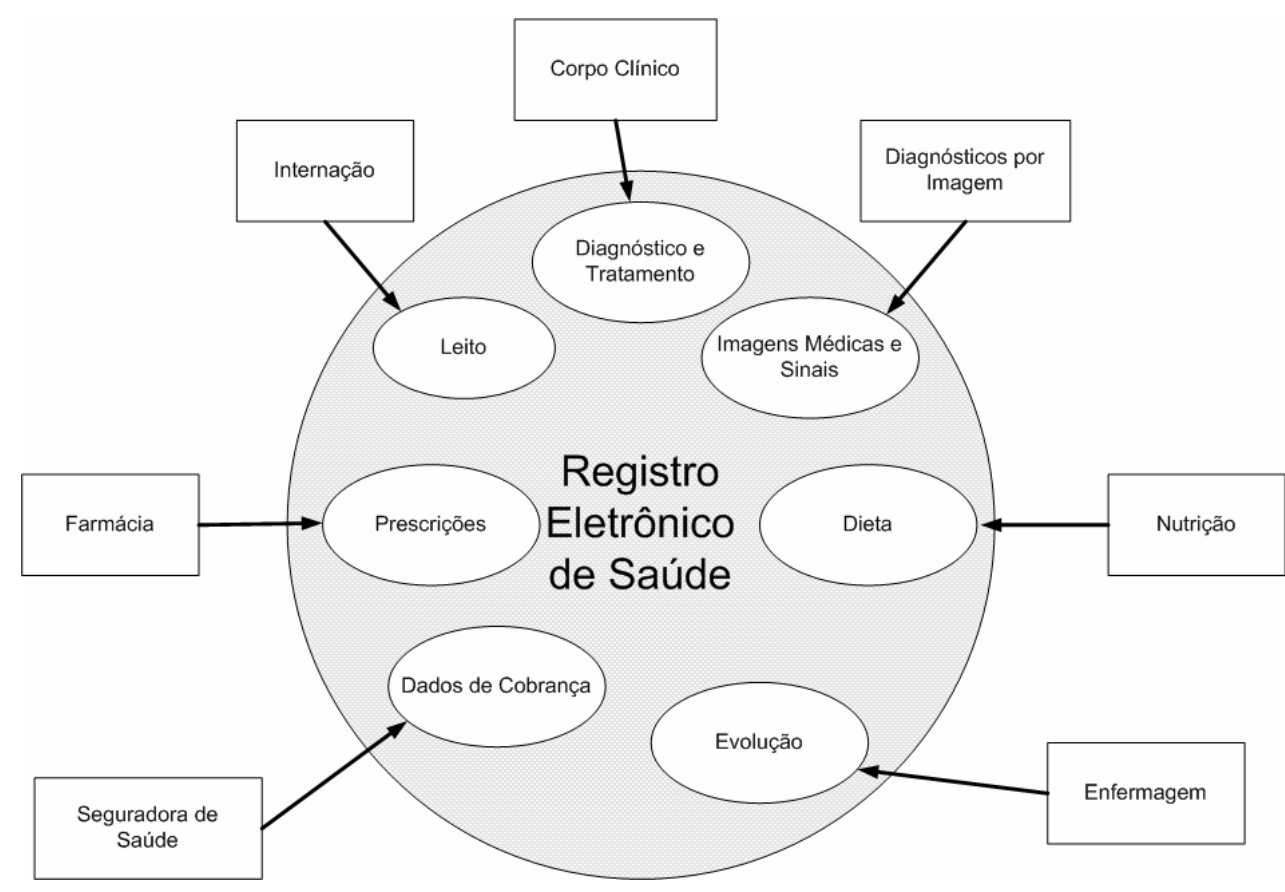

Figura 8 - O Registro Eletrônico de Saúde (RES) concentra várias informações relevantes acerca do paciente.

Dentro desse fluxo, as imagens médicas representam uma parcela bastante significativa em termos de quantidade e qualidade de informação e possuem um fluxo próprio, contemplando sua aquisição, armazenamento e recuperação (Figura 9). 


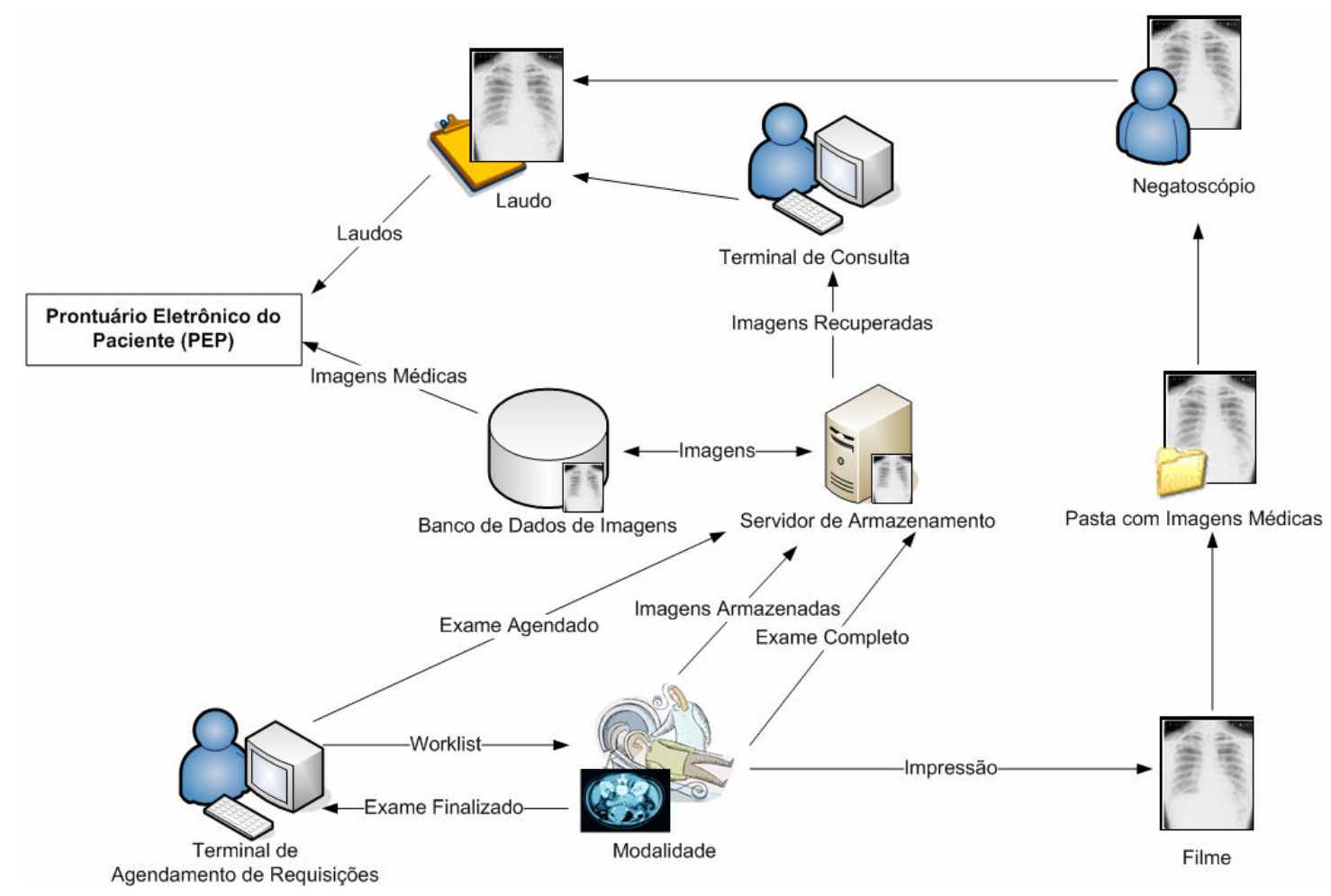

Figura 9 - Fluxo de aquisição, armazenamento e recuperação de imagens médicas em um típico estabelecimento de saúde.

Para a implementação da solução, utilizaram-se diagramas IDEF0 para a modelagem em alto nível dos fluxos e a modelagem de orientação a objetos, utilizando a linguagem Unified Modeling Language (UML), para o desenvolvimento, por causa da sua facilidade na criação de componentes bem definidos de software.

Por causa desta abordagem, escolheu-se naturalmente uma linguagem orientada a objetos para a implementação, optando-se pelo Java, por ser uma linguagem aberta e adequada para a codificação de objetos.

A implementação em si foi feita utilizando-se o método evolucionário, ou seja, uma implementação contínua de vários requisitos, com uma geração sucessiva de produtos de software. 


\subsection{Modelagem da Integridade e Autenticidade}

\subsubsection{Casos de uso}

Para levantar as situações em que esta solução pode ser utilizada, elicitou-se os possíveis casos de uso. Para este caso, há apenas dois casos possíveis: a atribuição das informações de integridade e autenticidade das imagens e a sua verificação.

A atribuição ocorre fundamentalmente quando a imagem é adquirida e armazenada, no caso ilustrado pela Figura 10. Em geral, é comum o uso de uma chave privada, como mostrada na figura, para a atribuição de segurança.

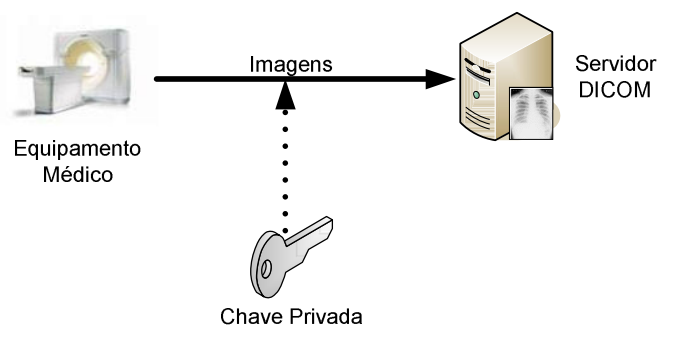

Figura 10 - As possíveis entidades envolvidas no fluxo para a atribuição da integridade e autenticidade.

A verificação é feita pelo usuário, quando da sua recuperação (Figura 11). Dependendo da infra-estrutura de segurança, pode existir um servidor de chaves públicas no processo.

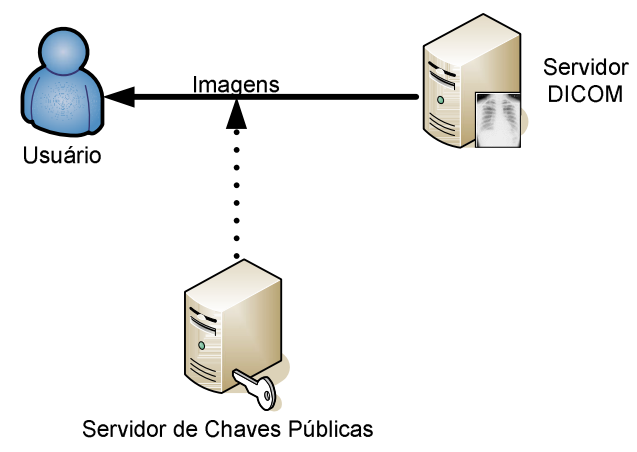

Figura 11 - As possíveis entidades envolvidas no fluxo para a verificação da integridade e autenticidade. 
Um caso particular é para clientes offline, quando as imagens estão armazenadas em mídias físicas (Figura 12).

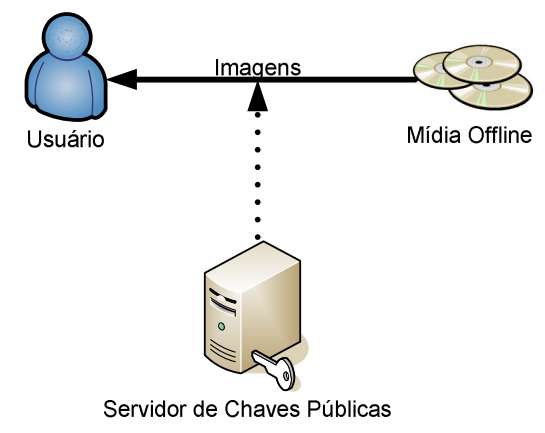

Figura 12 - $\mathrm{O}$ caso offline.

A forma como o usuário recupera as imagens é essencialmente a mesma.

\subsubsection{Diagramas IDEF0 nível 1}

Para a modelagem do fluxo da integridade e da autenticidade, foram elaborados diagramas IDEF0 nível 1, pois estes mostram com maiores detalhes o fluxo para se implementar cada um dos aspectos de segurança desejados.

De acordo com os casos de uso, é possível definir dois diagramas: a atribuição e a verificação da segurança. Como os dois serviços abordados estão fortemente correlacionados, optou-se por aglutinar os diagramas, gerando apenas um para atribuição e um para a verificação.

A atribuição obedece ao fluxo mostrado na Figura 13. 


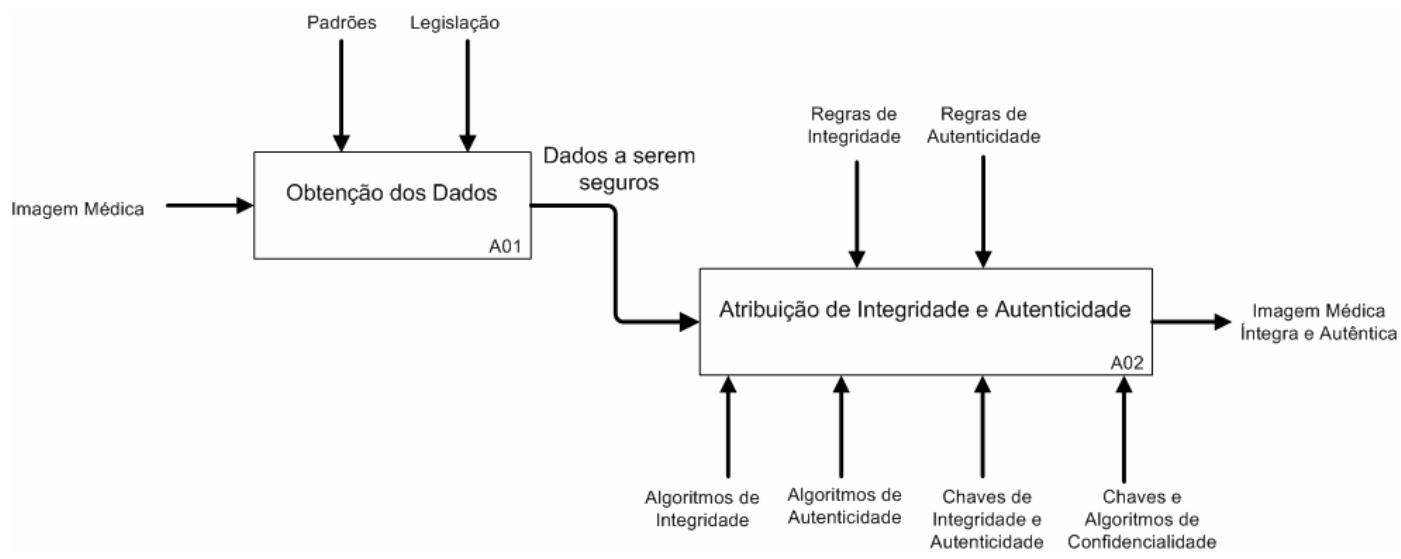

Figura 13 - O diagrama IDEF0 nível 1 para a atribuição de integridade e autenticidade.

E a verificação pode ser feita de acordo com o fluxo da Figura 14.

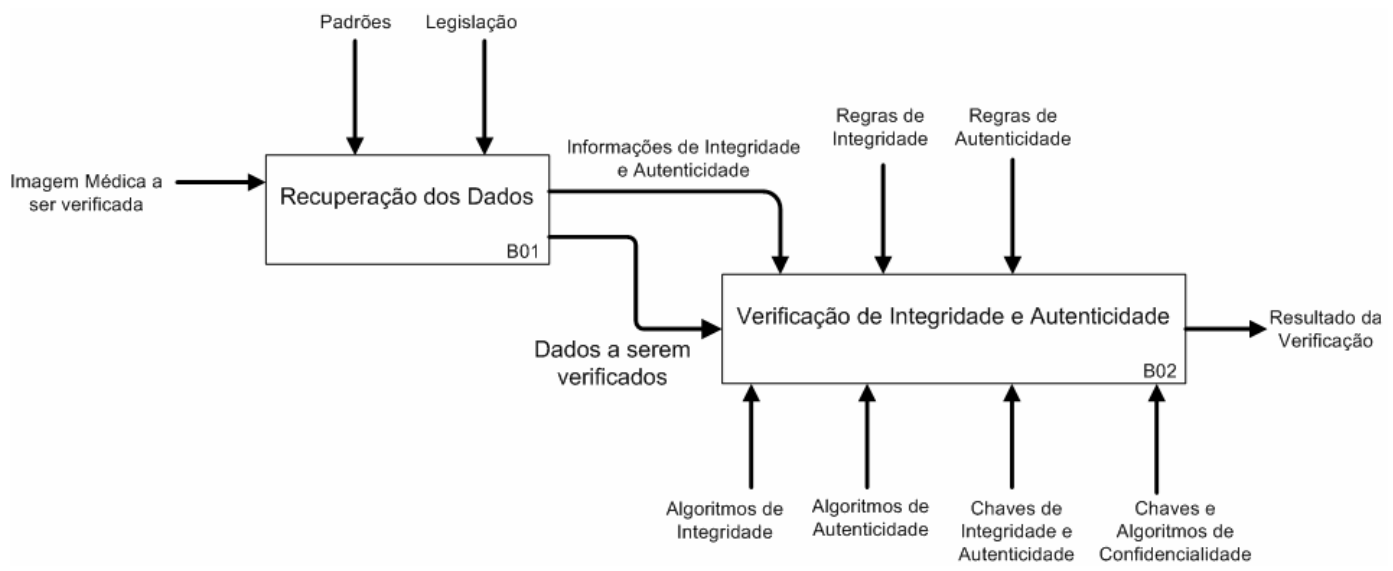

Figura 14 - O diagrama IDEF0 nível 1 para a verificação de integridade e autenticidade.

\subsubsection{Diagramas de Classe e Seqüência}

Uma vez definidos os fluxos, foram elaborados diagramas de classe e de seqüência.

Foi definida uma classe genérica chamada Serviço de Segurança, para que o modelo possa abarcar os outros serviços, tais como confidencialidade, identificação e 
auditabilidade. Tal classe está separada da Informação em si, de forma que a aplicação dos serviços seja independente do conteúdo e do tipo da informação.

Além disso, como mostra a Figura 15, foi feita uma abstração em múltiplos níveis para a segurança, para permitir a adição, remoção e alteração dos vários mecanismos e algoritmos existentes de forma transparente para o recurso. Esta abstração é bastante interessante, na medida em que a implementação fica bastante modular, independente e robusta, reduzindo os riscos de uma alteração no sistema causar resultados indesejados em outros módulos ou até mesmo em outros sistemas.

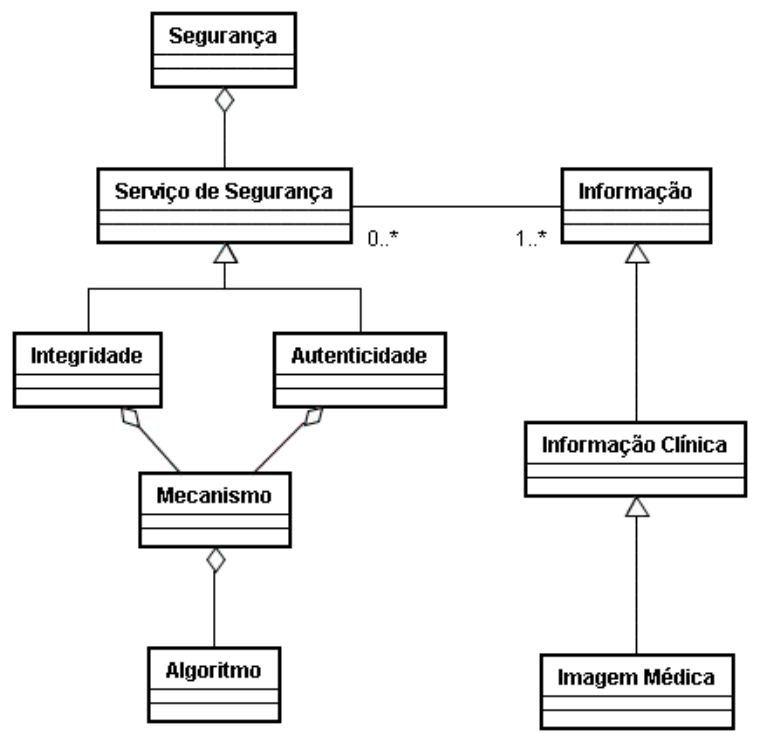

Figura 15 - Diagrama de Classes.

Existem basicamente duas seqüências importantes, quais sejam a sua atribuição e a verificação, como foi visto nos diagramas IDEF0 acima. Em termos de UML, podem ser gerados os seguintes diagramas (Figura 16 e Figura 17), que mostram a interação entre as diferentes classes para cada uma das seqüências. 


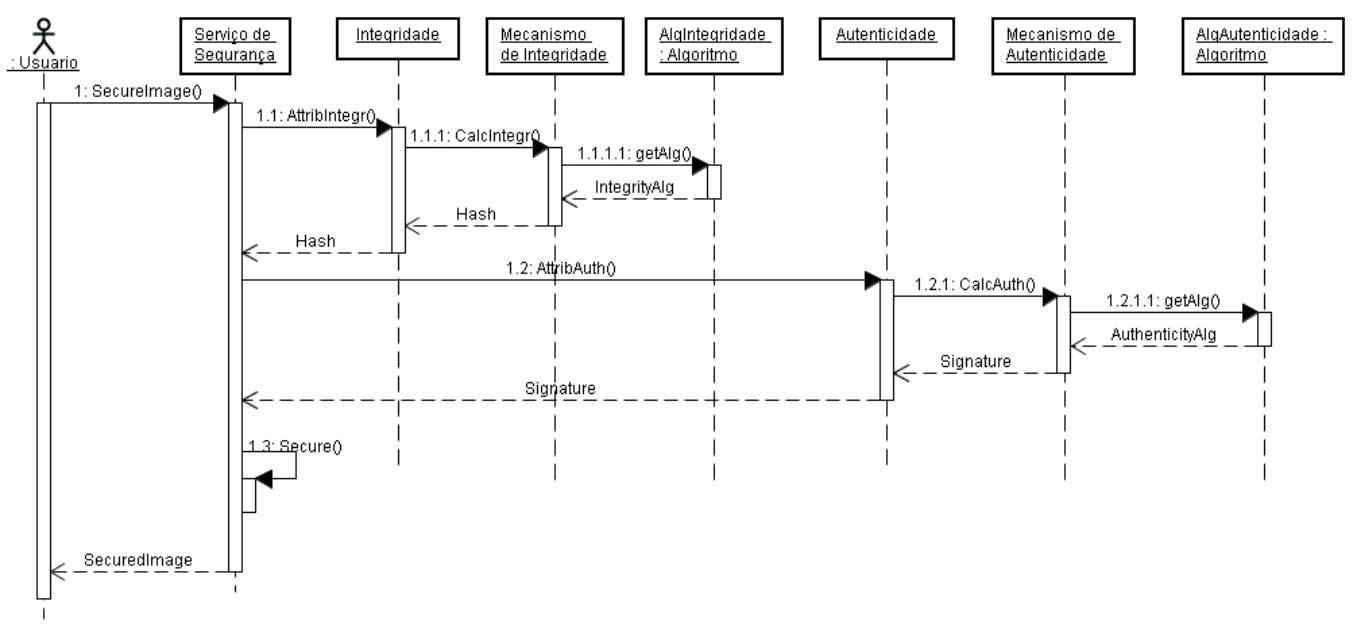

Figura 16 - Diagrama de Seqüência - Atribuição de Integridade.

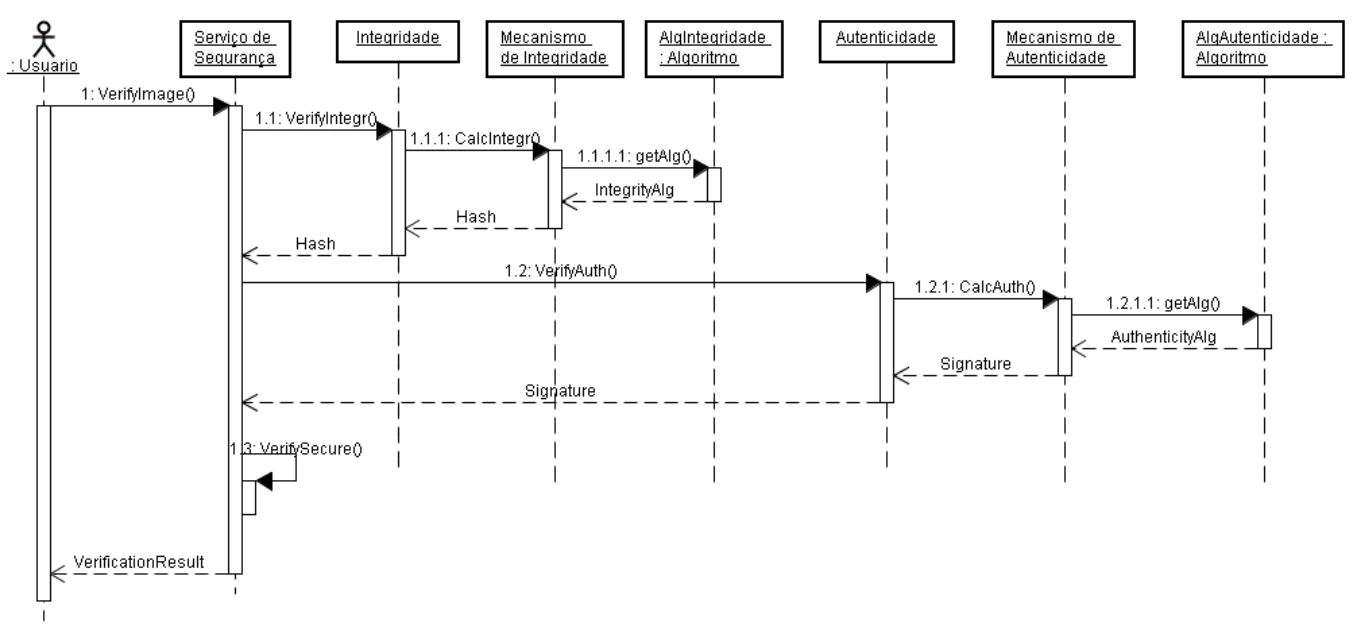

Figura 17 - Diagrama de Seqüência - Verificação de Integridade. 


\subsection{Abordagem proposta}

\subsubsection{Atribuição de segurança}

A abordagem proposta neste trabalho utiliza mecanismos de cifração de dados para prover integridade e autenticidade de imagens médicas. Assim sendo, armazena-se uma versão cifrada da imagem, ao invés dos dados originais.

Este método utiliza as estruturas de dados propostas no padrão DICOM, evitando a criação de estruturas adicionais ao mesmo tempo em que pode se candidatar como uma extensão possível para o padrão.

A atribuição de segurança, ilustrada na Figura 18, deve ter pelo menos as três seguintes entradas:

- os dados do cabeçalho, para autenticação de dados do paciente;

- a imagem original;

- os dados da entidade autenticadora, para determinação da origem dos dados. A entidade autenticadora pode ser uma pessoa (ex: um clínico ou um operador de um equipamento médico) ou uma instituição (ex: o centro de diagnósticos onde os dados foram adquiridos e armazenados).

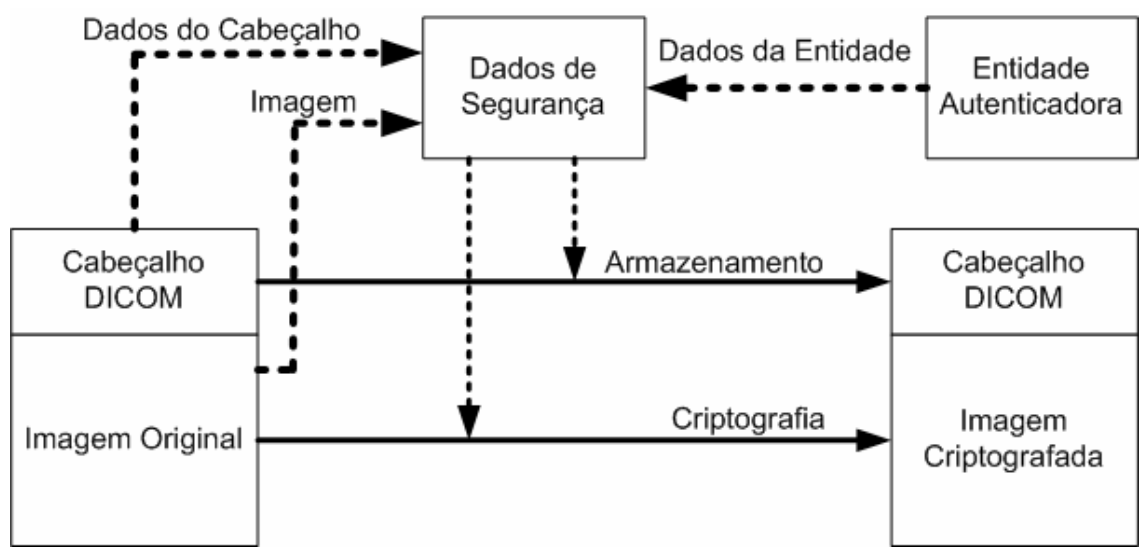

Figura 18 - Abordagem proposta para atribuição de segurança.

As saídas devem ser:

- a imagem criptografada; 
- uma representação dos dados de segurança utilizados para cifrar a imagem. Esta representação será armazenada no cabeçalho DICOM e utilizada para decifração dos dados. No âmbito deste trabalho, ela será a assinatura digital.

\subsubsection{Verificação de segurança}

O processo de verificação de segurança envolve a decifração dos dados e a verificação propriamente dita (Figura 19).

A partir do cabeçalho DICOM, são obtidas as informações necessárias para recuperar a imagem, que por sua vez é processada para verificar a sua integridade e autenticidade.

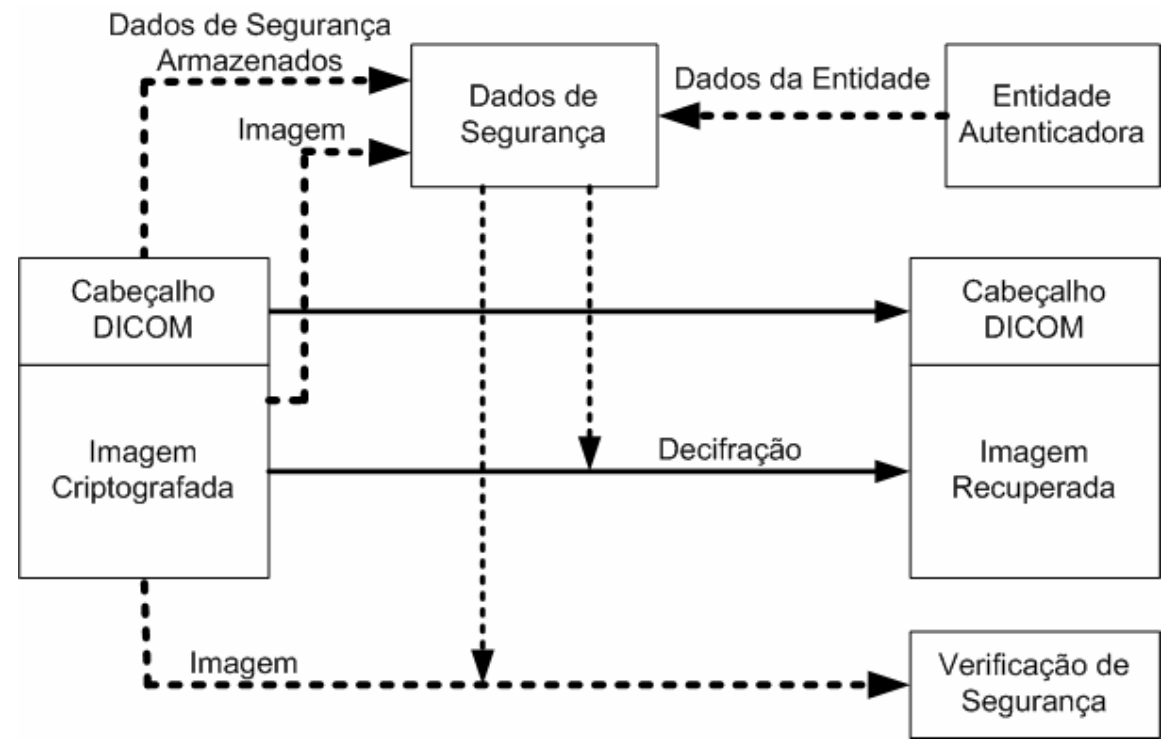

Figura 19 - Abordagem proposta para verificação de segurança.

No contexto deste trabalho, os dados da entidade autenticadora estão armazenados no cabeçalho DICOM. Assim, o cabeçalho é a única fonte de informação necessária para o processo de recuperação e verificação das imagens. Deve-se manter em mente que, se tais dados não estiverem no cabeçalho, então é necessário ter meios para acessá-los, para que o processo de verificação seja feito. 


\subsubsection{Geração dos Dados de Segurança}

Os dados de segurança, ilustrados na Figura 18 e na Figura 19, são de importância crucial para o processo. Basicamente, tais dados serão a fonte para a geração das chaves e dos vetores de inicialização para o processo de cifração e decifração.

Como está descrito na Subseção 4.3.1, os dados devem obrigatoriamente estar relacionados com a imagem propriamente dita e com os dados a serem autenticados do cabeçalho. Com isso, é possível a criação de um vínculo forte entre a imagem e os seus dados de integridade e autenticidade, uma vez que tais dados devem estar necessariamente presentes e corretos para que se possa recuperar as imagens originais.

Propõe-se dentro deste trabalho que a chave seja derivada da assinatura digital da imagem e que os vetores de inicialização (também chamados de nonce) sejam derivados dos dados do cabeçalho a serem autenticados.

É importante escolher com cuidado quais dados do cabeçalho serão escolhidos. É fundamental que pelo menos um deles seja único, de forma a reduzir a vulnerabilidade do processo. Além disso, é conveniente que tais dados estejam presentes em qualquer imagem e que tenham reduzida probabilidade de mudança durante as sucessivas manipulações e interações sofridas pela imagem no decorrer do seu ciclo de vida.

Para imagens DICOM, existe um identificador único chamado SOP Instance UID e este certamente deve ser contemplado no processo de cifração/decifração. Além dele, dados do paciente também devem ser considerados, para que haja um vínculo forte entre a imagem e o paciente. Outros dados podem obviamente ser inclusos, desde que atendam às considerações tecidas acima.

\subsection{Algoritmo proposto}

Para implementar a abordagem acima descrita, foi proposto o algoritmo que será descrito a seguir. 


\subsubsection{Atribuição de segurança}

Para o caso em que há apenas uma imagem (o frame 0), ocorre apenas a criptografia simétrica do primeiro frame utilizando-se a assinatura digital como chave, gerando-se a imagem criptografada 0’, como mostra a Figura 20.

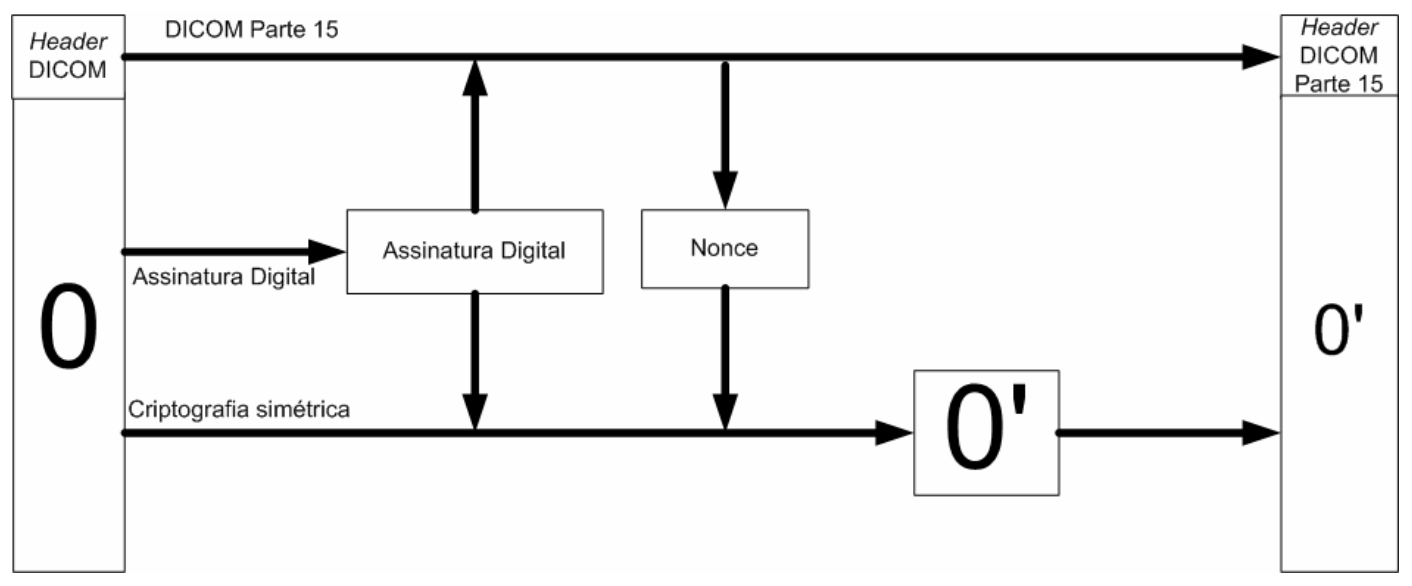

Figura 20 - Fluxo de adição de segurança.

A cifração da imagem, utilizando-se a assinatura digital como chave, faz com que as informações de integridade e autenticidade sejam vitais para a correta visualização dos dados, estabelecendo assim um vínculo forte entre a assinatura e a imagem.

Para alguns algoritmos de criptografia simétrica, é possível utilizar um dado de inicialização, chamado de nonce. Neste caso, o nonce será obtido a partir do resumo criptográfico de dados relevantes do cabeçalho, dentro das condições estabelecidas na subseção 4.3.3.

\subsubsection{Verificação de segurança}

Para a verificação da segurança, primeiramente é feita a decifração da imagem 0', recuperando-se a imagem original 0. Em seguida, é feita a verificação da assinatura digital (Figura 21). 

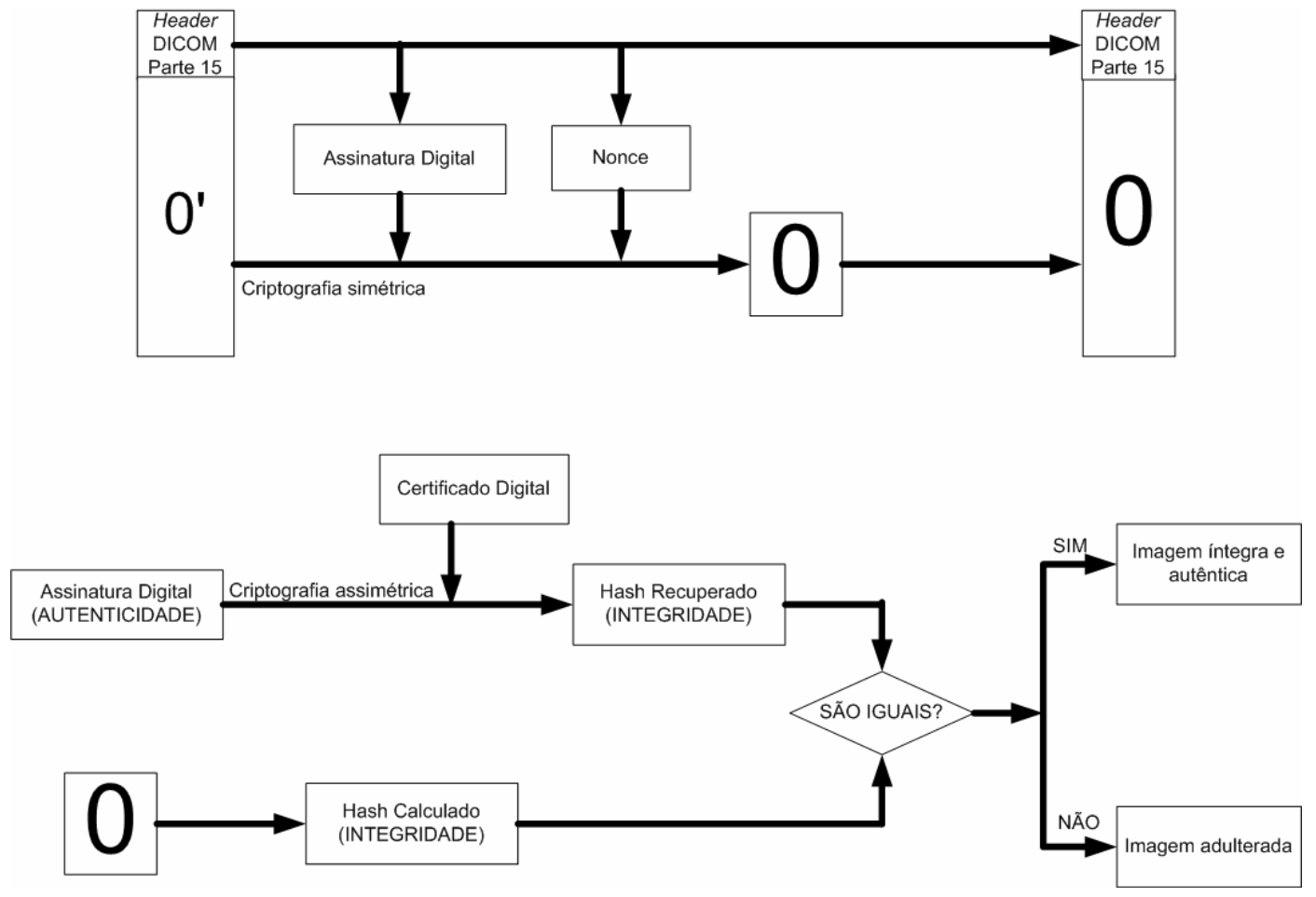

Figura 21 - Fluxo de verificação de segurança.

\subsubsection{Extensão para imagens multiframe}

Para que a abordagem possa ser utilizada também para imagens multiframe, deve-se atender aos seguintes pontos:

1) A abordagem deve ser modificada de forma a detectar qualquer adulteração em qualquer frame;

2) O algoritmo deve reduzir ao máximo o volume de dados a ser assinado digitalmente, sem comprometer a adição e a verificação de integridade e autenticidade das imagens. Com isto, espera-se que o desempenho do algoritmo seja adequado para o seu emprego em um ambiente de produção;

3) A abordagem deve ser tal que seja muito difícil derivar informações sobre as imagens originais a partir somente dos frames cifrados.

Com isso, foi desenvolvido o algoritmo que será apresentado a seguir. 


\subsubsection{Atribuição de segurança}

Para a aplicação do algoritmo, propôs-se o seguinte fluxo (Figura 22):

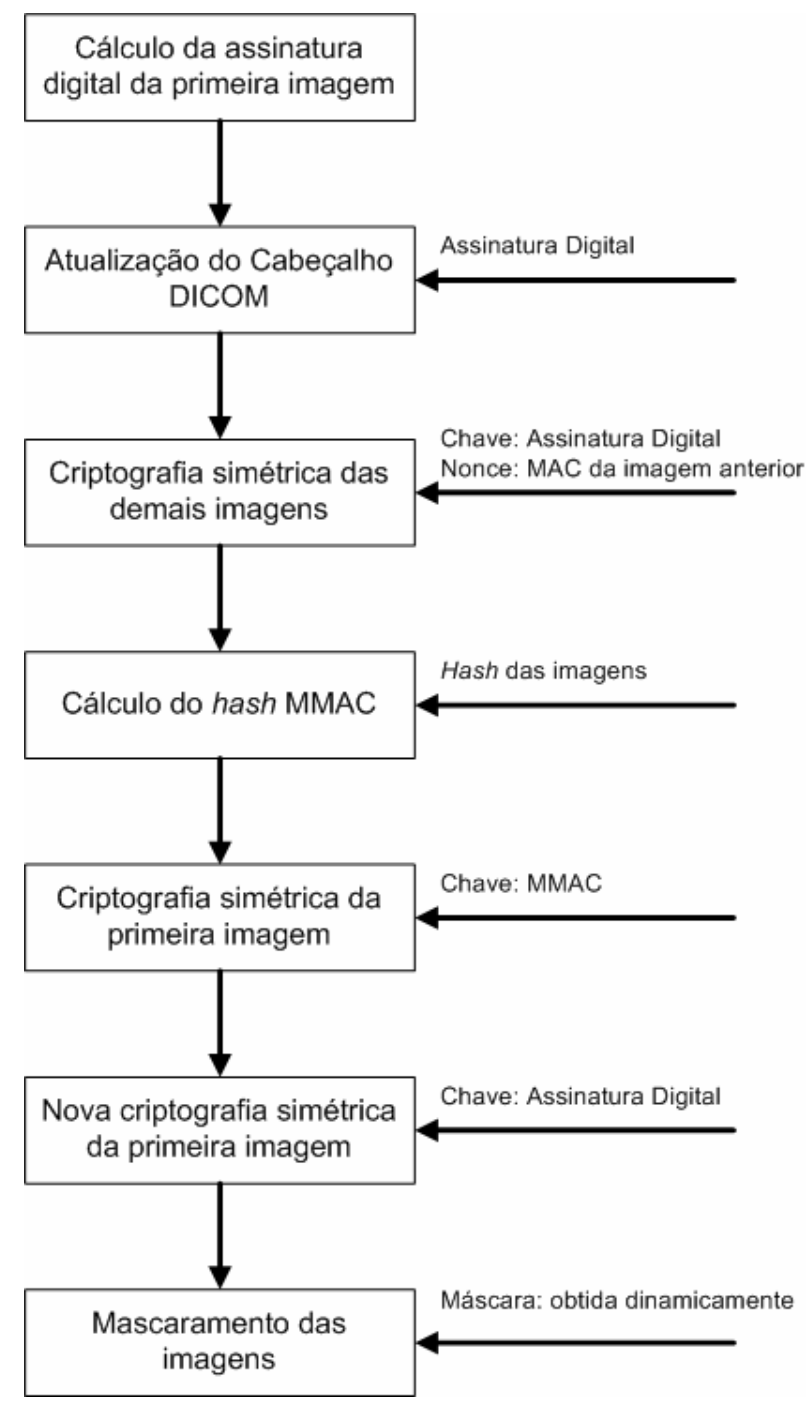

Figura 22 - Fluxo de adição de segurança.

A Figura 23 a seguir apresenta uma visão mais detalhada da atribuição de segurança. 


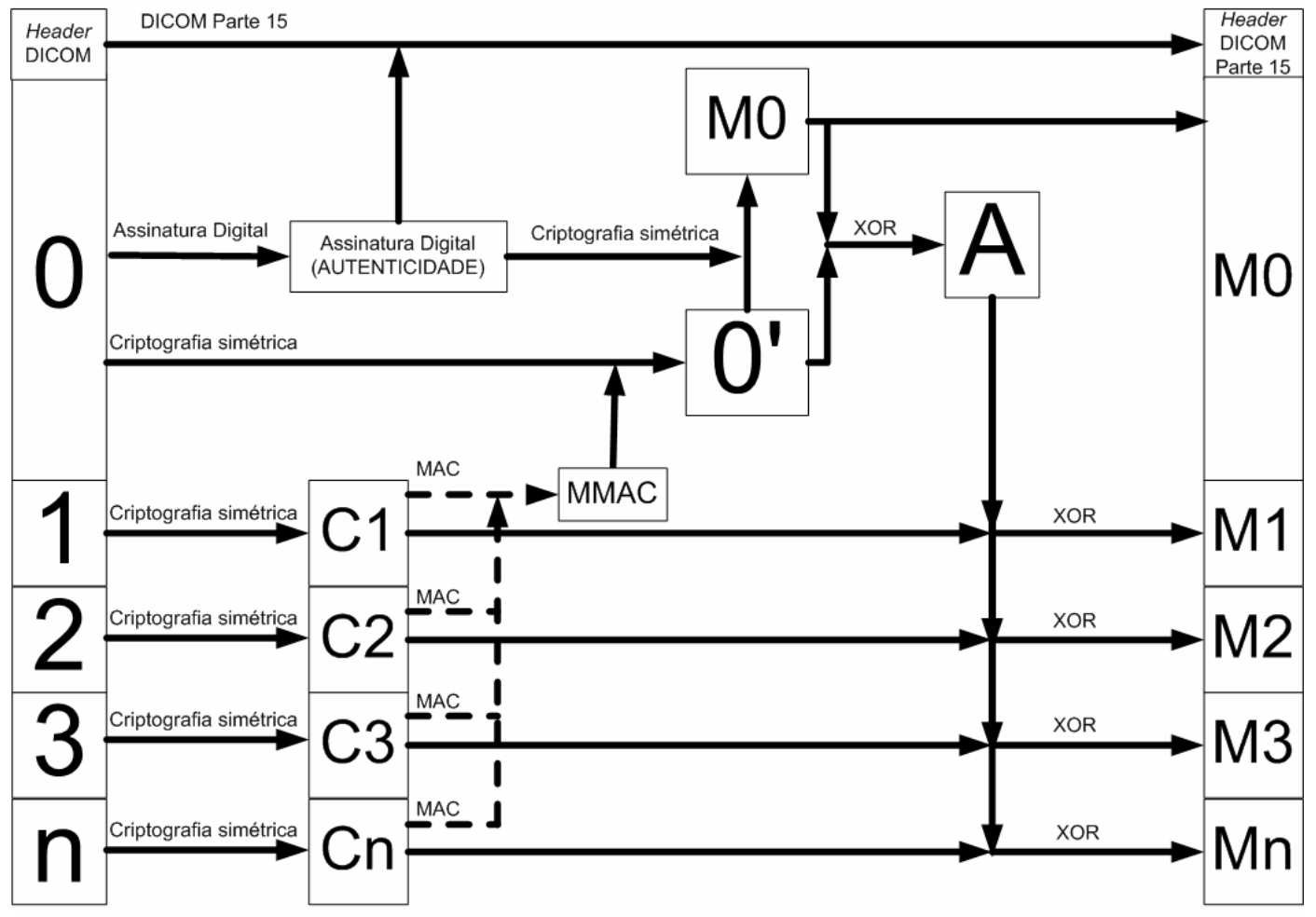

Figura 23 - Fluxo detalhado da adição de segurança para imagens multiframe.

A imagem original DICOM (à esquerda) é composta pelo cabeçalho (header) DICOM e as imagens (frames) $0,1,2,3, \ldots, \mathrm{n}$.

Primeiramente, é calculada a assinatura digital apenas da primeira imagem (imagem 0), e essa informação é armazenada no cabeçalho, de acordo com a parte 15 do padrão DICOM.

A etapa seguinte consiste na criptografia das imagens $1,2,3, \ldots, \mathrm{n}$, utilizandose a assinatura digital como chave e gerando as imagens criptografadas $\mathrm{C} 1, \mathrm{C} 2$, $\mathrm{C} 3, \ldots, \mathrm{Cn}$, a partir das quais é gerado o MMAC, um Message Authentication Code (MAC). Este processo será descrito com mais detalhes posteriormente.

O MMAC, por sua vez, é utilizado para criptografar simetricamente a primeira imagem (0), gerando-se a imagem 0'. Esta também é criptografada simetricamente, utilizando-se a assinatura digital como chave e nonce igual a zero, gerando-se a imagem M0.

Por fim, a imagem M0 é combinada com a imagem 0’ através de um simples processo de XOR (“ou exclusivo”), obtendo-se a máscara A, que também é aplicada 
através de um XOR sobre as imagens $\mathrm{C} 1, \mathrm{C} 2, \mathrm{C} 3, \ldots, \mathrm{Cn}$, gerando as imagens $\mathrm{M} 1$, $\mathrm{M} 2, \mathrm{M} 3, \ldots, \mathrm{Mn}$.

A imagem final irá conter o cabeçalho DICOM de acordo com a parte 15 e as imagens M0, M1, M2, M3,..., Mn.

A encriptação dos frames $1,2,3, \ldots$, n, e o cálculo do MMAC são feitos da seguinte forma (Figura 24):

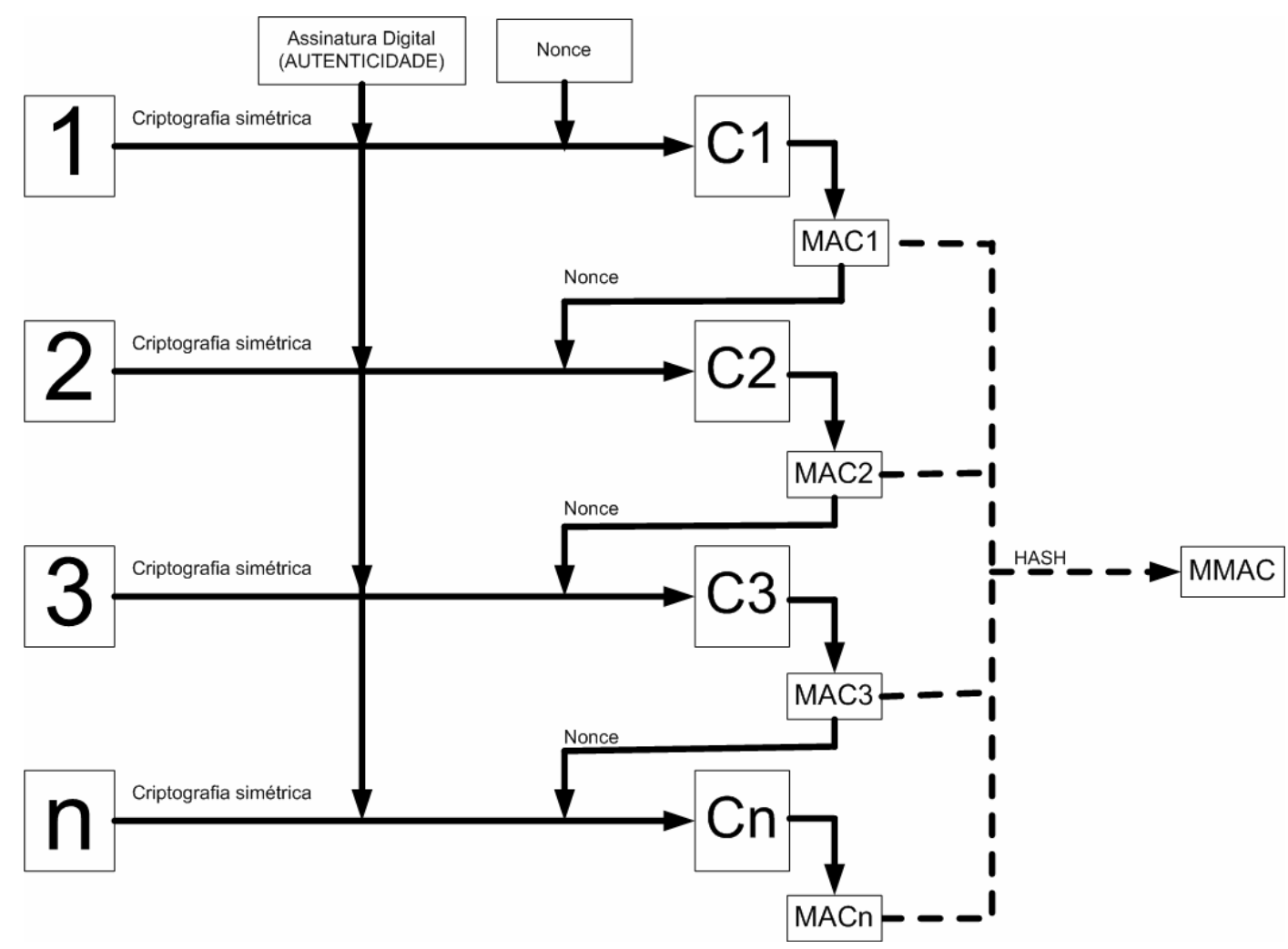

Figura 24 - Detalhe do fluxo de adição de segurança.

Para a geração da imagem $\mathrm{C} 1$, é usada a assinatura como chave e obtém-se um nonce (dado de inicialização) a partir dos dados do cabeçalho. A criptografia irá resultar na imagem codificada $\mathrm{C} 1$ e no $\mathrm{MAC} 1$. Esta informação é, por sua vez, utilizada como o nonce do próximo processo de criptografia, em um processo em cascata.

Ao final do processo, são obtidas as imagens criptografadas $\mathrm{C} 1, \mathrm{C} 2, \mathrm{C} 3, \ldots$, $\mathrm{Cn}$ e os respectivos MAC1, MAC2, MAC3,..., MACn. Estes serão as entradas para o cálculo do MMAC, que é o Message Authentication Code dos MAC, sendo um 
resumo criptográfico de todos os MAC relativos aos frames. Assim, o MMAC irá conter informações de integridade de todas as imagens (com exceção da primeira imagem 0). 


\subsubsection{Verificação da segurança}

A recuperação das imagens originais é feita da seguinte forma (Figura 25):

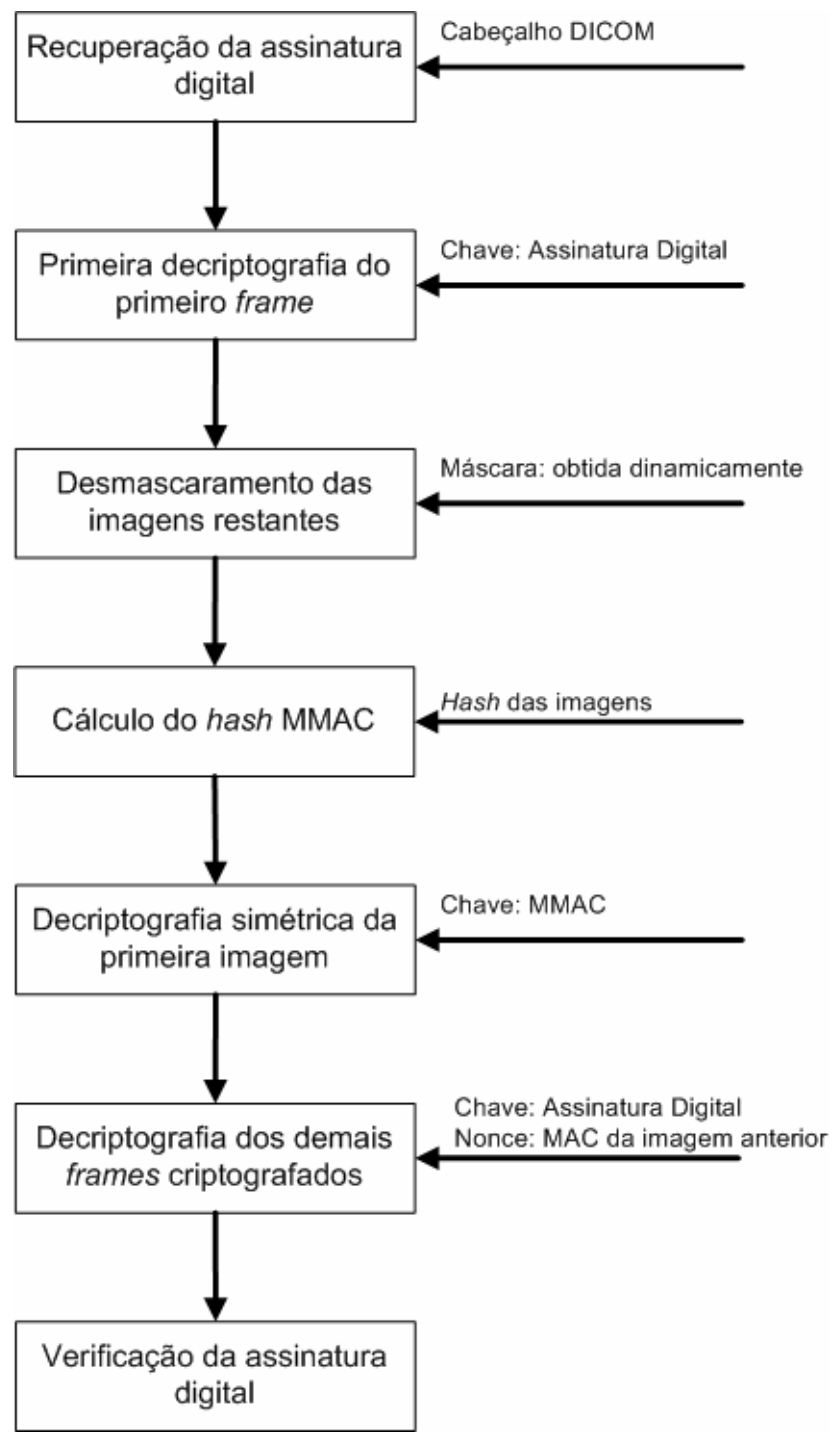

Figura 25 - Fluxo de verificação de segurança.

A Figura 26 mostra o processo detalhado da verificação. Como era de se esperar, o processo de verificação é bastante similar ao processo de atribuição. Cabe notar que a verificação não compreende apenas a validade dos dados de integridade $\mathrm{e}$ autenticidade, mas também a recuperação propriamente dita das imagens originais a partir das imagens criptografadas. 


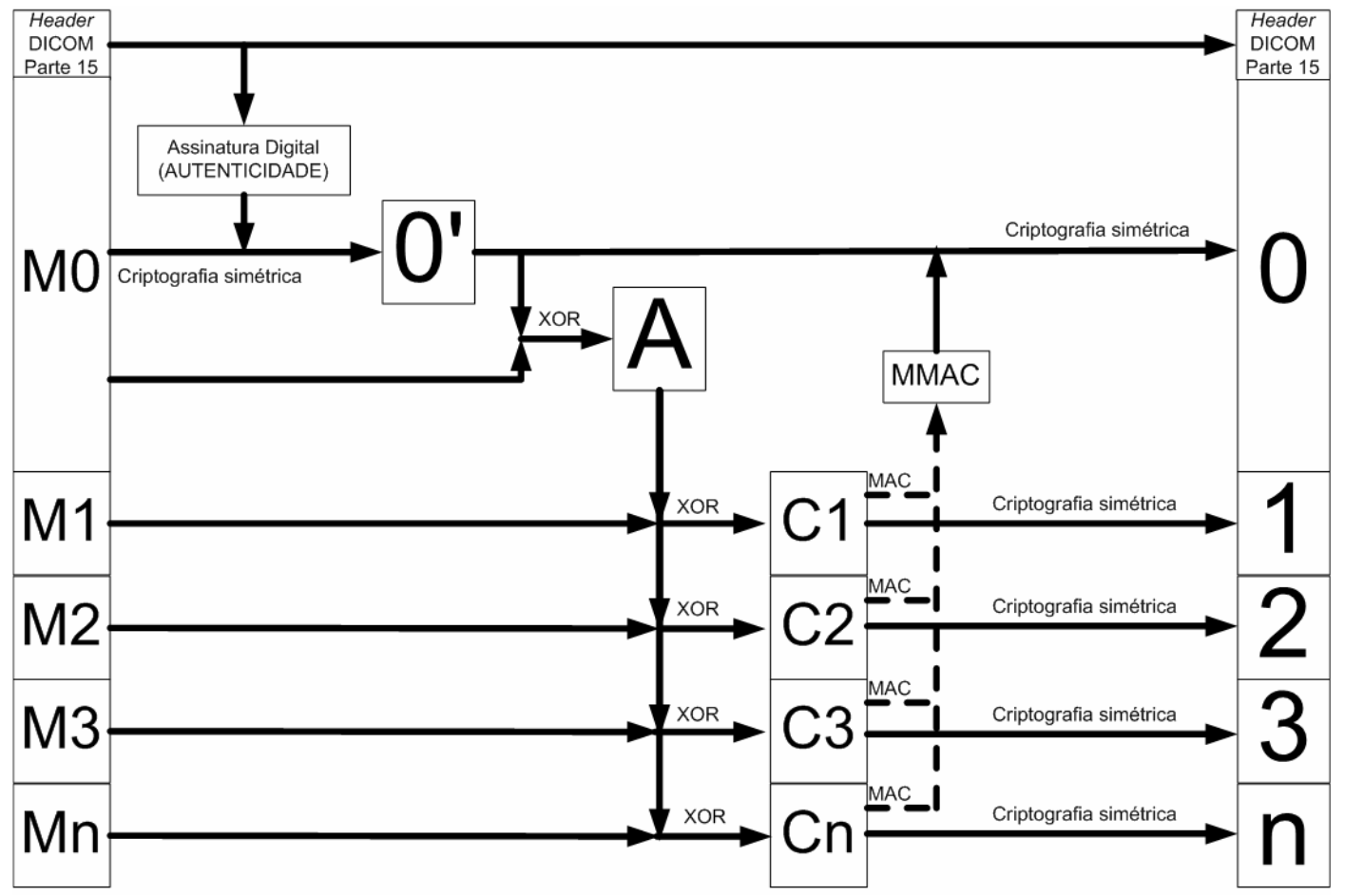

Figura 26 - Fluxo detalhado de verificação de segurança para imagens multiframe.

Primeiramente, a assinatura digital é recuperada a partir do cabeçalho. Com isso, pode-se decriptografar a imagem M0, gerando-se 0'. Com isso, pode-se combinar M0 e 0' através de um processo de XOR, gerando-se a máscara A.

Tal máscara é aplicada para M1, M2, M3,..,Mn, gerando-se C1,C2,C3,..,Cn. Estas, por sua vez, são decifradas através de um esquema em cascata idêntico ao da atribuição. Com isso, recuperam-se as imagens originais $1,2,3, \ldots, \mathrm{n}$, bem como os respectivos hash $\mathrm{MAC} 1, \mathrm{MAC} 2, \mathrm{MAC} 3, . ., \mathrm{MACn}$.

Estes hash são utilizados para se obter o hash MMAC, da mesma forma como foi feita para a cifração das imagens. Por fim, o MMAC é utilizado como chave para se recuperar a primeira imagem 0 . Com isso, todas as imagens originais $0,1,2$, $3, \ldots, n$, são recuperadas. E, a partir delas, é possível verificar a sua integridade e autenticidade.

Tal verificação é feita da forma como é mostrada na Figura 27. Deve-se manter em mente que a assinatura digital propriamente dita é verificada apenas com relação à primeira imagem (imagem 0). Entretanto, a validade da verificação se estende para os demais frames, uma vez que a primeira imagem será recuperada em função de todas as demais. Assim, qualquer adulteração será devidamente detectada no processo. 


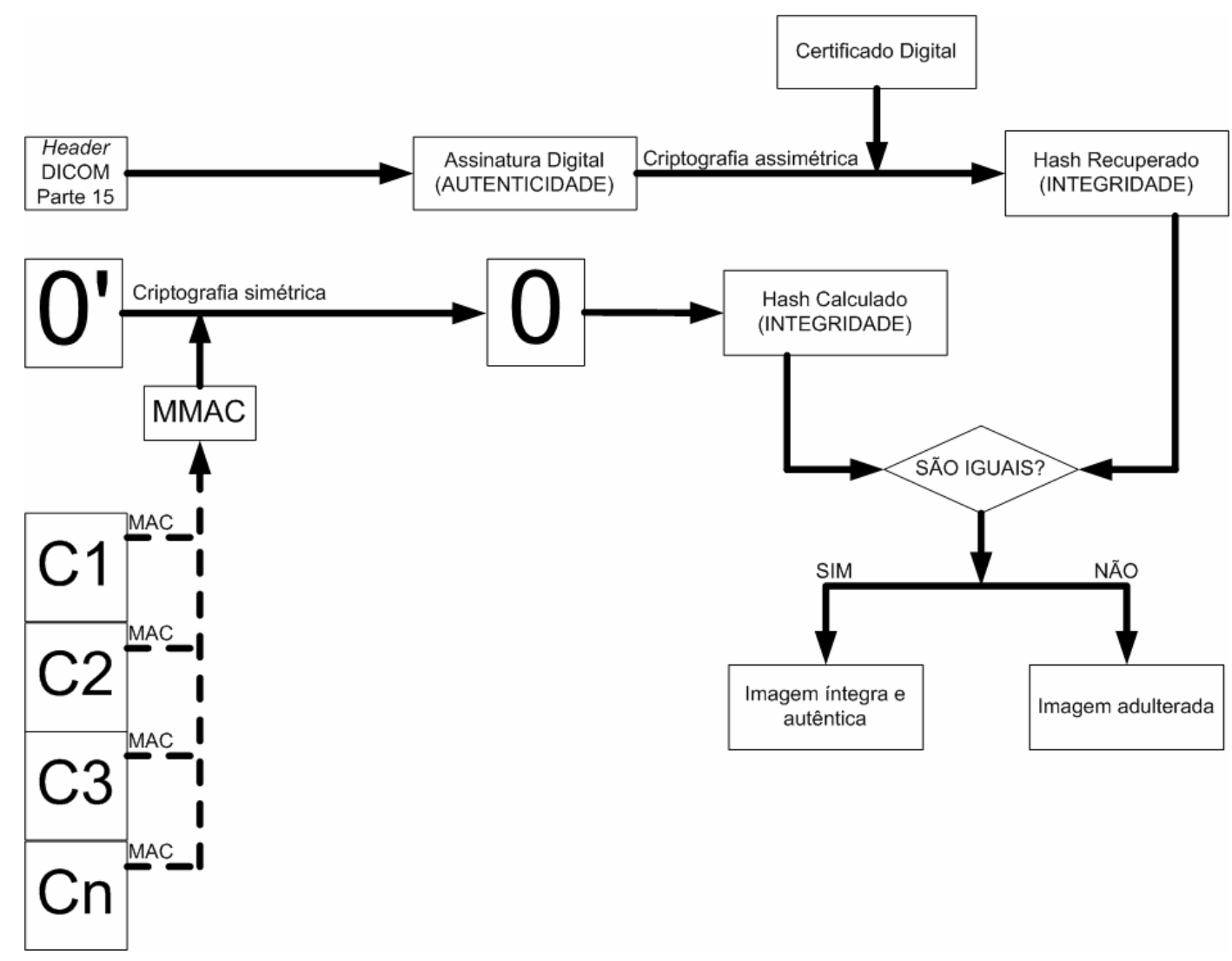

Figura 27 - Verificação propriamente dita da assinatura digital.

\subsubsection{Considerações sobre a construção do algoritmo}

O algoritmo foi desenvolvido a partir do seguinte desafio: "como garantir a integridade e autenticidade sem precisar assinar todas as imagens digitalmente".

Foi escolhida a primeira imagem, sem perda da generalidade, para ser assinada. Outras escolhas podem ser feitas, sendo que algumas podem ser interessantes, como será visto na discussão.

O uso da assinatura digital como base para a chave de cifração foi adotado para que houvesse um vínculo forte entre a imagem a ser visualizada e as informações de integridade e autenticidade. Deve-se notar que a criptografia dos frames $1,2,3, \ldots, \mathrm{n}$ faz com que qualquer adulteração nos frames M1, M2,..., Mn e/ou na assinatura digital dificulte a recuperação das imagens originais.

Entretanto, isso não é o suficiente, uma vez que a remoção de frames inteiros não é detectada. Por isso, foi introduzido o cálculo do hash MMAC. Isso permite ter evidências sobre a adulteração ou eliminação dos frames. 
Uma característica que deve ser ressaltada é o uso do MAC do frame n-1 para a criptografia do frame $\mathrm{n}$. Adotou-se esta abordagem, pois um frame $\mathrm{n}$ tende a ser bastante similar aos frames $\mathrm{n}-1$ e $\mathrm{n}+1$. Criptogrando-se simetricamente com a mesma chave e o mesmo nonce, certamente os resultados $\mathrm{Cn}-1, \mathrm{Cn}$ e $\mathrm{Cn}+1$ também serão similares, podendo ser uma vulnerabilidade em potencial. Assim sendo, manteve-se a chave (gerada a partir da assinatura digital), mas o nonce varia a cada vez que a criptografia é aplicada, dificultando-se a quebra da privacidade.

Deve-se notar que, se a assinatura digital do arquivo (presente no cabeçalho DICOM) for perdida/eliminada ou adulterada, nenhuma das imagens será recuperada, mantendo-se a privacidade do paciente. Além disso, qualquer adulteração em um frame, bem como a remoção de um frame inteiro, será detectada quando da verificação. No caso particular da remoção, há um efeito adicional: se o frame $\mathrm{j}$ for removido, não será possível recuperar nenhum frame $\mathrm{k}, \mathrm{k}>\mathrm{j}$, por causa da construção em cascata do algoritmo.

Com isso, pode-se dizer que há um vínculo forte entre a imagem médica e as suas informações de integridade e autenticidade, na medida em que estas devem estar necessariamente presentes e corretas no cabeçalho DICOM para a correta visualização das imagens.

Além disso, o uso dos dados do cabeçalho como nonce possibilita uma autenticação de tais dados, na medida em que eles devem estar íntegros para que o processo de verificação possa ser realizado com sucesso. Isso é uma característica adicional interessante, possibilitando autenticar informações relevantes como as do paciente e do especialista.

A aplicação da máscara A não é estritamente necessária, mas foi adotada para conferir um nível maior de segurança, já que o mascaramento leva a um embaralhamento adicional dos bits. Com este procedimento, o vínculo citado acima se torna mais forte. Além disso, como a máscara A não é armazenada, torna-se mais complicado para se recuperar as imagens originais sem as informações contidas na assinatura digital. Por outro lado, existe a questão do desempenho, pois a aplicação da máscara certamente demanda maior tempo de processamento.

Assim sendo, é possível propor não um, mas sim dois algoritmos, que podem ser utilizados de acordo com o compromisso que se assume acerca da relação segurança-desempenho. 
O primeiro algoritmo é exatamente o apresentado, onde a segurança ocupa um destaque maior. O segundo é o algoritmo proposto sem a aplicação da máscara, de forma que a segurança da imagem é menor, mas há um ganho correspondente no desempenho (Figura 28 e Figura 29).

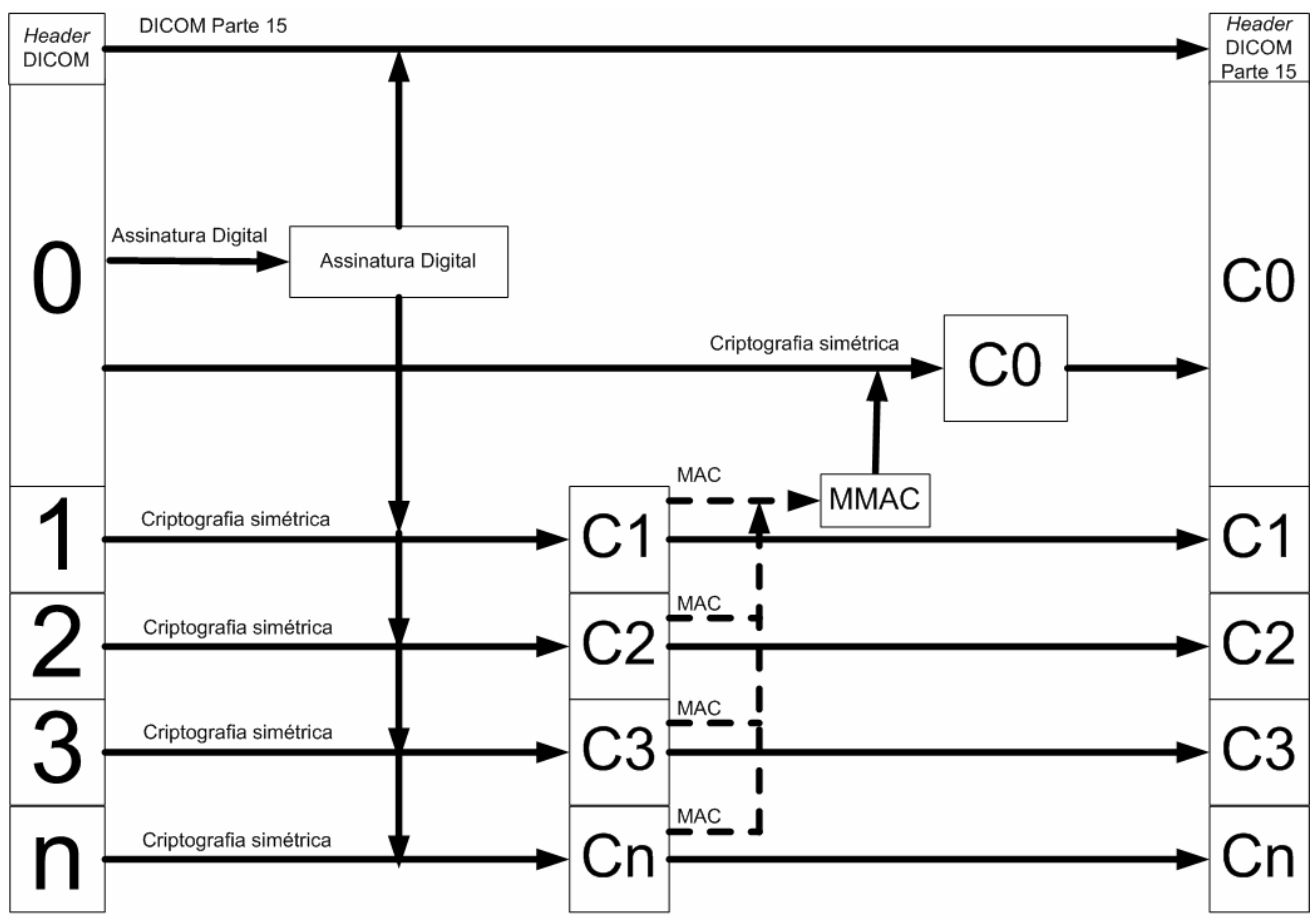

Figura 28 - A aplicação da segurança para a versão simplificada do algoritmo. 


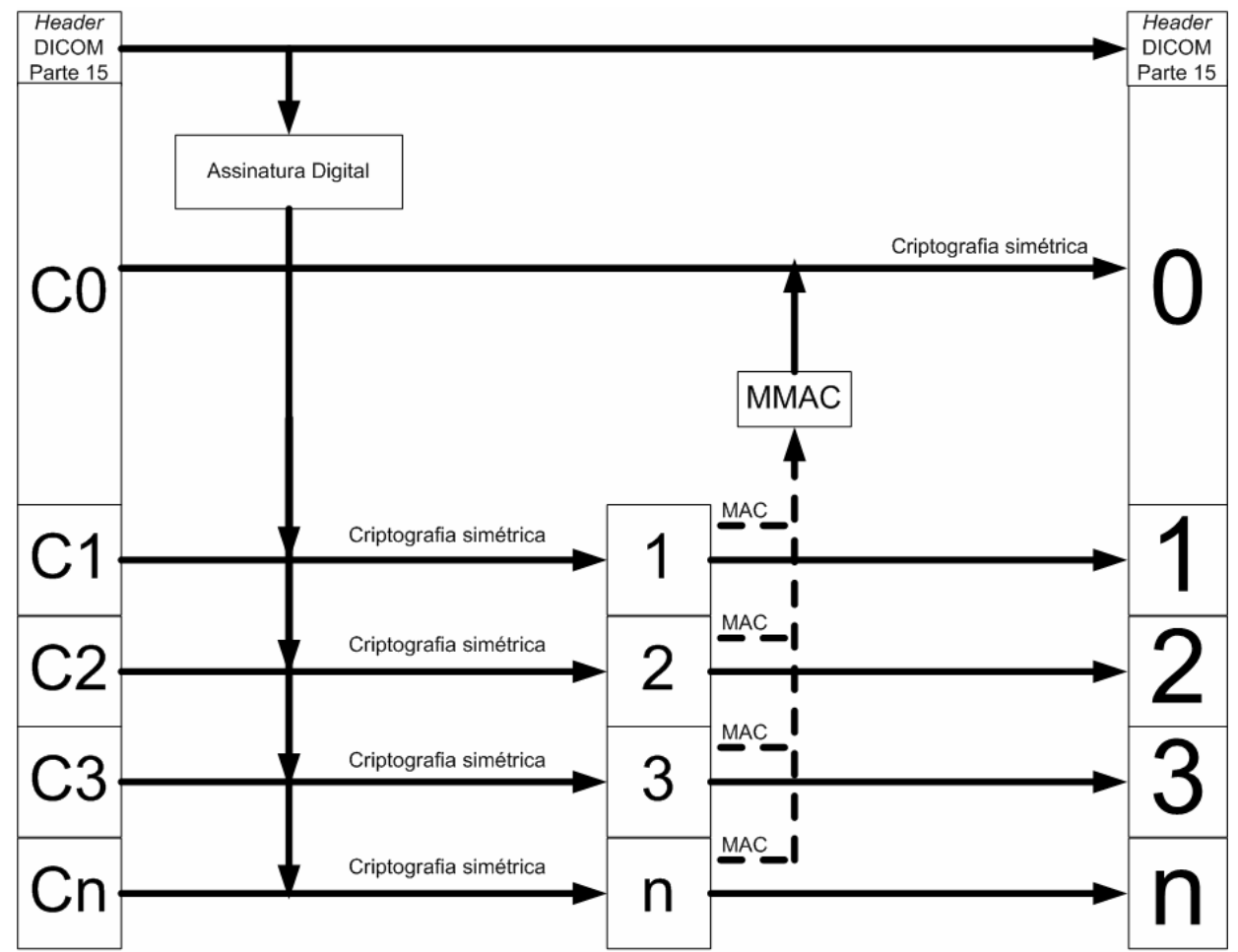

Figura 29 - A verificação da segurança para a versão simplificada do algoritmo.

\subsubsection{Simplificações que introduzem potenciais vulnerabilidades no algoritmo}

Existem algumas simplificações do algoritmo que podem comprometer, em maior ou menor grau, a sua segurança. Algumas simplificações possíveis, mas menos convenientes, são:

1) O uso puro e simples do "ou exclusivo"

Esta é a simplificação mais radical, onde a primeira imagem ou a sua transformação é aplicada como máscara sobre as demais imagens, utilizando-se a operação de "ou exclusivo". Entretanto, esta simplicidade faz com que a remoção de frames inteiros não seja detectada. Além disso, um agressor poderia adulterar os dados de forma que o "ou exclusivo" não possa detectar a adulteração. 
2) O uso em cascata do "ou exclusivo"

Esta é uma abordagem ainda mais ingênua, onde o frame n é mascarado pelo frame n-1. Neste caso, não há a necessidade de se conhecer a chave para se recuperar as imagens originais, uma vez que:

Seja $\mathrm{C}$ a imagem mascarada por (A XOR B), gerando $\mathrm{C}^{\prime}=((\mathrm{A}$ XOR B) XOR C). Assim, a imagem $D$, imediatamente posterior a $C$, seria mascarada por $C^{\prime}=((A$ XOR B) XOR C), gerando D' = (((A XOR B) XOR C) XOR D).

Ora, tendo-se C' e D', é trivial recuperar D, mesmo sem conhecer a máscara. Basta realizar a operação C' XOR D' e a imagem D será recuperada totalmente. Repetindo-se estes passos, é possível recuperar integralmente todas as imagens com exceção da primeira.

3) O uso apenas do hash, ao invés do par cifração/hash, para o mascaramento

Esta é uma proposta interessante, pois a máscara gerada seria tal que poderia detectar adulteração e remoção das imagens, com um tempo de processamento menor.

Entretanto, uma imagem n é bastante similar às imagens $(n-1)$ e $(n+1)$. Assim, sendo, a aplicação de uma mesma máscara M geraria imagens n', (n-1)’ e (n+1)’ que também são bastante similares entre si. Para uma seqüência suficientemente grande de imagens (ex: imagens de IVUS), existiria uma potencial vulnerabilidade, onde um agressor poderia utilizar a semelhança entre as imagens como uma informação $a$ priori para derivar informações acerca da imagem.

\subsection{Detalhes da Implementação}

Um pré-requisito essencial para a implementação é a existência de uma infraestrutura consolidada para intercâmbio digital de imagens no padrão DICOM, que, apesar da sua relevância, não será discutida neste trabalho.

A programação foi totalmente realizada em Java, pois é independente de plataforma e totalmente orientada a objetos, facilitando o design da solução.

O algoritmo utilizado para a assinatura digital foi o RSA com o SHA-1, que é a abordagem mais popular. No futuro, devem-se utilizar algoritmos mais recentes e 
mais robustos, uma vez que o SHA-1 está bastante fragilizado em termos criptográficos.

Para a criptografia simétrica, utilizou-se o algoritmo Phelix. E o cálculo do hash para a obtenção do MMAC foi feito utilizando-se o algoritmo Whirlpool.

$\mathrm{O}$ uso de algoritmos diversos de criptografia tem por objetivo reduzir as vulnerabilidades que podem ocorrer quando da quebra de um algoritmo. Podia-se obviamente escolher o SHA-1 ao invés do Whirlpool, mas a quebra do SHA-1 geraria duas vulnerabilidades (na assinatura digital e na obtenção do MMAC). Assim sendo, optou-se por pulverizar os algoritmos utilizados.

Da mesma forma, o fato do Phelix ser um algoritmo recente faz com que ainda não existam estudos mais aprofundados sobre a sua robustez a ataques, embora os resultados iniciais sejam bastante promissores. Assim sendo, utilizou-se um outro algoritmo para o cálculo do MMAC.

Foram também utilizados alguns pacotes e soluções já existentes para atender a determinados aspectos de segurança e de imagens médicas, os quais serão apresentados a seguir.

\subsubsection{Pacote de segurança do Java}

O Java possui um pacote exclusivo para a implementação de mecanismos de segurança, chamado de JCA (Java Cryptographic Architecture). Ele faz parte do ambiente de execução do Java 2 e é composta por uma sére de classes que provêm funções tais como assinaturas digitais e message digests (JAVA CRYPTOGRAPHIC ARCHITECURE, 2004). O JCA foi apresentado na primeira versão da API de segurança do Java, no Java Development Kit (JDK) 1.1 e, nas versões posteriores, o Java 2 Standard Development Kit (SDK) estendeu de maneira significativa as funcionalidades do JCA, incluindo o suporte a certificados X.509 v3 e controle de acesso flexível e extensível.

O JCA pode ser complementado pelo JCE (Java Cryptographic Extension), integrado atualmente no Java 2 SDK v 1.4, que adiciona algumas funcionalidades simples de criptografia ao JCA, tais como Message Authentication Code (MAC), de forma que, em conjunto, os dois pacotes provêem uma API completa e independente de plataforma para criptografia. 
O JCA foi projetado de acordo com dois princípios: independência de implementação e interoperabilidade; independência e extensibilidade de algoritmos. Em outras palavras, é possível utilizar serviços de segurança, tais como assinaturas digitais e message digests, sem se preocupar com os detalhes de implementação nem com os algoritmos que formam a base de tais conceitos. Quando a independência completa de algoritmos não é possível, o JCA provê APIs padronizados e específicos para cada algoritmo. Quando a independência de implementação não é desejável, o JCA permite que os desenvolvedores indiquem uma implementação específica.

A independência de algoritmos é alcançada através da definição de engines (serviços) de criptografia e da definição de classes que irão prover a funcionalidade desses engines. A independência da implementação é obtida através de uma arquitetura baseada em provider (provedor), que consiste em um conjunto de pacotes que implementam um ou mais serviços de segurança. A interoperabilidade de implementação significa que as várias implementações existentes podem operar umas com outras, usar as chaves umas das outras ou verificar a assinatura umas das outras. Isso significa, por exemplo, que para um dado algoritmo, uma chave gerada por um provedor pode ser usada por outro. A extensibilidade do algoritmo significa que os novos algoritmos que se encaixem em uma das classes suportadas de engine podem ser adicionados com facilidade.

\subsubsection{JDT}

O JDT (Java DICOM Toolkit) é um conjunto de ferramentas que provê uma série de classes em Java para a implementação de soluções em DICOM, incluindo um dicionário com todas as entidades definidas na edição de 2003 do padrão, juntamente com as ferramentas necessárias para a comunicação DICOM (SOFTLINK JAVA DICOM TOOLKIT, 2004).

Com relação à parte de imagens, existe suporte à codificação Run-Length Encoding (RLE) e JPEG. É possível ler e escrever dados em DICOM para streams em Java, existindo um mapeamento direto entre as representações de valores do DICOM e os tipos primitivos encontrados em Java. 


\subsubsection{Phelix}

Para a criptografia simétrica, foi utilizado o algoritmo Phelix (WHITING et al, 2004). Este é um algoritmo extremamente recente de stream cipher, com várias propriedades interessantes, em particular: a sua velocidade (maior do que o AES) e a geração quase simultânea do hash, juntamente com os dados criptografados.

Sendo um algoritmo recente, deve-se obviamente ter em mente que ainda não é largamente aceito como um algoritmo seguro, mas até agora não se descobriu uma forma eficiente de quebrá-la. O fato de ser classificado para a segunda fase do programa eSTREAM na categoria Focus também é relevante.

\subsection{Passos da Implementação}

Como citado anteriormente, utilizou-se o desenvolvimento evolucionário. Os passos definidos para a implementação até o estágio atual foram:

1) desenvolver módulos de adicionar e verificar a integridade e autenticidade através da assinatura digital;

2) tornar a solução DICOM-compliant de acordo com o perfil Base RSA profile definido no Suplemento 41 do padrão;

3) implementar a interface de leitura/escrita com certificados digitais;

4) codificar os métodos para adição da segurança;

5) codificar os métodos para verificação da segurança.

\subsection{Implementação Atual}

Os passos acima foram implementados com sucesso. Desenvolveu-se uma classe para calcular a assinatura digital e outra para armazenar a assinatura no cabeçalho DICOM.

Com isso, pode-se assinar uma imagem DICOM de acordo com a Parte 15, como mostra o exemplo da Figura 30. Isso permite que possa ser feita a verificação posterior da integridade e autenticidade da imagem, e é fundamental para a implementação do algoritmo proposto neste trabalho. 

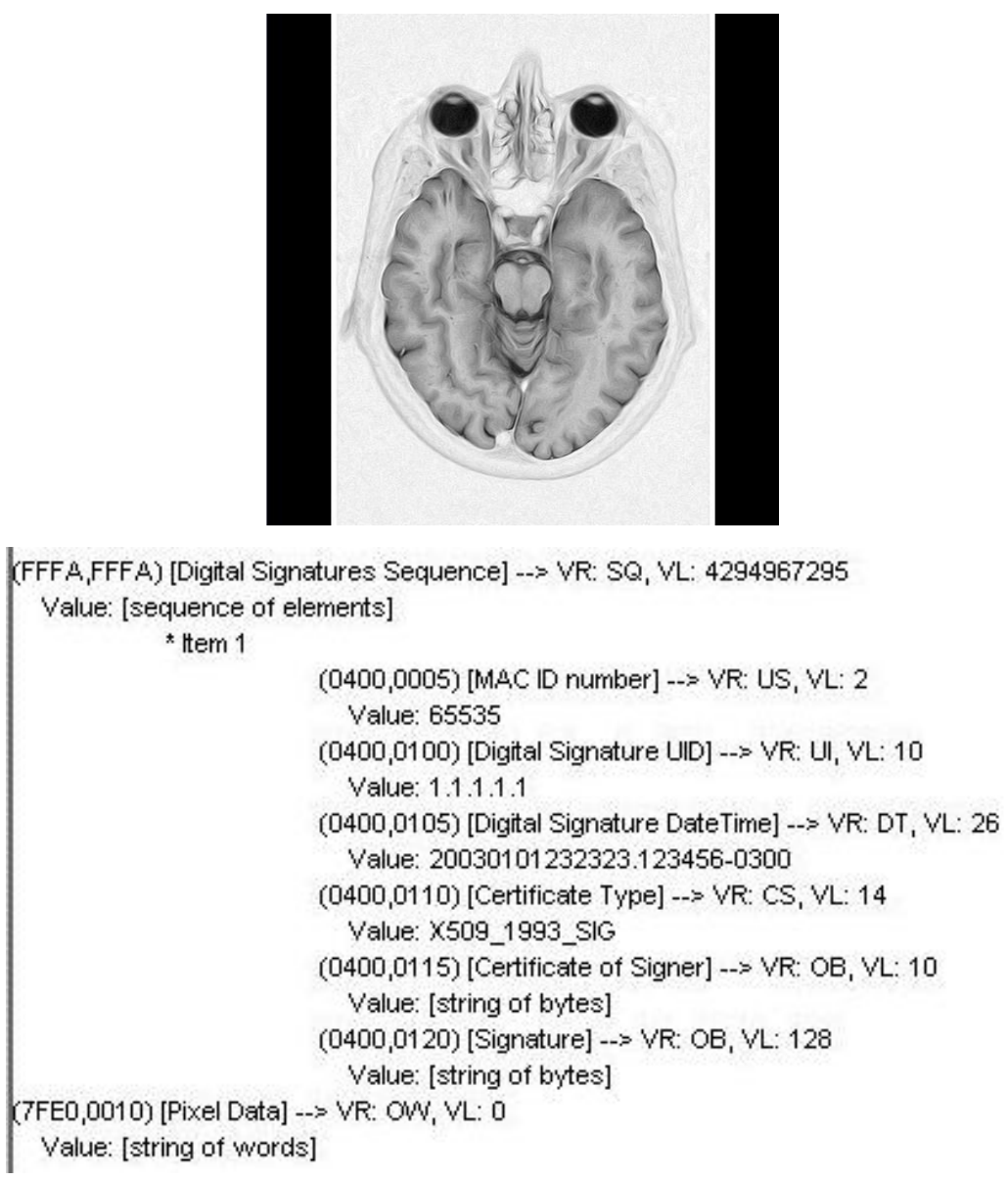

Figura 30 - Exemplo de uma imagem DICOM (acima) e os dados da assinatura digital em seu cabeçalho (abaixo).

A obtenção das chaves pública e privada do usuário também foi implementada, com a geração de certificados digitais locais para a validação da solução. Quando a imagem é assinada, a assinatura é guardada no cabeçalho da imagem, juntamente com o certificado digital contendo a chave pública para o processo de verificação.

A criptografia das imagens foi desenvolvida com sucesso, seguindo-se os passos propostos no algoritmo. Com isso, gerou-se uma classe que é responsável pela cifração e decifração dos dados. Em particular, a implementação permite a criptografia de imagens multiframe. A Figura 31 mostra uma imagem multiframe e o resultado após a criptografia.

Uma característica da implementação é a geração de diversas imagens temporárias tanto para cifração quanto para a decifração. Para arquivos grandes - o 
conceito de "grande" é relativo e depende do perfil da estação em que o processamento é realizado - é impraticável alocar todos os dados na memória. Assim sendo, optou-se pela escrita em disco, permitindo o processamento de arquivos de quaisquer tamanhos, desde que exista espaço livre suficiente em disco. 


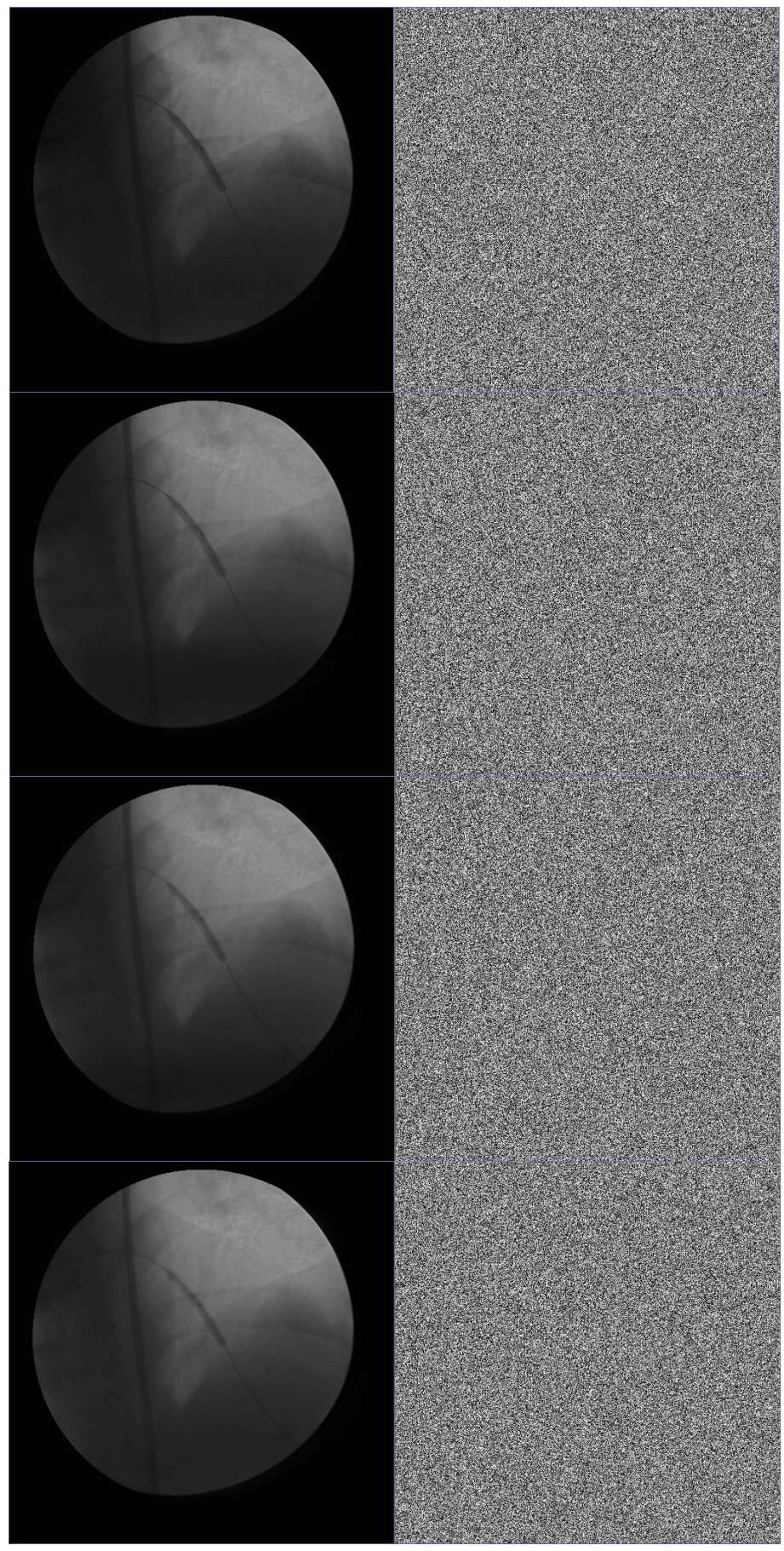

Figura 31 - Exemplo de imagem multiframe (à esquerda) com os respectivos frames criptografados (à direita). 


\subsection{Síntese}

Neste capítulo, foi modelado o problema e os possíveis casos de uso. Com isso, foram gerados diagramas para modelar a estrutura e o comportamento da solução.

Com isso, foi proposta a abordagem, utilizando mecanismos criptográficos, para integridade e autenticidade em imagens médicas. Tal abordagem foi implementada através de um algoritmo em cascata utilizando os dados da imagem e do cabeçalho DICOM para cifrar a imagem e estabelecer um vínculo forte entre a imagem e suas informações de integridade e autenticidade.

A codificação propriamente dita foi feita utilizando-se a linguagem Java e ferramentas adequadas para o processamento. Os algoritmos de segurança (criptografia simétrica, hash e assinatura digital) foram escolhidos dentro de critérios para atender a determinados requisitos da solução. 


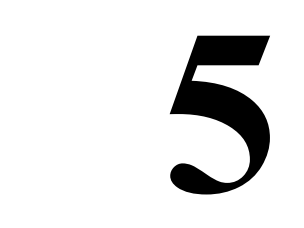

\section{Resultados}

"You may never know what results come of your action,

but if you do nothing there will be no result."

MAHATMA GANDHI

\section{Resumo deste Capítulo}

- descrição da implementação

- algoritmos utilizados para comparação

- fatores relevantes para o desempenho do algoritmo

- análise comparativa de desempenho para imagens multiframe e multislice

- avaliação de similaridade

\subsection{Detecção de Violação da Integridade e Autenticidade}

A detecção da adulteração da imagem, por menor que ela seja, é uma característica fundamental que o algoritmo deve prover. A Figura 32 mostra o resultado de uma adulteração em um único bit no segundo frame.

Pela própria construção do algoritmo, o primeiro e todos os frames subseqüentes ao frame adulterado serão degradados, ou seja, não será possível recuperá-los corretamente. No exemplo da figura, a existência de apenas três frames faz com que a imagem toda esteja degradada. O usuário vê, assim, apenas ruído quando da visualização. 


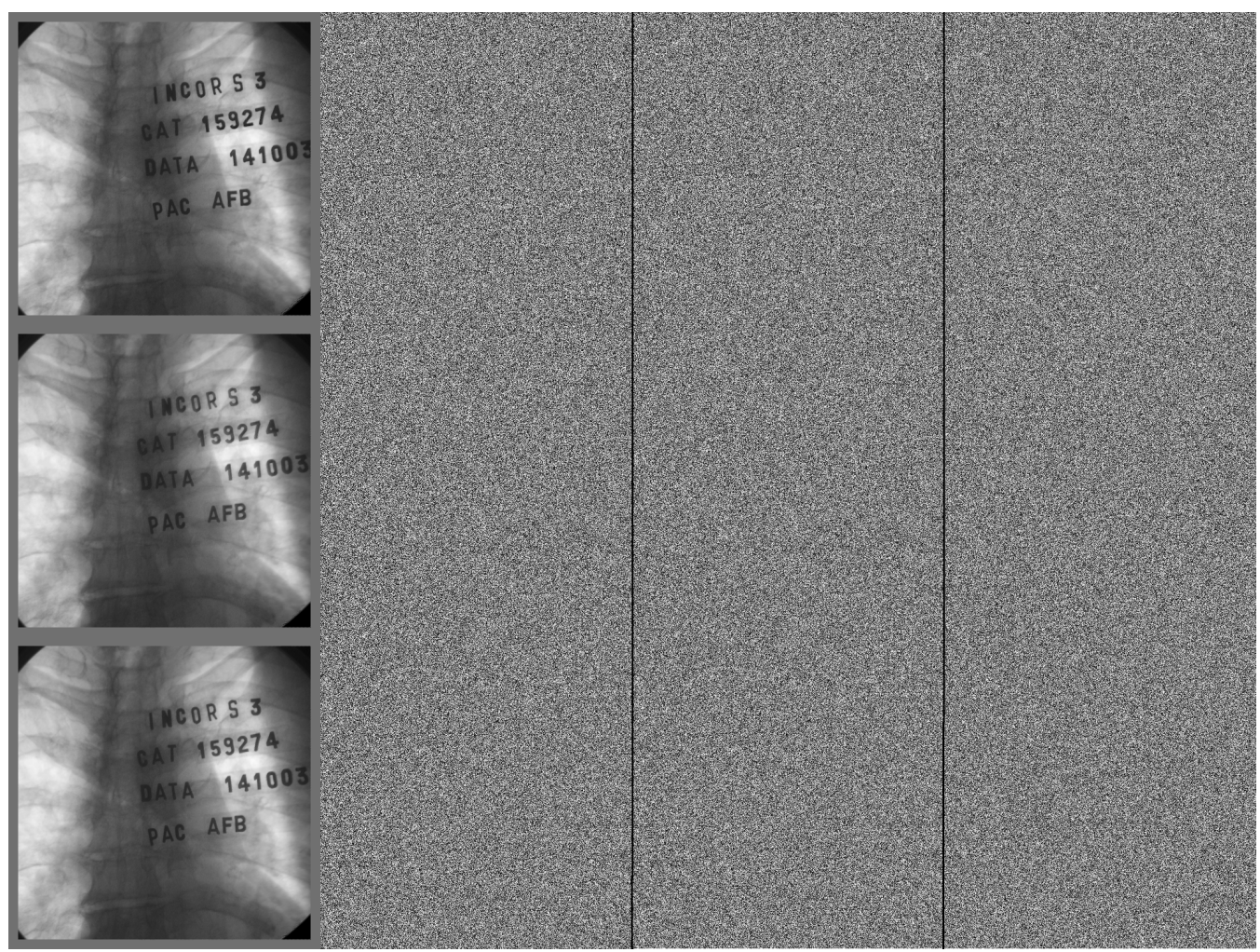

Figura 32 - O resultado da adulteração da imagem cifrada em um bit no segundo

frame. Da esquerda para a direita: a imagem original, sua versão cifrada, a adulteração em um bit e a imagem recuperada (decifrada).

Por outro lado, se a adulteração acontecer em um frame $\mathrm{n}, \mathrm{n}>2$, todos os frames $\mathrm{p}<\mathrm{n}$ continuarão sendo recuperados normalmente, com a exceção do primeiro $(p=1)$. A Figura 33 ilustra bem esse caso, mostrando o efeito da adulteração no último frame, fazendo com que ainda seja possível visualizar uma parte dos dados.

Com isso, observa-se que o algoritmo oferece provas visuais ao usuário acerca da integridade e da autenticidade das imagens. É relevante apontar o fato de que a prova da adulteração é a geração de ruído, o que permite diferenciar facilmente os dados íntegros dos dados violados.

Por outro lado, a geração de tais provas é apenas parcial, ou seja, é possível ter situações em que o usuário não terá tal evidência visual em toda a imagem. Entretanto, a ausência da evidência visual em algumas porções da imagem significa que estas estão íntegras a priori. Deve-se também observar que o fato de poder recuperar partes do dado original pode ser uma vulnerabilidade para a quebra do algoritmo. 


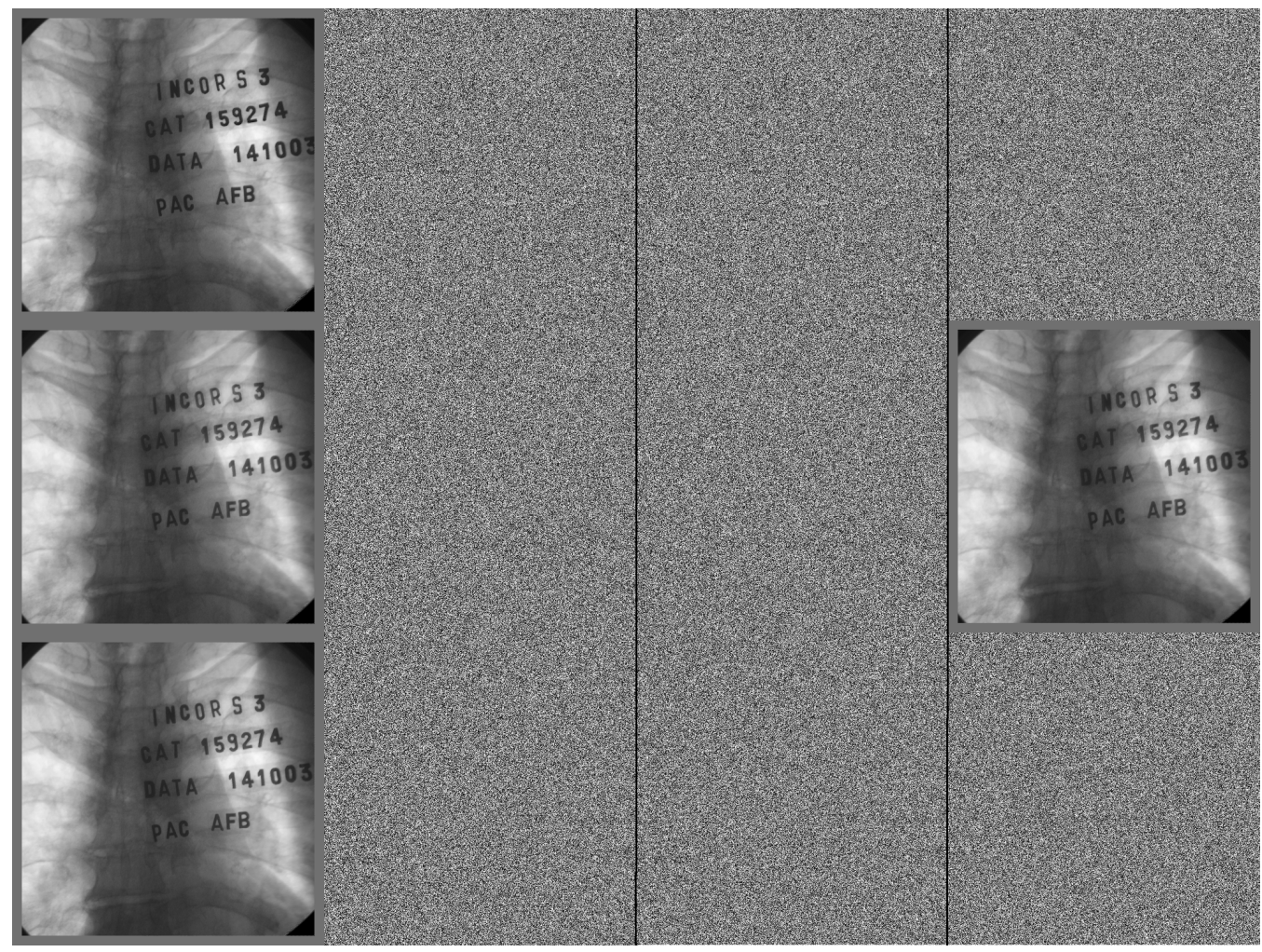

Figura 33 - O resultado da adulteração da imagem cifrada em um bit no último

frame. Da esquerda para a direita: a imagem original, sua versão cifrada, a adulteração em um bit e a imagem recuperada (decifrada).

\subsection{Fatores relevantes para o desempenho}

A eficiência do algoritmo proposto para a cifração e decifração dos dados é intrinsecamente dependente da velocidade dos processamentos realizados no algoritmo.

Desta forma, é necessário conhecer quais etapas do processamento são mais onerosos em termos de tempo, para que otimizações possam ser consideradas. Assim, para explicitar melhor as parcelas de tempo, foram escolhidas cinco seqüências de imagens de IVUS (ultra-som intravascular) de tamanhos superiores a $100 \mathrm{MB}$.

Para a cifração, os fatores mais importantes são a criptografia em si das imagens e a aplicação da máscara, como mostra o gráfico abaixo para as cinco maiores imagens utilizadas na avaliação (Figura 34). 
Fatores atuantes na cifração

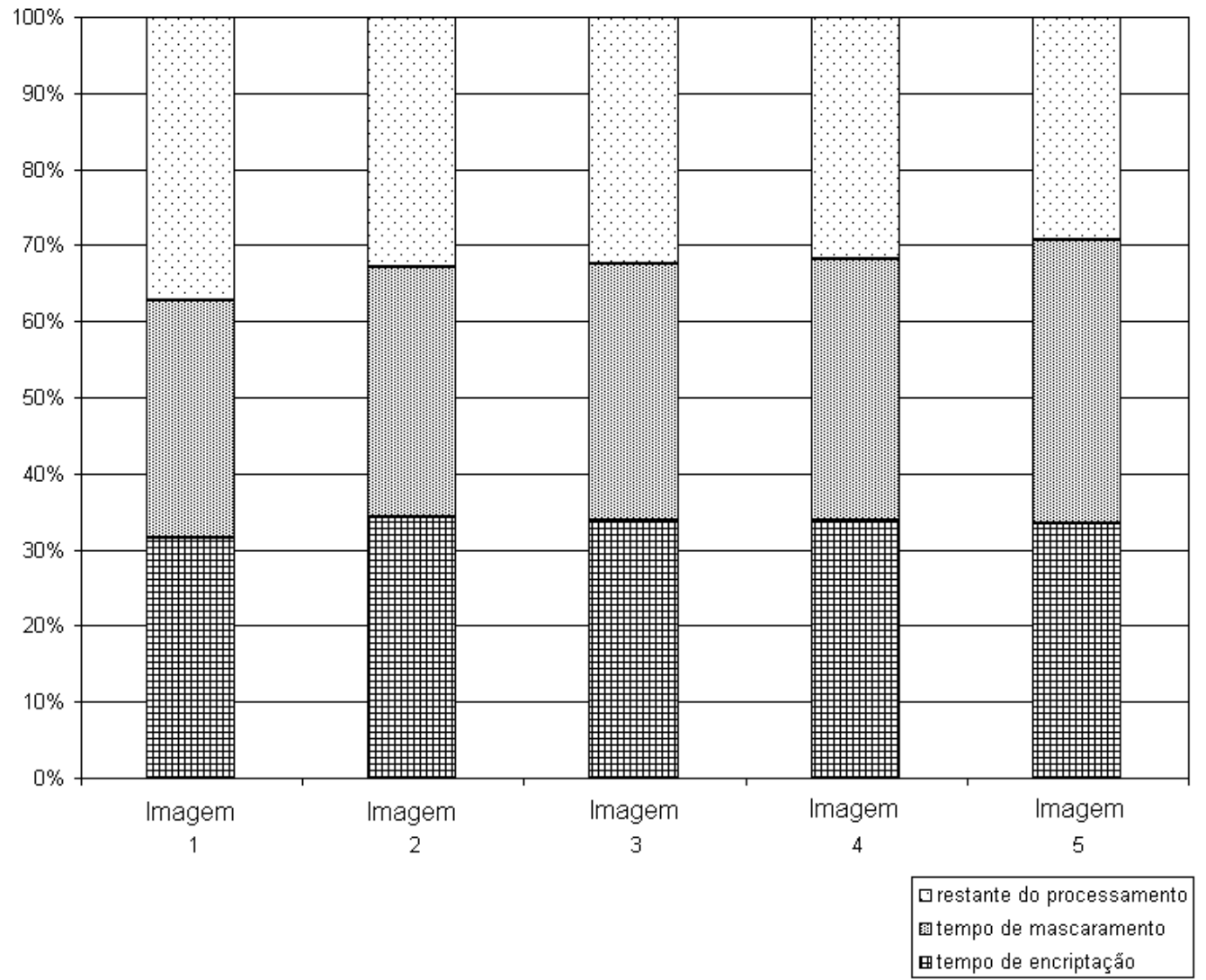

Figura 34 - Fatores atuantes na cifração.

E, para a decifração, os fatores que possuem maior peso são o tempo de leitura do cabeçalho DICOM (o que inclui o pré-processamento da imagem), o mascaramento, a decifração em si e o tempo em escrita em disco dos dados recuperados, como mostra o seguinte gráfico para as mesmas cinco imagens (Figura 35): 
Fatores atuantes na decifração

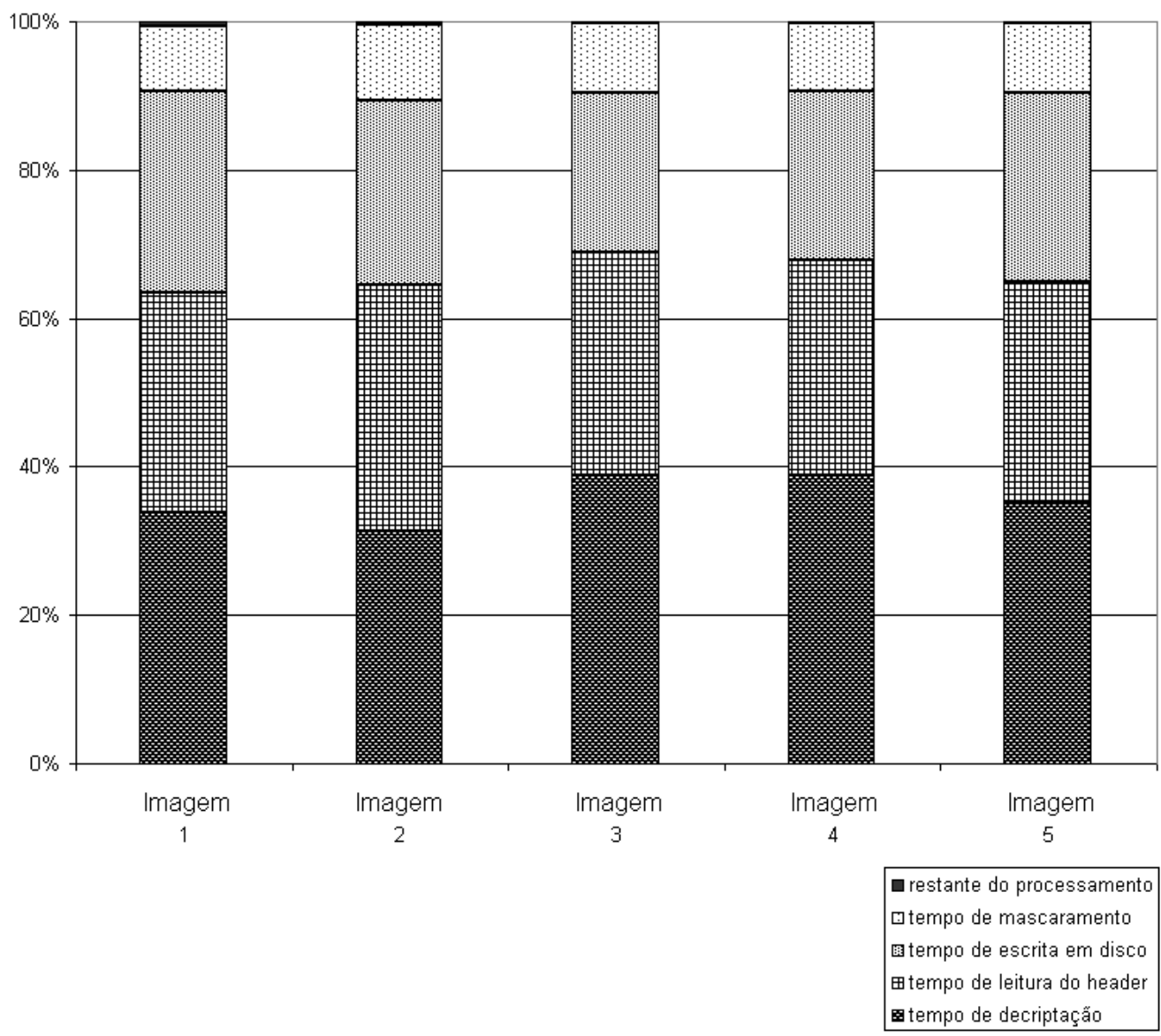

Figura 35 - Fatores atuantes na decifração.

Em termos de implementação, a otimização dos algoritmos de mascaramento e de cifração/decifração não é algo trivial. Para o processo de decifração, que é o mais crítico em termos de desempenho, uma vez que afeta diretamente o usuário final, deve-se então tentar melhorar prioritariamente os tempos de leitura do cabeçalho DICOM e o tempo de escrita em disco dos dados recuperados.

A construção em forma de cascata para a cifração/decifração e o processo de mascaramento faz com que as imagens intermediárias só sejam descartadas após o término de todo o processamento. Como a implementação deve ser capaz de lidar com arquivos grandes, optou-se por armazenar arquivos temporários em disco para evitar estouro de memória, embora incorresse em um custo maior de tempo. Esta característica da implementação será abordada na discussão. 


\subsection{Avaliação comparativa de desempenho}

A questão do desempenho pode ser crucial para a viabilidade do sistema. Para se analisar a performance do algorimo, testes de avaliação de desempenho foram realizados.

A avaliação se deu em duas frentes: o desempenho para imagens multislice, em que o armazenamento é feito em séries de arquivos contendo uma única imagem (slice), e para multiframe, em que um único arquivo contém todas as informações adquiridas do equipamento; A primeira visa avaliar a velocidade para um grande número de imagens de tamanho reduzido (menor do que $1 \mathrm{MB}$ por imagem), enquanto que a segunda pretende realizar a medição para dados volumosos armazenados em um único arquivo.

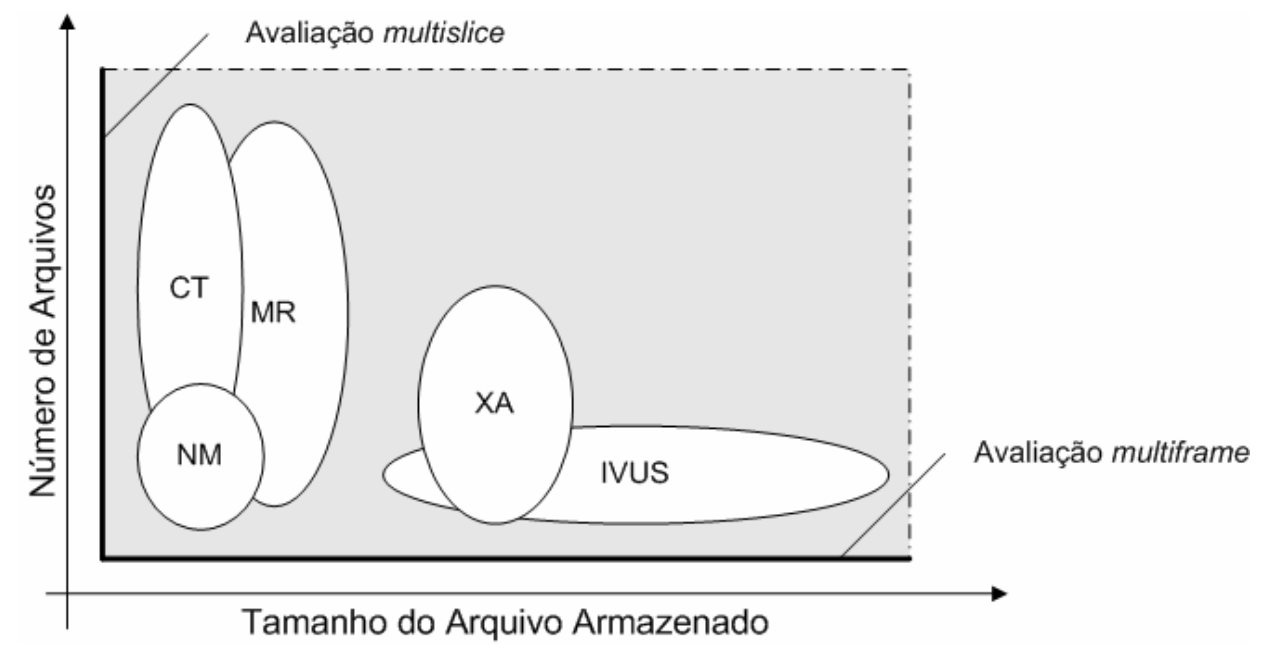

Figura 36 - Gráfico ilustrativo mostrando o perfil de algumas modalidades em termos de armazenamento a cada estudo realizado.

Com isso, é possível levantar estimativas de intervalos de tempos de cifração e decifração em função do tamanho e do número de imagens. A Figura 36 mostra o perfil de armazenamento para algumas modalidades a cada estudo realizado.

\subsubsection{Algoritmos utilizados}

Para a avaliação, foram escolhidos seis algoritmos, além do proposto neste trabalho, para uma análise comparativa do desempenho, que serão descritos a seguir. 


\subsubsection{Assinatura digital sem otimização}

Um dos algoritmos foi a assinatura digital sem otimização, também denominada neste trabalho de assinatura digital convencional, onde a assinatura foi feita byte a byte, lendo-se cada dado do disco. Cabe lembrar que a leitura byte a byte do disco envolve uma demora considerável por causa do acesso ao disco. Além disso, a assinatura do arquivo inteiro é a abordagem mais lenta possível, pois é a que assina o maior volume possível de dados. Assim, este foi considerado o worst case algorithm.

\subsubsection{Assinatura digital otimizada}

A assinatura digital otimizada é idêntica à assinatura convencional, com a diferença de que a maior parte do processamento foi feita em memória. Isso permite uma velocidade muito maior no processamento quando comparado ao método anterior.

\subsubsection{Algoritmo proposto, sem o mascaramento}

Uma das variantes para a abordagem discutida neste trabalho é a retirada do mascaramento XOR na etapa final do algoritmo, supondo-se que o mascaramento não aumente significativamente a segurança. É interessante avaliar o desempenho deste algoritmo, pois pode ser uma alternativa para prover integridade e autenticidade a um custo temporal menor, embora sacrifique a segurança adicional do mascaramento.

\subsubsection{Algoritmo utilizando AES em Galois Counter Mode (GCM)}

Uma outra forma possível de se implementar a abordagem proposta é utilizando AES (Advanced Encryption Standard) em Galois Counter Mode (GCM).

O AES é um algoritmo de criptografia simétrica desenvolvida por Rijmen e Daemen, padronizada pelo NIST (National Institute of Standards and Technology) em 2002 e um dos algoritmos mais populares atualmente de criptografia.

Esse algoritmo possui alguns modos de operação, ou seja, maneiras de utilização visando atingir determinados objetivos. Dentre eles, o Galois Counter Mode (GCM) é de interesse no escopo deste trabalho, pois provê uma cifração com autenticação, gerando os dados criptografados e um dado de autenticação, chamado 
de Authentication Tag, que permite a verificação de integridade. Este modo também foi padronizado pelo NIST (MCGREW E VIEGA, 2005).

O Authentication Tag foi por sua vez assinado utilizando-se ECDSA (Elliptic Curve Digital Signature Algorithm). Este algoritmo também é bastante utilizado atualmente, tendo a propriedade bastante interessante de gerar assinaturas mais curtas do que o algoritmo DSA (Digital Signature Algorithm), ao mesmo tempo em que mantém as mesmas propriedades de segurança (ACCREDITED STANDARDS COMMITTEE X9, 2005).

Assim, para a avaliação, escolheu-se utilizar o AES em GCM com uma chave de 256 bits e um vetor de inicialização de 96 bits. A assinatura foi feita utilizando-se ECDSA com uma chave de 256 bits, e armazenada nos ditames estabelecidos pela Parte 15 do padrão DICOM.

Uma observação que deve ser feita é o nível de segurança: o ECDSA em 256 bits é equivalente ao RSA em 3072 bits, significando tempos maiores de processamento. Entretanto, para fins desta avaliação, assumiu-se que o acréscimo de tempo é pequeno quando comparado ao restante do processamento.

O processo de cifração em si inicia-se com a obtenção da chave e do vetor de inicialização. A partir dos dados do cabeçalho, é computado um hash utilizando-se o algoritmo Whirlpool. A partir dele, são extraídos a chave e o vetor de inicialização para a cifração (Figura 37).

No final deste processo, é gerado o Authentication Tag, que é assinado e armazenado no cabeçalho DICOM.

O processo de recuperação dos dados é semelhante: é obtido o hash dos dados do cabeçalho, a partir do qual se realiza o processo de decifração e a geração do Authentication Tag. Este, por sua vez, é comparado com a assinatura digital armazenada no cabeçalho para que se possa inferir sobre a integridade e a autencidade da imagem. 


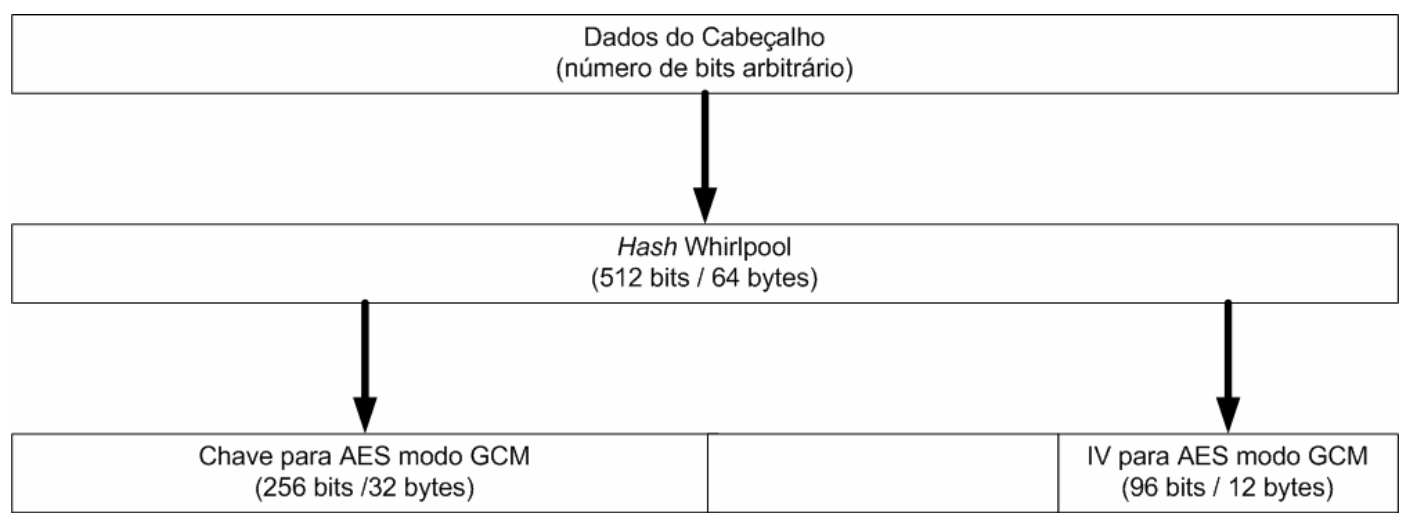

Figura 37 - Obtenção da chave e do vetor de inicialização para AES em modo

GCM.

\subsubsection{Algoritmo de marca d'água com substituição no bit menos significativo $(L S B)$}

Para o processo de avaliação comparativa, é necessário incluir algoritmos utilizando marcas d'água, uma vez que inúmeros trabalhos propõem o seu uso para a integridade e autenticidade em imagens médicas.

Assim, implementou-se um algoritmo baseado no trabalho de Zhou e Huang (2001), onde a região de interesse (ROI) da imagem é assinada digitalmente e a assinatura é armazenada na própria imagem, utilizando-se um algoritmo para gerar as coordenadas onde a assinatura será gravada.

O trabalho em questão se foca especificamente em dados de mamografia, e inúmeros parâmetros não se aplicam para outras modalidades, como ultra-som. Além disso, não é trivial adaptar tais parâmetros para diferentes tipos de modalidades. Assim sendo, optou-se por implementar um algoritmo que emulasse o custo computacional do mecanismo proposto por Zhou e Huang.

Uma outra limitação desse trabalho, da forma como foi originalmente proposto, é a ausência de propostas para imagens multiframe. Para fins desta avaliação, cada frame foi assinada e marcada digitalmente.

\subsubsection{Algoritmo de marca d'água utilizando wavelets de Haar}

Este algoritmo foi baseado em um trabalho publicado por Giakoumaki et al (2006), propondo a decomposição em 4 níveis para a inserção da marca d'água nos 
coeficientes de Haar. O algoritmo implementado também emula o custo computacional do algoritmo proposto.

Este algoritmo possui a mesma limitação do algoritmo anterior, que é a ausência de propostas para imagens multiframe. Para fins desta avaliação, cada frame foi assinada e marcada digitalmente.

\subsubsection{Resultados}

Foram obtidos gráficos para o desempenho da cifração/decifração de imagens multislice e multiframe para os algoritmos descritos na seção anterior. Para a identificação dos algoritmos, a seguinte notação foi utilizada:

- LKB: o algoritmo proposto neste trabalho;

- LKB Light: o algoritmo sem o mascaramento XOR;

- LKB-GCM: a cifração utilizando AES em Galois Counter Mode;

- LKB-Haar: a marca d'água utilizando wavelets Haar;

- LKB-LSB: a marca d'água utilizando substituição no bit menos significativo.

\subsubsection{Condições dos Testes}

Todas as simulações foram executadas em um Pentium 4, 3GHz, $1 \mathrm{~GB}$ RAM, dedicado exclusivamente para o teste, visando reduzir interferências de processos que poderiam ser disparados e interferir na avaliação.

Os testes foram executados seqüencialmente para a medição dos tempos. Cada avaliação foi executada cinco vezes, com o objetivo de reduzir flutuações. Todavia, deve-se ressaltar que, para cargas muito grandes e portanto muito demoradas, a probabilidade de acontecer alguma interferência é bastante alta, o que se refletiu na variação do comportamento dos gráficos para testes com grande número de imagens.

\subsubsection{Avaliação para imagens multislice}

A avaliação multislice foi feita para imagens de CT (Tomografia Computadorizada). A tomografia foi escolhida por ser uma modalidade que armazena cada seção em um arquivo diferente e, para exames de corpo inteiro, pode 
ultrapassar 1500 arquivos (seções), configurando-se como um caso de estudo ideal. Para este projeto, foram utilizadas imagens disponíveis no Osirix (OSIRIX, 2006).

A Figura 38 mostra graficamente o desempenho dos algoritmos para a aplicação dos mecanismos de integridade e autenticidade. Deve-se notar que todos mostraram uma resposta aproximadamente linear entre o número de imagens e o tempo gasto no processamento.

O pior algoritmo foi a assinatura digital convencional, demorando quase uma hora para assinar séries mais volumosas. A marca d'água utilizando wavelets de Haar mostrou também um desempenho bastante pobre, sendo melhor apenas do que a assinatura digital convencional.

Os demais algoritmos mostraram comportamentos bastante semelhantes, demorando por volta de dez minutos para cifrar uma série de mil e quinhentas imagens, como mostra a Figura 39. Entretanto, não é usual ter séries tão volumosas. Tomografias da região torácica, por exemplo, costumam ter por volta de quinhentas imagens. Dentro dessa perspectiva, pode-se esperar que o processo de adição de informações de segurança leve aproximadamente três minutos. 
Tempo gasto para a aplicação dos mecanismos de segurança

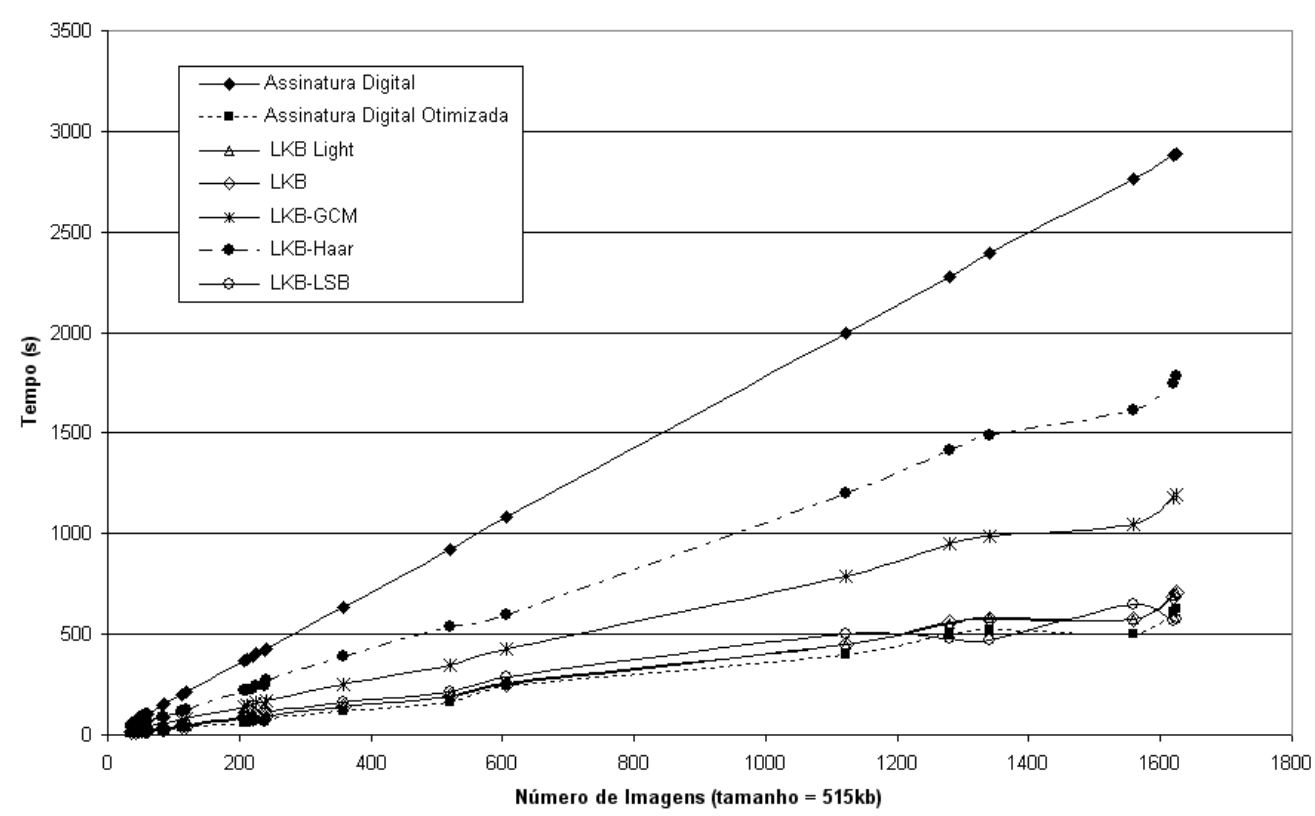

Figura 38 - Tempo gasto para aplicação dos mecanismos de segurança em imagens multislice.

Tempo gasto para a aplicação dos mecanismos de segurança

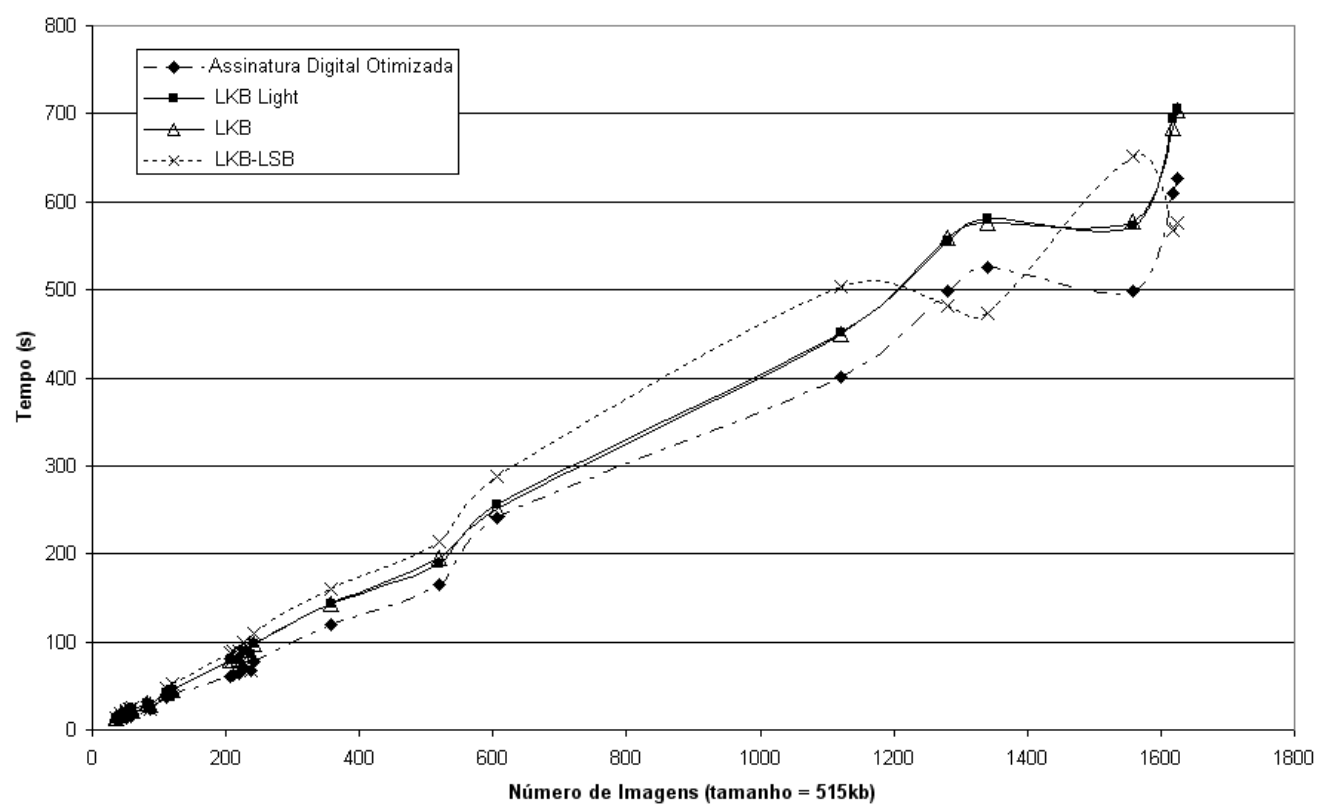

Figura 39 - Tempo gasto para aplicação dos mecanismos de segurança em imagens multislice para os quatro algoritmos de melhor desempenho. 
A avaliação para a verificação de integridade e autenticidade das imagens multislice mostrou um comportamento similar, como exibido pela Figura 40. Novamente, a assinatura digital convencional levou um tempo considerável para a verificação, necessitando de quase cinqüenta minutos em caso de séries maiores.

A marca d'água utilizando wavelets de Haar foi o algoritmo com o segundo pior desempenho. O uso de AES em Galois Counter Mode ficou em terceiro lugar, levando mais de quinze minutos para conjuntos com mais de mil e quatrocentros slices. Cabe notar que o desempenho dessa abordagem se provou significativamente mais lenta que os quatro algoritmos restantes.

A Figura 41 mostra que os dois algoritmos mais rápidos são a assinatura digital otimizada e a marca d'água utilizando substituição no bit menos significativo, levando aproximadamente oito minutos para verificar as séries mais volumosas. O método em cascata proposto neste trabalho provou ser aproximadamente um minuto mais lento que os dois, e a sua versão sem o mascaramento mostrou ter um desempenho praticamente idêntico.

Supondo-se novamente um conjunto de quinhentos slices, a abordagem proposta neste trabalho consumiria aproximadamente três minutos para realizar a verificação, um custo similar ao da sua aplicação. Os dois métodos mais velozes apresentam tempos menores para a verificação quando comparados aos tempos para a geração e armazenamento das informações de integridade e autenticidade.

Discussões mais aprofundadas sobre os resultados obtidos estão presentes na Subseção 5.3.3 e no Capítulo 6. 
Tempo gasto para a verificação dos mecanismos de segurança

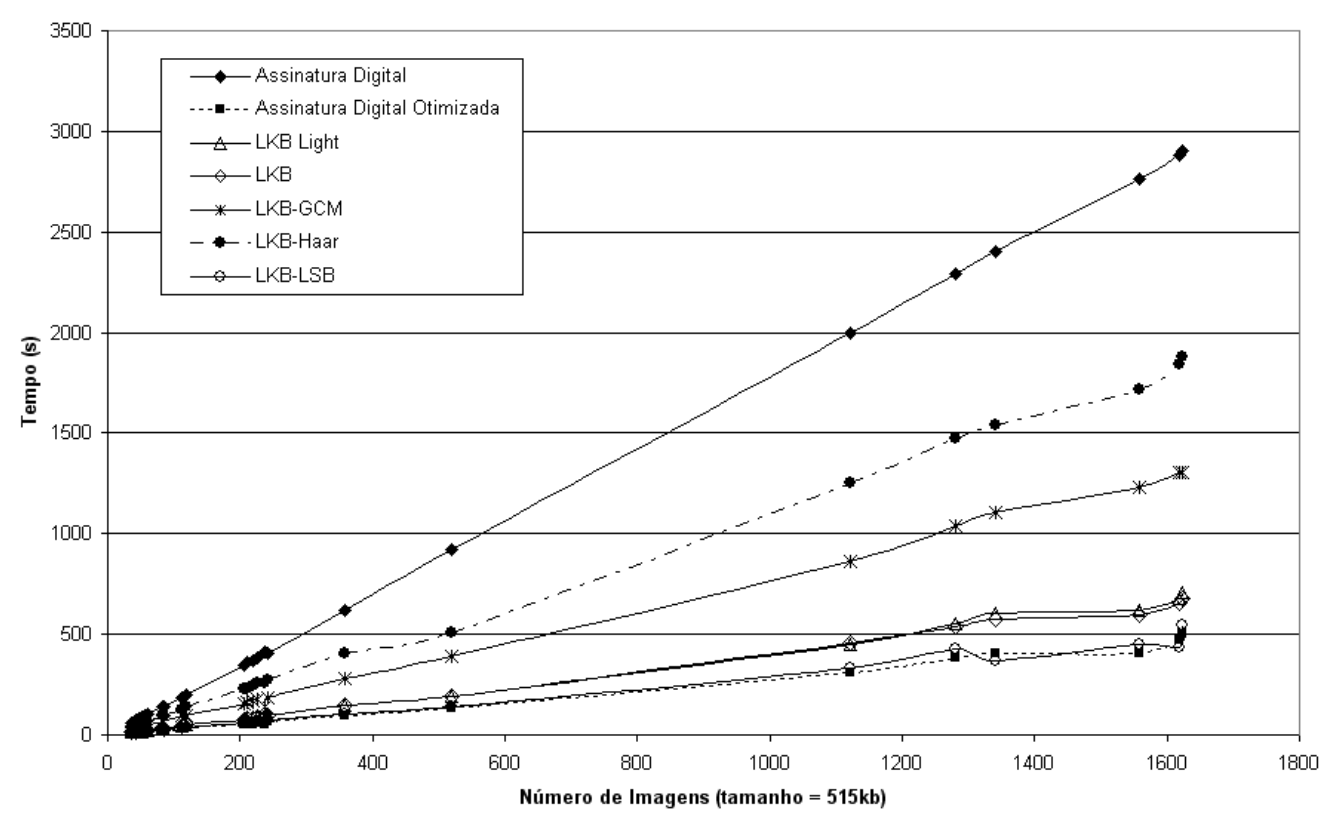

Figura 40 - Tempo gasto para verificação dos mecanismos de segurança em imagens multislice.

Tempo gasto para a verificação dos mecanismos de segurança

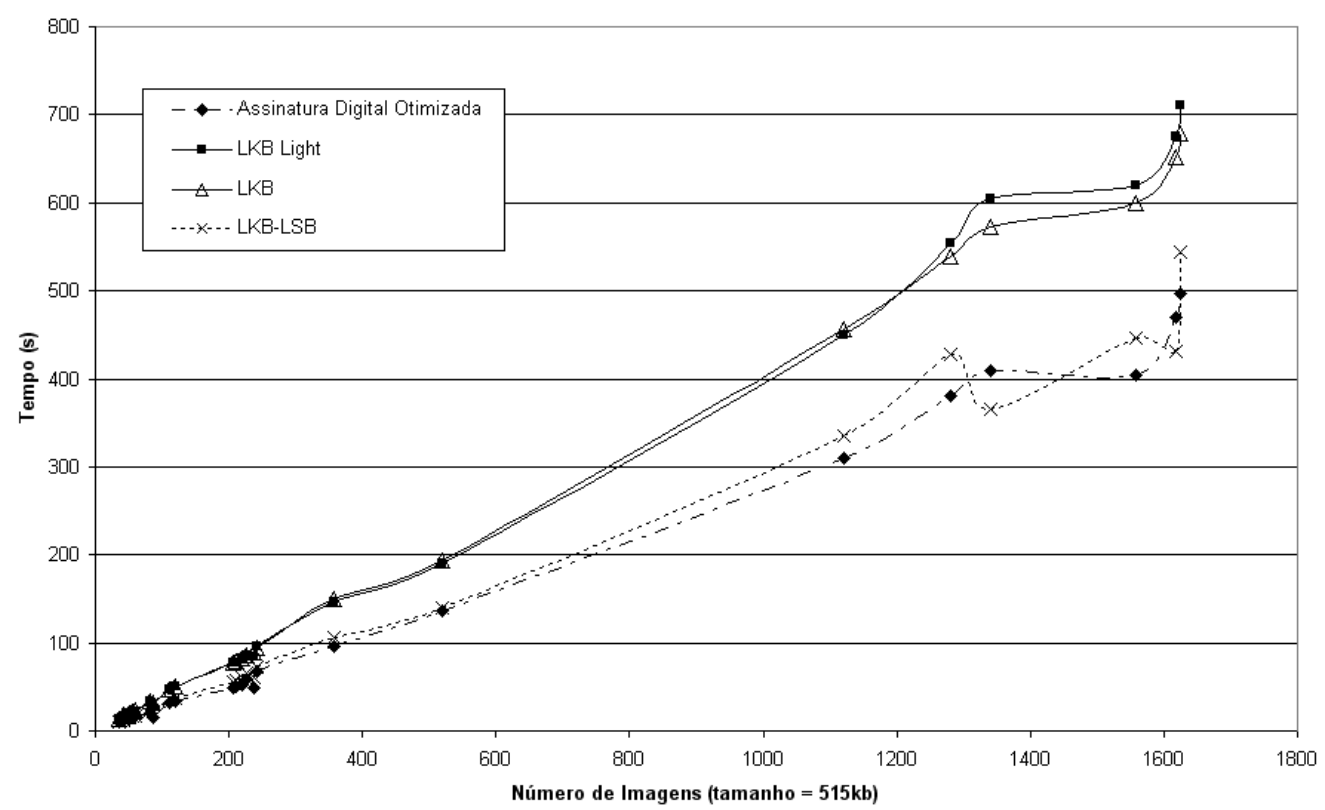

Figura 41 - Tempo gasto para verificação dos mecanismos de segurança em imagens multislice para os quatro algoritmos de melhor desempenho. 


\subsubsection{Avaliação para imagens multiframe}

A avaliação multiframe foi feita para imagens de IVUS (Ultra-som Intravascular), de dimensões $480 \times 480$ e profundidade de 8 bits. A escolha se deu pelo fato de serem armazenados em um único arquivo com uma grande quantidade de frames, que facilmente chegam à casa de centenas. Assim sendo, o IVUS se mostra um caso de estudo ideal para esta análise. Dentro deste trabalho, foram utilizados dados obtidos no InCor (Instituto do Coração), devidamente anonimizados para manter a privacidade do paciente.

A Figura 42 e a Figura 43 mostram gráficos comparativos para a adição de integridade e autenticidade nas imagens testadas, enquanto que a Figura 44 e a Figura 45 mostram gráficos equivalentes para o processo de verificação.

O comportamento demonstrado pelos algoritmos foi similar ao visto para a avaliação multislice. Novamente, a assinatura digital se mostrou a pior solução em termos de desempenho, seguido pelo algoritmo utilizando wavelets de Haar. É interessante notar que o desempenho dos demais algoritmos foi em muito superior, tanto para a cifração quanto para a decifração.

Os tempos obtidos são melhores para multiframe, no caso dos algoritmos de melhor desempenho, e melhores para multislice, nos caso dos algoritmos de pior desempenho. Mais do que isso, os primeiros necessitaram de um menor dispêndio de tempo para a verificação dos atributos de integridade e autenticidade.

Tanto para a aplicação quanto para a verificação dos mecanismos de segurança, a assinatura digital otimizada se provou ser a mais veloz. O uso de marca d'água no bit menos significativo mostrou uma velocidade maior para a verificação e uma performance pior para a adição da segurança.

A abordagem proposta neste trabalho e o AES em GCM apresentaram curvas praticamente idênticas, com uma ligeira vantagem para a abordagem desta tese quando do processo de verificação. Ao mesmo tempo, a versão sem o mascaramento marcou tempos consistentemente menores do que os dois. 
Tempo gasto para a aplicação dos mecanismos de segurança em imagens multiframe

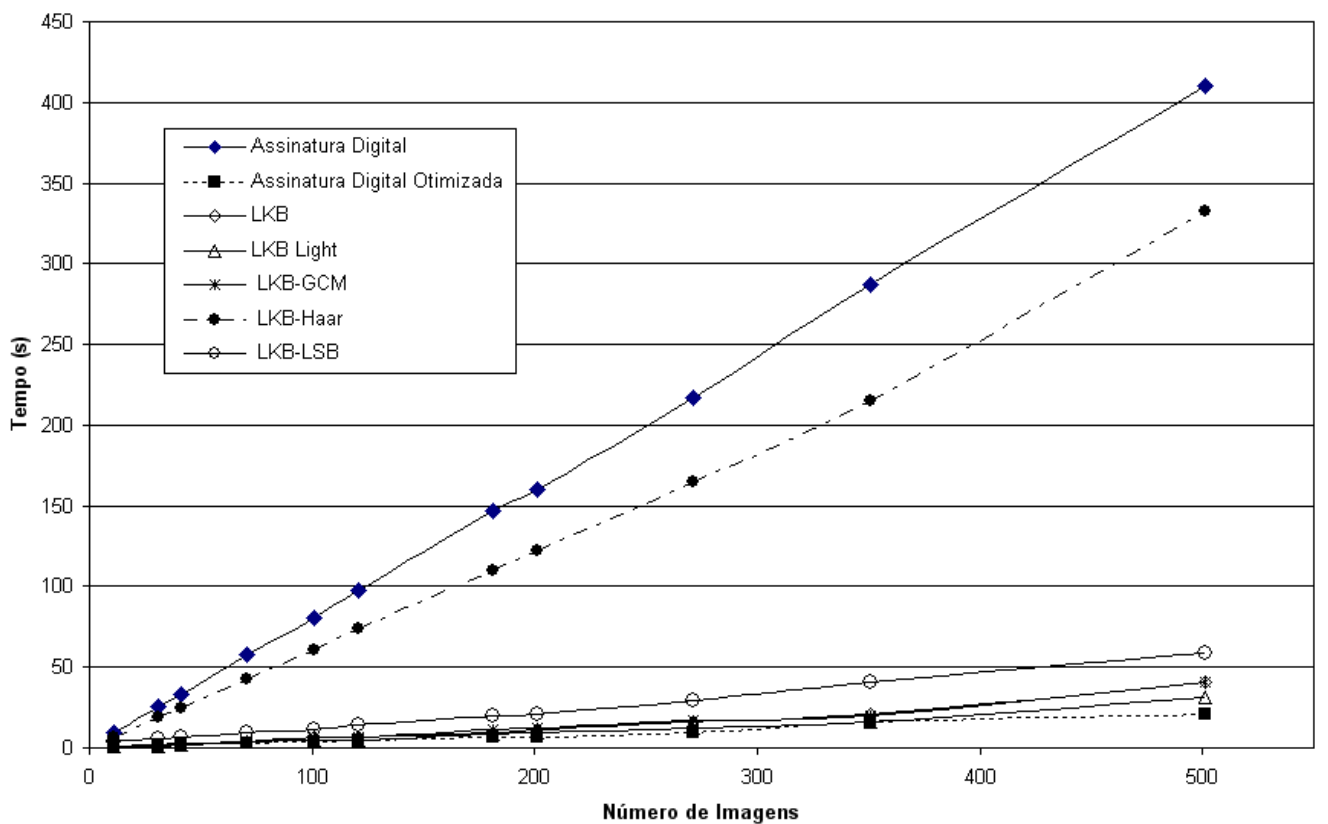

Figura 42 - Tempo gasto para aplicação dos mecanismos de segurança em imagens multiframe.

Tempo gasto para a aplicação dos mecanismos de segurança em imagens multiframe

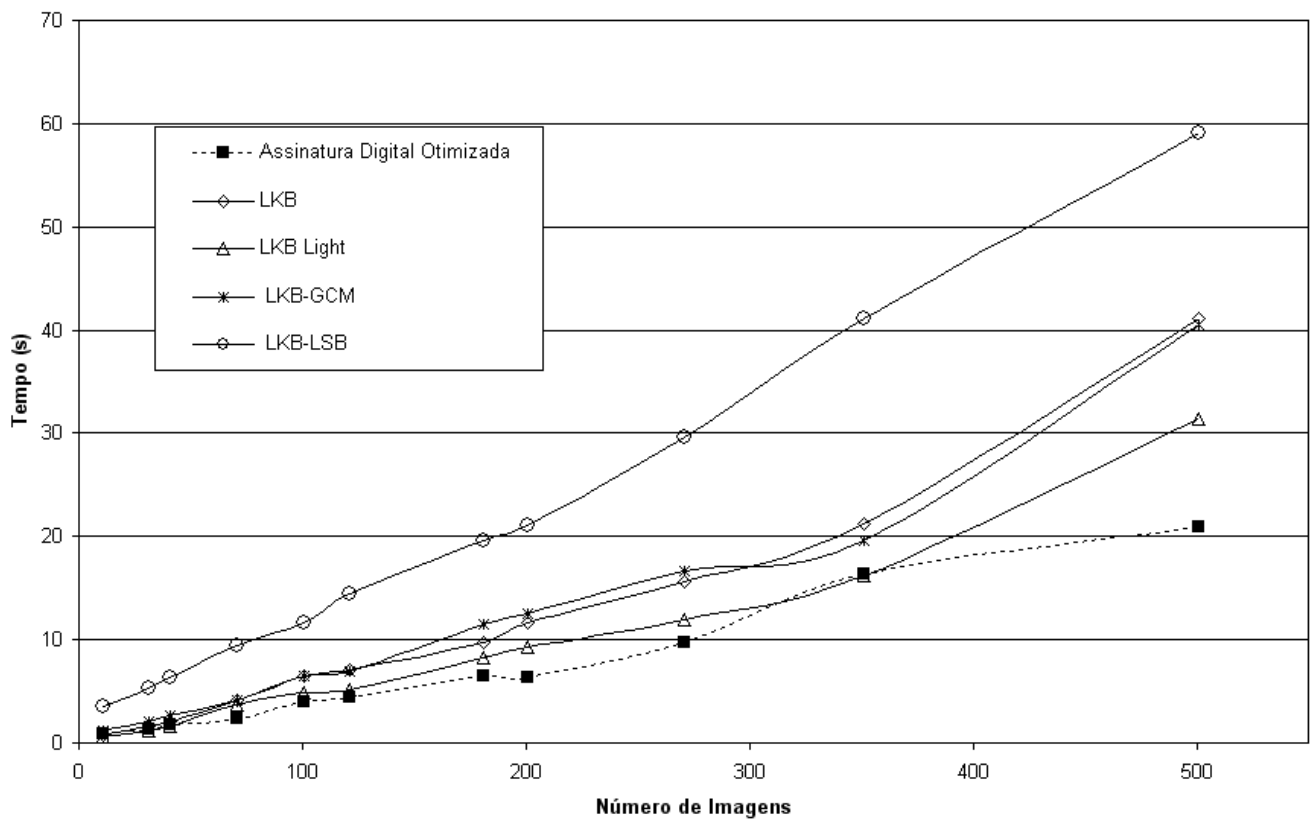

Figura 43 - Tempo gasto para aplicação dos mecanismos de segurança em imagens multiframe para os cinco algoritmos de melhor desempenho. 


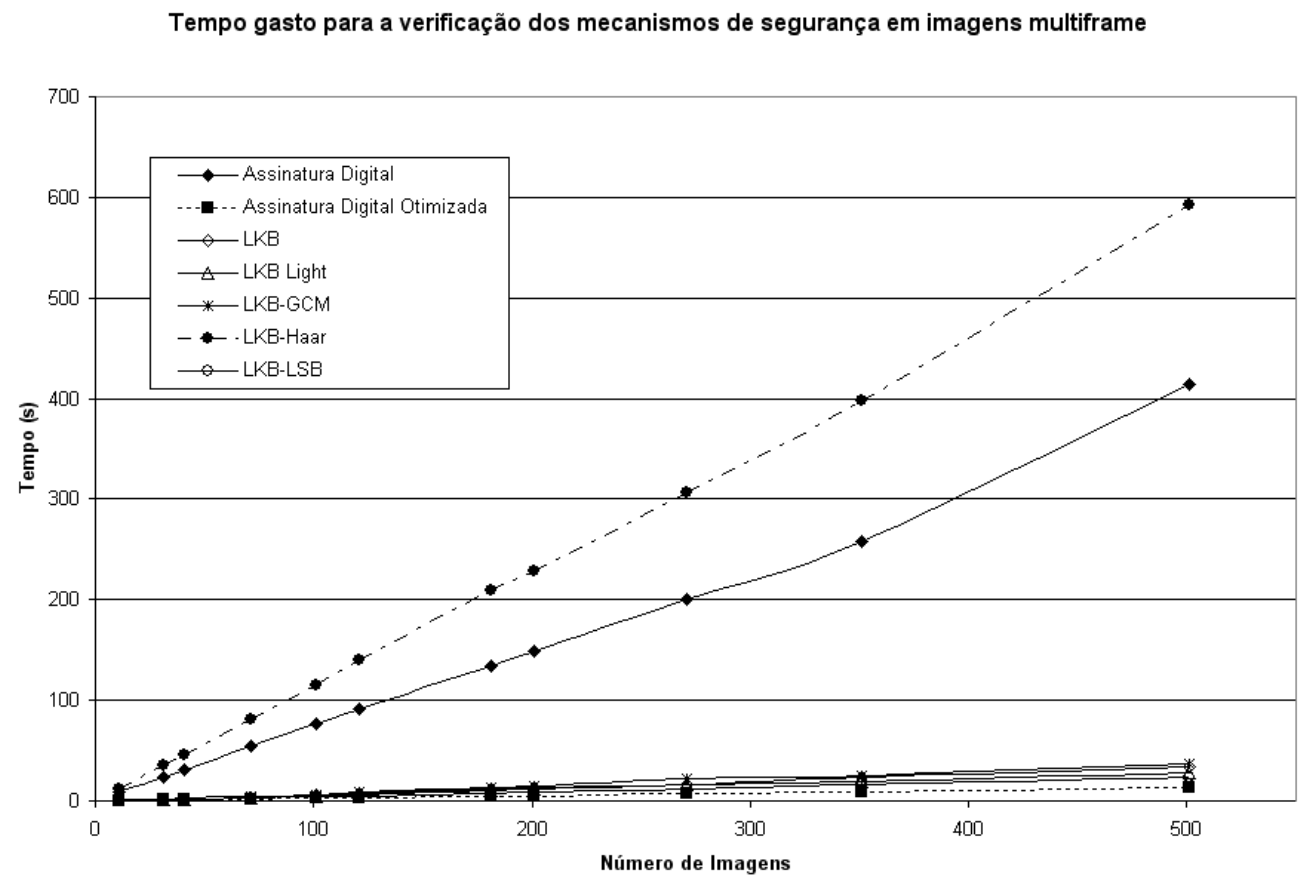

Figura 44 - Tempo gasto para verificação dos mecanismos de segurança em imagens multiframe.

Tempo gasto para a verificação dos mecanismos de segurança em imagens multiframe

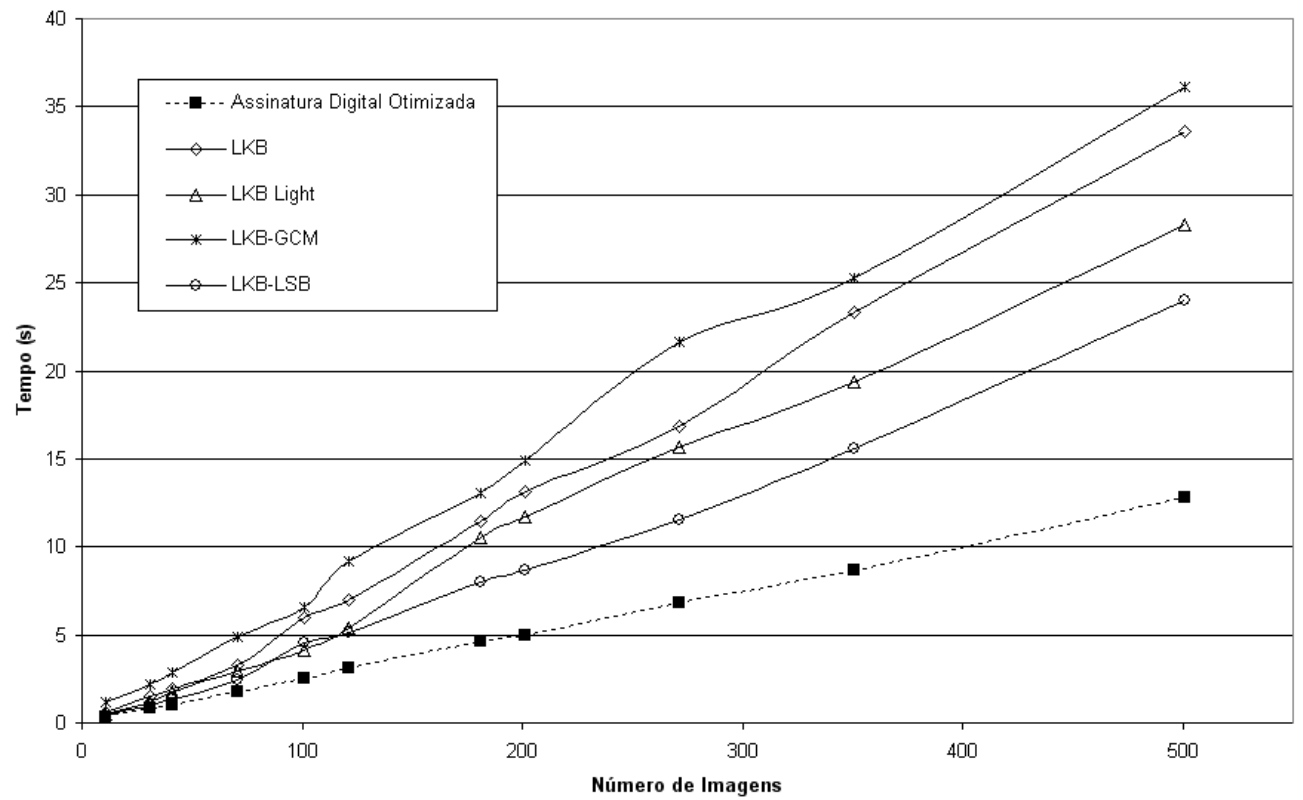

Figura 45 - Tempo gasto para verificação dos mecanismos de segurança em imagens multiframe para os cinco algoritmos de melhor desempenho. 


\subsubsection{Considerações sobre o desempenho dos algoritmos}

Os resultados ruins alcançados pela assinatura digital convencional já eram esperados, uma vez que ela depende de sucessivos acessos a disco para a leitura dos dados, um processo que é bastante custoso em termos de tempo.

Por outro lado, a assinatura digital otimizada, isto é, com a maior parte do processamento feito em memória, mostrou ser o mecanismo mais veloz, tanto para a aplicação da segurança quanto para a sua verificação.

O algoritmo utilizando wavelets de Haar possui um desempenho computacional sofrível. Isso porque cada frame (ou slice) passa por duas transformações (a decomposição e a transformada inversa) para a aplicação e para a verificação dos atributos de segurança, sem contar o processo de assinatura digital em si.

Para imagens multislice, o desempenho dos algoritmos LKB e LKB Light foram praticamente iguais. Isso era esperado, já que a diferença dos algoritmos se faz sentir para imagens multiframe. De fato, para imagens multiframe, o desempenho do algoritmo LKB Light se mostrou melhor do que o do algoritmo LKB.

O algoritmo utilizando AES em Galois Counter Mode se provou um pouco mais lento que os algoritmos LKB para imagens multislice. Isso já era esperado, pois a inicialização dos parâmetros para o GCM é lenta. Por outro lado, para imagens multiframe, onde a inicialização é feita uma única vez, o desempenho se mostrou quase idêntico ao algoritmo LKB.

Por fim, o algoritmo utilizando marca d'água em LSB se mostrou bastante competitivo para imagens multislice. Por outro lado, para imagens multiframe, o algoritmo se mostrou mais lento para a aplicação da marca d'água, devido à geração em si da imagem marcada. Por outro lado, a verificação da marca d'água foi veloz, pois não havia necessidade de gerar novas imagens.

\subsection{Avaliação de similaridade}

Uma outra avaliação que foi executada foi a avaliação de similaridade. Como foi citado anteriormente, a semelhança das imagens pode se tornar uma vulnerabilidade potencial para a quebra de segurança. 
Existem inúmeras formas de se medir a similaridade, como informação mútua e RIU (Ratio Image Uniformity), utilizadas em registro de imagens (HAJNAL et al, 2001). Dentro deste trabalho, optou-se por utilizar a correlação, por esta ser a medida mais clássica.

Para este trabalho, duas similaridades foram avaliadas para o algoritmo proposto na subseção 4.4. Todas as avaliações foram feitas para 30 imagens (frames ou slices) e uma média foi obtida quando foi cabível.

A primeira é a similaridade entre imagens consecutivas, ou seja, (n-1), n e $(n+1)$. A Tabela 1 mostra que ela é bastante elevada para dados sem criptografia.

\begin{tabular}{|c|c|}
\hline Modalidade & Média da correlação entre frames (ou slices) sucessivos \\
\hline XA & $0,9183 \pm 0,0358$ \\
\hline MR & $0,7025 \pm 0,1740$ \\
\hline NM & $0,8754 \pm 0,0658$ \\
\hline US & $0,6664 \pm 0,1279$ \\
\hline CT & $0,4739 \pm 0,0828$ \\
\hline
\end{tabular}

Tabela 1 - Média da correlação para as imagens sem criptografia.

Porém, para as imagens criptografadas, a correlação entre os frames se mostrou desprezível. Esse era o resultado desejado, reduzindo uma possível vulnerabilidade de segurança.

\begin{tabular}{|c|c|}
\hline Modalidade & Média da correlação entre frames (ou slices) sucessivos \\
\hline XA & $\mid$ correlação $\mid<0,001$ \\
\hline MR & $\mid$ correlação $\mid<0,01$ \\
\hline NM & $\mid$ correlação $\mid<0,001$ \\
\hline US & $\mid$ correlação $\mid<0,001$ \\
\hline CT & $\mid$ correlação $\mid<0,001$ \\
\hline
\end{tabular}

Tabela 2 - Média da correlação para as imagens criptografadas.

A segunda similaridade avaliada foi a correlação entre as imagens originais e as criptografadas. Como mostra a Tabela 3, ela também se mostrou extremamente baixa, como esperado, como uma confirmação da prova de que os dados cifrados pouco se assemelham aos dados originais. 


\begin{tabular}{|c|c|}
\hline Modalidade & Média da correlação original-LKB \\
\hline XA & $\mid$ correlação $\mid<0,001$ \\
\hline MR & $\mid$ correlação $\mid<0,01$ \\
\hline NM & $\mid$ correlação $\mid<0,01$ \\
\hline US & $\mid$ correlação $\mid<0,001$ \\
\hline CT & $\mid$ correlação $\mid<0,001$ \\
\hline
\end{tabular}

Tabela 3 - Média da correlação entre as imagens originais e as imagens criptografadas.

\subsection{Síntese}

A abordagem proposta neste trabalho foi implementada com sucesso utilizando-se a linguagem Java. Com isso, mostrou-se a viabilidade de utilizar algoritmos de criptografia para garantir uma ligação mais forte entre a imagem e as suas informações de integridade de autenticidade, representadas pela assinatura digital.

A imagem foi assinada e cifrada de acordo com o algoritmo apresentado, armazenando-se a assinatura digital no cabeçalho DICOM de acordo com a forma estabelecida dentro da Parte 15 do padrão.

A implementação foi avaliada em dois aspectos: desempenho e similaridade. A avaliação de desempenho foi feita em termos de imagens multiframe e multislice, mostrando ser uma das implementações mais velozes para atribuição e verificação de qualquer tipo de imagem médica. Além disso, a baixa similaridade dos dados cifrados é uma característica bastante interessante da solução apresentada. 


\section{Discussão}

"It is a capital mistake to theorize before one has data.

Insensibly one begins to twist facts to suit theories, instead of theories to suit facts."

SHERLOCK HOLMES

\section{Resumo deste Capítulo}

- síntese dos resultados alcançados dentro deste trabalho

- possíveis extensões

A abordagem proposta abre uma nova alternativa frente às propostas existentes, lançando mão de mecanismos criptográficos para cifrar a imagem, visando prover integridade e autenticidade fortes. Com isso, solucionam-se as limitações presentes na literatura, ao mesmo tempo em que se mantém as características desejadas em termos de robustez e integridade da informação, como ilustra a Tabela 4 .

\begin{tabular}{|c|c|c|c|}
\hline & Metadados & Marca d'Água & Abordagem Proposta \\
\hline $\begin{array}{c}\text { Ligação forte entre o dado } \\
\text { e a assinatura digital? }\end{array}$ & Não & Sim & Sim \\
\hline $\begin{array}{c}\text { Armazenamento } \text { sem } \\
\text { adulterar a imagem } \\
\text { original? }\end{array}$ & Sim & Não & Sim \\
\hline
\end{tabular}

Tabela 4 - Comparação da abordagem proposta com as alternativas existentes. 
O algoritmo proposto atende aos requisitos estabelecidos, provendo integridade e autenticidade às imagens médicas digitais no formato DICOM através da assinatura digital e da criptografia. $\mathrm{O}$ algoritmo também pode ser completamente divulgado, à exceção da chave privada, sem comprometer a sua segurança.

Uma característica adicional interessante é a autenticação de partes do cabeçalho, se eles forem utilizados para a geração do nonce. Por outro lado, a escolha dos dados do cabeçalho a serem autenticados é algo que deve ser realizado cautelosamente. Dados que podem sofrer alterações durante o ciclo de vida da imagem não devem fazer parte do processo.

\subsection{Considerações acerca do algoritmo}

É essencial notar que, apesar do uso da criptografia, o algoritmo proposto não pretende garantir a confidencialidade dos dados em si, na medida em que a chave (gerada a partir da assinatura digital) sempre está anexa à imagem. Entretanto, a perda ou a degradação da chave fará com que os dados originais não sejam recuperados com facilidade, permitindo uma maior privacidade dos dados.

A boa escolha dos mecanismos criptográficos utilizados na implementação é de importância crucial para a segurança do algoritmo apresentado, uma vez que a quebra de qualquer um deles fragiliza de forma extremamente contundente a abordagem proposta. Assim, métodos adequados devem ser escolhidos para a geração da assinatura digital, para a geração do resumo MMAC e para a criptografia simétrica.

Para a assinatura digital, foi escolhido SHA-1 com RSA para manter a compatibilidade com o padrão DICOM. Entretanto, dada a fragilidade atual do SHA1, deve-se pensar em substituir por algoritmos mais fortes - o SHA-2 com RSA seria uma alternativa.

A geração do resumo criptográfico MMAC também deve ser implementada por métodos fortes, ou seja, que ainda não tiveram deterministicamente obtidos uma prova de colisão, com dois dados distintos gerando o mesmo resumo. Por isso, foi escolhido o Whirlpool.

E a escolha do Phelix para a criptografia simétrica das imagens se deu por causa da sua velocidade e por não ter sido quebrado. Entretanto, deve-se ressaltar que 
há uma preferência por cifras de bloco ao invés de stream ciphers como o Phelix, pois aqueles são mais bem conhecidos em termos de robustez. Assim, algoritmos como o AES em Galois Counter Mode também devem ser considerados como uma alternativa plausível, apesar dos testes mostrarem um desempenho ligeiramente inferior para imagens multislice.

A solução proposta se baseia em algoritmos reconhecidamente rápidos, com a exceção da criptografia assimétrica, representada pela assinatura digital. Mas certamente devem ser feitas maiores otimizações para reduzir mais os custos de desempenho, facilitando a colocação em produção da abordagem apresentada.

\subsubsection{Mudança de Visão}

Ao contrário das abordagens existentes, este algoritmo privilegia a integridade e a autenticidade, ao custo da disponibilidade, uma vez que não é possível a visualização da imagem sem que esta tenha passado pela verificação acerca da sua integridade e autenticidade.

Esta é uma grande mudança de visão com relação às implementações atuais, nas quais todas as imagens podem ser visualizadas, independentemente da presença das informações de segurança. É um primeiro passo para que apenas as imagens confiáveis possam ser vistas pelo usuário final - imagens degradadas seriam exibidas apenas como ruído.

Por outro lado, isso traz consigo uma sensibilidade muito maior à adulteração. Um mínimo de degradação das informações é suficiente para inutilizá-las total ou parcialmente, o que pode prejudicar quando do armazenamento e manutenção das imagens como evidência legal. Uma pessoa com os devidos privilégios poderia se livrar de evidências comprometedoras com maior facilidade, bastando alterar minimamente os dados. Essa é uma característica que certamente deve ser levada em consideração quando da sua eventual adoção em um ambiente de produção.

Ao mesmo tempo, estudos mais aprofundados devem ser feitos quanto à adequação da solução proposta neste trabalho com relação a padrões estabelecidos nacional e internacionalmente em termos de segurança da informação. 


\subsubsection{A Abordagem Proposta e o Padrão DICOM}

A abordagem proposta lança mão da estrutura especificada na Parte 15 do padrão para o armazenamento de informações. É importante ressaltar que o DICOM estabelece uma série de diretivas para a segurança da informação como um todo para o enforcement da segurança. Entretanto, as formas atualmente disponíveis para a garantia da integridade e autenticidade da imagem são tais que é possível reduzir facilmente o nível de segurança ao se remover a assinatura digital. Com isso, o usuário fica sem meios de saber se a imagem foi adulterada ou não.

A abordagem deste trabalho não dificulta a remoção, mas a remoção é imediatamente detectada. Mais do que isso, o usuário é capaz de afirmar que houve a adulteração, uma vez que a presença da assinatura digital correta é condição sine qua non para a correta visualização das imagens.

A incorporação do método proposto nesta pesquisa ao padrão DICOM deverá implicar na adição de informações que permitam identificar o uso do método. Assim, deve-se definir um Transfer Syntax apropriado para a identificação. Adicionalmente, uma Tag que permita identificar o estado (cifrado ou não) da imagem pode ser interessante para processar adequadamente as informações.

\subsection{Discussão acerca da Implementação}

A implementação foi feita com sucesso, sendo possível adicionar integridade e autenticidade às imagens médicas armazenadas em formato DICOM, através de mecanismos criptográficos. A associação das informações de segurança com a imagem em si pode ser considerada como sendo forte, uma vez que a presença da assinatura digital original é uma condição necessária para a correta visualização das imagens originais.

Uma característica que deve ser apontada para a implementação realizada é a possibilidade de detecção, mas não de prevenção nem de correção de eventuais adulterações introduzidas. Tanto a prevenção como a correção não podem ser implementadas de uma forma trivial, necessitando de um sistema muito mais complexo para que sejam efetivamente introduzidas no ambiente digital.

Além disso, a compatibilidade com o padrão DICOM foi mantida em parte, com o armazenamento da assinatura digital de acordo com as diretrizes especificadas 
na parte 15. É importante ressaltar, contudo, que a adoção desta abordagem necessita de adaptações adequadas nos clientes e servidores DICOM existentes, de forma que o usuário final possa visualizar de maneira correta as informações.

Um aspecto que deve ser ressaltado é a ausência de confidencialidade das informações pessoais do paciente presentes no cabeçalho. Os dados do cabeçalho DICOM são armazenados sem nenhuma encriptação e, apesar de não ser o foco deste trabalho, essa é uma vulnerabilidade que pode ser bastante explorada para se violar a privacidade do paciente. Assim sendo, torna-se necessário a implementação futura de ferramentas adicionais para melhoria dos serviços de segurança na área da saúde.

O processo de cifração em si também pode ser ligeiramente alterado, de forma que a última imagem seja utilizada, ao invés da primeira, para gerar os dados da criptografia simétrica. Com isso, o processo de decifração será tal que a recuperação das informações será feita seqüencialmente a partir do primeiro frame. Isso possibilitará que um visualizador exiba os frames à medida em que estes forem sendo recuperados, reduzindo o tempo de espera e levando a uma melhor percepção por parte do usuário final.

\subsection{Conclusões sugeridas pelas avaliações realizadas}

A abordagem apresentada, implementada através do algoritmo proposto neste trabalho, mostrou um desempenho bastante competitivo quando comparado aos demais métodos.

Os métodos mais velozes, entretanto, não provêem o mesmo nível de segurança. Assim, as avaliações mostraram que é possível adicionar maior segurança a um baixo custo em termos de tempo. Em contrapartida, a performance ainda deve ser mais otimizada para que o usuário visualize a imagem recuperada o mais rápido possível. Uma demora de minutos, como foi vista para séries grandes de slices, é inaceitável para casos de emergência.

Para tanto, a otimização da leitura e escrita em disco é essencial. Os gráficos obtidos mostram que o acesso ao disco consome um tempo considerável, necessitando de maiores aperfeiçoamentos para reduzi-lo. Além disso, a otimização dos processos de criptografia simétrica também pode ser considerada para reduzir os 
tempos. Uma implementação em hardware também é uma alternativa possível para prover maior velocidade.

Além disso, deve-se levar em consideração a geração de dados temporários em disco. Isso acarreta obviamente uma demora maior, que poderia ser reduzida com a transferência de partes do processamento para a memória. Entretanto, a disponibilidade de memória varia de acordo com o servidor ou estação, o que impede uma definição estática da quantidade a ser alocada. Uma alocação dinâmica pode ser cogitada, visando reduzir a quantidade de acesso ao disco.

Essa técnica não é simples de ser implementada, sendo certamente um desafio futuro a ser atendido. Presume-se que uma otimização mais sofisticada resulte em uma melhoria apreciável nos tempos dispendidos.

A adoção da versão sem o mascaramento também é uma alternativa possível para reduzir os tempos. Em termos visuais, os arquivos gerados por esta versão pouco diferem da versão completa, na medida em que se assemelham a puro ruído (Figura 46). Assim, apesar de oferecer uma segurança um pouco menor, o ganho em termos de performance pode melhorar a relação custo-benefício para a adoção do algoritmo em um ambiente real.

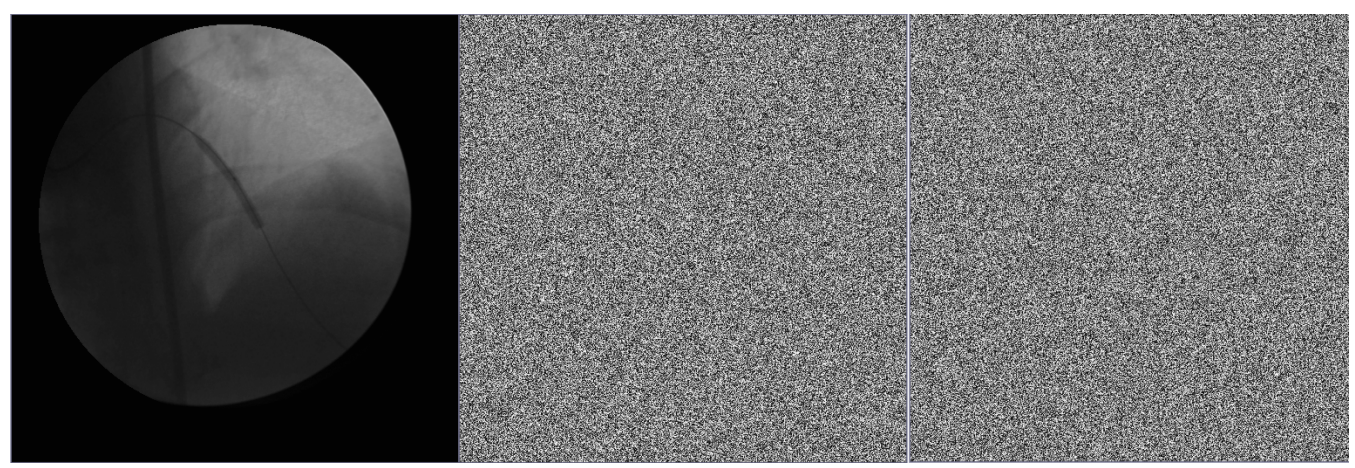

Figura 46 - Figura que compara o resultado da cifração. À esquerda, a imagem original. Ao centro, a imagem cifrada de acordo com o algoritmo completo e à direita, cifrada sem o mascaramento.

\subsection{Possíveis Extensões e Desafios Futuros}

O principal desafio é a melhoria no desempenho. A otimização da performance é uma condição imprescindível para uma adoção efetiva em um 
ambiente de produção. Caso contrário, a percepção do usuário final será negativa, podendo até mesmo comprometer a utilização dos sistemas de arquivamento e comunicação de imagens (PACS - Picture Archiving and Communication System) como um todo.

Uma extensão possível para este trabalho é inserir o algoritmo em uma arquitetura de segurança para imagens médicas, de forma que estas estejam adequadamente seguras no seu fluxo em uma instituição de saúde.

Uma outra extensão que pode ser considerada é o desenvolvimento de algoritmos, dentro desta mesma abordagem, que produzam provas visuais acerca da integridade e autenticidade da imagem como resultado do processamento.

Isso permitiria que apenas as imagens íntegras e autênticas fossem visualizadas corretamente - imagens degradadas exibiriam ruído, sendo uma evidência óbvia de adulteração. $\mathrm{O}$ algoritmo apresentado neste trabalho possui parcialmente esta característica, mas uma adulteração no último frame não irá necessariamente produzir uma prova visual facilmente identificável.

Existe também a questão das imagens offline, que deve ser considerada. Neste caso, o acesso do usuário às chaves públicas do assinante é crucial para a recuperação adequada das informações. Assim, a presença do certificado digital no cabeçalho DICOM é de importância fundamental e devem existir formas de garantir tal presença.

Um outro caso que também deve ser corretamente abordado é o intercâmbio interinstitucional de imagens médicas. É bastante interessante que as imagens mantenham as suas propriedades de integridade e autenticidade, de forma que seja possível atribuir e recuperar tais atributos em um ambiente mais amplo e distribuído. Assim, devem-se propor protocolos adequados para que as imagens possam ser transferidas de forma segura, sem comprometer a sua visualização.

Por fim, cabe lembrar que os dois serviços de segurança discutidos neste trabalho são apenas uma parcela de um contexto maior. Existem outros serviços de segurança, como confidencialidade e auditabilidade, que não podem ser ignorados e devem ser seguramente levados em consideração, através de extensões da arquitetura, dos modelos e da implementação propostos. Com isso, será possível oferecer não apenas autenticidade e integridade, mas sim segurança de imagens 
médicas, desde a sua aquisição até o seu armazenamento, processamento e visualização.

Ao mesmo tempo, a abstração realizada na modelagem deste trabalho permite que outros dados além de imagens médicas possam desfrutar dos serviços de segurança oferecidos, permitindo que virtualmente qualquer tipo de dado possa ter um nível adequado de segurança para que o sistema possa atingir o grande objetivo de garantir a privacidade do paciente. Neste caso, deve-se analisar a viabilidade do uso algoritmo proposto para outros tipos de dados.

\subsection{Síntese}

Neste capítulo, foram levantados os pontos mais relevantes que surgiram no desenvolvimento deste trabalho.

Um ponto que deve ser enfatizado é a questão da confidencialidade. Embora certamente seja relevante no contexto de imagens médicas, este trabalho aborda-a apenas de maneira marginal, para o caso em que as informações de integridade e autenticidade são degradadas e/ou perdidas. Para imagens confiáveis não há confidencialidade alguma, uma vez que todas as informações para a decifração dos dados estão presentes.

A adoção de mecanismos criptográficos adequados, tanto em termos de robustez quanto em termos de velocidade, é de importância vital para que o algoritmo atinja os objetivos propostos. Assim sendo, eles devem ser escolhidos cuidadosamente.

O desempenho da implementação se mostrou encorajador dentro das avaliações realizadas. Entretanto, melhorias devem ser realizadas para reduzir os tempos para a atribuição e para a verificação dos atributos de integridade e autenticidade das imagens.

Como a metodologia proposta neste trabalho se baseia fortemente no padrão DICOM, é possível incorporá-la ao padrão de forma relativamente simples. É crucial que protocolos de transferência das imagens sejam estabelecidos de forma clara, para que as informações possam ser enviadas, recebidas, processadas e visualizadas adequadamente. 
Paralelamente, é possível estender a abordagem deste trabalho para outros tipos de dados, como sinais e laudos. Mas são necessárias análises de viabilidade. O próprio DICOM permite o armazenamento de tais dados, e isso pode ser considerado para tal extensão. 


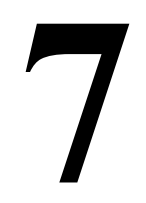

\section{Conclusão}

"What we call the beginning is often the end. And to make an end is to make a beginning. The end is where we start from." T.S. ELLIOT

O algoritmo proposto atende aos requisitos estabelecidos, provendo integridade e autenticidade às imagens médicas digitais no formato DICOM através da assinatura digital e da criptografia. $\mathrm{O}$ algoritmo também pode ser completamente divulgado, à exceção da chave, sem comprometer a sua segurança.

Há também uma compatibilidade parcial com a parte 15 do padrão DICOM no tocante ao armazenamento da assinatura digital. Com isso, não é gerado nenhum overhead adicional em termos de armazenamento. Além disso, é possível incorporar a abordagem proposta ao padrão com um mínimo de adaptação, bastando definir perfis de segurança apropriados para que duas entidades possam trocar informações de forma correta.

Os modelos gerados descrevem satisfatoriamente os processos mais relevantes e as entidades mais importantes, possibilitando a pronta codificação de forma simples e componentizada.

A implementação foi executada com êxito, oferecendo métodos de detecção de violações de autenticidade e integridade e provando a viabilidade da introdução de tais serviços de segurança no fluxo de imagens médicas.

É importante ressaltar que a abordagem possui uma sensibilidade maior à adulteração das informações. A menor degradação dos dados já é suficiente para 
inutilizá-los total ou parcialmente e esta característica deve ser considerada quando da sua adoção em um ambiente real.

Uma outra característica a ser destacada é a mudança na forma como as imagens são recuperadas. Nas propostas existentes até agora, era possível visualizar todas as imagens, estando estas íntegras ou não, para então realizar a verificação dos seus atributos de segurança.

$\mathrm{Na}$ abordagem deste trabalho, o processo de decifração antes da visualização acarreta um processamento adicional, mas permite uma ênfase maior à verificação da integridade e autenticidade da imagem antes da sua visualização.

Por fim, deve-se observar que esta pesquisa está inserida em um desafio mais amplo, que é garantir a segurança da informação em níveis adequados a todos os níveis de infra-estrutura na área da Saúde, tanto em termos intra-institucionais quanto interinstitucionais.

Isso permite um elevado grau de confiabilidade nos serviços de saúde oferecidos e, para tanto, é vital desenvolver mecanismos para garantir aspectos de segurança como integridade e autenticidade. Este trabalho é parte deste esforço para desenvolver e prover serviços de saúde de alta qualidade para a população. 


\section{Referências Bibliográficas}

"If I have seen a little further, it is by standing on the shoulders of giants." ISAAC NEWTON

ACCREDITED STANDARDS COMMITTEE X9. American National Standard X9.62-2005, "Public Key Cryptography for the Financial Services Industry, The Elliptic Curve Digital Signature Algorithm (ECDSA)”, 2005.

ALBANESI M.G., FERRETTI M., GUERRINI F. A Taxonomy for Image Authentication Techiniques and Its Application to the Current State of the Art. Image Analysis and Processing, 2001. Proceedings. 11th International Conference on, 26$28,2001$.

ANAND D., NIRANJAN U.C. Watermarking medical images with patient information. $20^{\text {th }}$ Annual International Conference of the IEEE Engineering in Medicine and Biology Society, 20(2):703-706, 1998.

ANDERSON, R. J. Security in clinical information systems. Computer Laboratory, University of Cambridge, 1996. 
AOKI, K., ICHIKAWA, T., KANDA, M., MATSUI, M., MORIAI, S., NAKAJIMA, J., TOKITA, T. Camellia: A 128-Bit Block Cipher Suitable for Multiple Platforms - Design and Analysis. Selected Areas in Cryptography: pp. 39-56, Mitsubishi, NTT, 2000.

ASSOCIAÇÃO MÉDICA MUNDIAL. Declaração de Lisboa, sobre os direitos do paciente.. Adotada pela 34 ${ }^{\mathrm{a}}$ Assembléia Geral da Associação Médica Mundial em Lisboa, Portugal, setembro/outubro de 1981 e emendada pela $47^{\mathrm{a}}$ Assembléia Geral da Associação Médica Mundial em Bali, Indonésia, setembro de 1995. Disponível em $<$ http://www.dhnet.org.br/direitos/codetica/medica/14Lisboa.html $>$. Acessado em 03 de junho de 2004.

ASSOCIAÇÃO MÉDICA MUNDIAL. Declaração de Munique, sobre o uso do computador em medicina. Baseada em Resolução adotada pela $27^{\mathrm{a}}$ Assembléia Geral da Associação Médica Mundial, Munique, República Federal da Alemanha, outubro de 1973 e emendada pela 35 assembléia Geral da Associação Médica Mundial em Veneza, Itália, outubro de 1983. Disponível em < http://www.dhnet.org.br/direitos/codetica/medica/19Munique.html $>$. Acessado em 03 de junho de 2004.

ASSOCIAÇÃO MÉDICA MUNDIAL. Declaração de Tel Aviv, sobre responsabilidades e normas éticas na utilização da telemedicina. Adotada pela $51^{\mathrm{a}}$ Assembléia Geral da Associação Médica Mundial em Tel Aviv, Israel, em outubro de $1999 . \quad$ Disponível em < http://www.dhnet.org.br/direitos/codetica/medica/27Telaviv.html >. Acessado em 03 de junho de 2004.

ATREYA M., HAMMOND B., PAINE S., STARRETT P., WU S. Digital Signatures. RSA Press, McGraw-Hill, 2002.

BARRETO, P.S.L.M. Criptografia robusta e marcas d'água frágeis: construção e análise de algoritmos para localizar alterações em imagens digitais. 2003. 150f. Tese 
(Doutorado em Engenharia) - Escola Politécnica, Universidade de São Paulo, São Paulo, 2003.

BARRETO, P.S.L.M. A Crise das Funções de Hash. Invited talk, VII Simpósio Segurança em Informática -- SSI'2005, São José dos Campos, Brasil, 2005. Disponível em < $\underline{\text { http://paginas.terra.com.br/informatica/paulobarreto/SSI2005PauloBarreto.pdf }}>$. Acessado em 05 de setembro de 2007.

BARRETO, P.S.L.M., RIJMEN, V. The WHIRLPOOL Hashing Function. Disponível em < http://planeta.terra.com.br/informatica/paulobarreto/whirlpool.zip $>$ . Acessado em 03 de março de 2006.

BERNARDING J., THIEL A., GRZESIK A. A JAVA-based DICOM server with integration of clinical findings and DICOM-conform data encryption. International Journal of Medical Informatics 64:429-438, 2001.

BLEUMER, G. Introduction to the SEISMED guidelines. SEISMED(A2033) / SP14 / HILD / DEL / 05.07.95, 1995.

BLEUMER, G. Security for decentralized health information systems. International Journal of Biomedical Computing 35(1): 139-145, 1994.

BRASIL. Constituição (1988). Constituição da República Federativa do Brasil. São Paulo, SP: Saraiva, 2001.

BRASIL. Ministério da Saúde. Portaria do Ministério da Saúde nº1286 de 26/10/93art. $8^{\circ}$ e nº 74 de 04/05/94, 1994.

BRASIL. Novo Código Civil Brasileiro - art. 225., 2001.

BRASIL. Projeto de Lei PL-3494/2000, 2000. Dispõe sobre a estruturação e o uso de bancos de dados sobre a pessoa e disciplina o rito processual do "habeas data". 
Disponível em < http://www.camara.gov.br/sileg/Prop_Detalhe.asp?id=19753 $>$. Acessado em 29 de agosto de 2006.

BRASIL. Projeto de Lei PL-6981/2002, 2002. Estabelece normas para a proteção e tratamento dos dados pessoais e dá outras providências.. Disponível em < http://www.camara.gov.br/sileg/Prop_Detalhe.asp?id=56678 $>$. Acessado em 29 de agosto de 2006.

BRASIL. Projeto de Lei PL-20/2003, 2003. Estabelece o Código Nacional de Direitos dos Uusários das Ações e dos Serviços de Saúde e dá outras providências. Disponível em < http://www.camara.gov.br/sileg/Prop_Detalhe.asp?id=104343 $>$. Acessado em 31 de maio de 2004.

CAO F., HUANG H.K., ZHOU X.Q. Medical image security in a HIPAA mandated PACS environment. Computerized Medical Imaging and Graphics 27:185-196, 2003.

CINTRA, L. P. Da responsabilidade civil dos estabelecimentos de saúde . Jus Navigandi, Teresina, a. 6, n. 52, nov. 2001. Disponível em: < http://www1.jus.com.br/doutrina/texto.asp? $\mathrm{id}=2458>$. Acessado em 03 de junho de 2004.

COATRIEUX G., MAÎTRE H., SANKUR B., ROLLAND Y., COLLOREC R.Relevance of watermarking in medical imaging. 2000 IEEE EMBS Conference on Information Technology Applications in Biomedicine, 250-255, 2000.

COATRIEUX G., MAÎTRE H., SANKUR B. Strict integrity control of biomedical images. In: SPIE Conference 4314: Security and Watermarking of Multimedia Contents III, 2001.

CÓDIGO DE ÉTICA DA IMIA PARA PROFISSIONAIS DE INFORMÁTICA EM SAÚDE. Disponível em < http://www.sbis.org.br/codigo_etica_imia.htm $>$. Acessado em 10 de fevereiro de 2004. 
CONSELHO FEDERAL DE MEDICINA. Código de Ética Médica. Resolução CFM $\mathrm{n}^{\mathrm{o}}$ 1.246/88, de 08.01.88 (Diário Ofícial da União 26.01.88).

CONSELHO FEDERAL DE MEDICINA. Resolução CFM no. 1639/2002. Aprova as "Normas Técnicas para o Uso de Sistemas Informatizados para a Guarda e Manuseio do Prontuário Médico", dispõe sobre tempo de guarda dos prontuários, estabelece critérios para certificação dos sistemas de informação e dá outras providências. 2002.

CONSELHO REGIONAL DE MEDICINA DO ESTADO DE SÃO PAULO. Resolução CREMESP n ${ }^{\circ}$ 97, de 20 de fevereiro de 2001. Diário Oficial do Estado; Poder Executivo, São Paulo, SP, n. 45, 9 mar. 2001. Seção 1.

CONSELHO DA EUROPA. Convenção para a Proteção dos Direitos do Homem e da Dignidade do Ser Humano face às Aplicações da Biologia e da Medicina: Convenção sobre os direitos do Homem e a Biomedicina. Adotada e aberta à assinatura em Oviedo, a 4 de Abril de 1997. Entrada em vigor na ordem internacional: 1 de Dezembro de 1999. Disponível em < http://www.dhnet.org.br/direitos/sip/euro/PrincipaisInstrumentos/16.htm $>$. Acessado em 03 de junho de 2004.

COPPERSMITH D., MINTZER F., WU C.W., YEUNG M. M. Fragile Imperceptible Watermark with Privacy Control. In: SPIE Security and Watermarking of Multimedia Contents II, Proceedings of, 1999.

DCM4CHE HOME PAGE. Disponível em < http://dcm4che.sourceforge.net $>$. Acessado em 18 de junho de 2004.

DWIVEDI A., BALI R.K., BELSIS M.A., NAGUIB R. N. G., EVERY P., NASSAR N. S. Towards a practical healthcare information security model for healthcare institutions. $4^{\text {th }}$ Annual IEEE Conference on Information Technology Applications in Biomedicine, Proceedings of, 114-117, 2003. 
ESTREAM. eStream Project. Disponível em < http://www.ecrypt.eu.org/stream/ $>$, Acessado em 03 de junho de 2006.

FRIDRICH J. Image watermarking for tamper detection. ICIP, Proceedings of, 1998.

FRIEDMAN, G.L. The trustworthy digital camera: restoring credibility to the photographic image. IEEE Transaction on Consumer Electronics, vol 39, 1993.

GARMS J., SOMERFIELD D. Professional Java Security. Wrox Press, 2001.

GIAKOUMAKI A., PAVLOPOULOS S., KOUTSOURIS D. Secure and efficient health data management through multiple watermarking on medical images. Medical and Biological Engineering and Computing, 44:619-631, 2006.

GRIMSON J., GRIMSON W., HASSELBRING W. 2000. The SI challenge in health care. Communications of the ACM, 43(6): 49-55.

HAJNAL J., HILL D.L.G., HAWKES D.J. Medical Image Registration. CRC Press, 2001.

HAMILTON D. L. Identification and evaluation of the security requirements in medical applications. $5^{\text {th }}$ Annual IEEE Symposium on Computer-Based Medical Systems, Session 2B: Pictural Archival and Communications Systems, 129-137, 1992.

HOWARD J. An Analysis of Security Incidents on the Internet 1989-1995, Carnegie Mellon University, 1997.

IETF, RFC 1321: The MD5 Message-Digest Algorithm, 1992. Disponível em < http://tools.ietf.org/html/rfc1321 >. Acessado em 20 de junho de 2006.

IETF, RFC 3174: US Secure Hash Algorithm 1 (SHA1), 2001. Disponível em < http://tools.ietf.org/html/rfc3174 >. Acessado em 20 de junho de 2006. 
IMIA. Código de Ética da IMIA para Profissionais de Informática em Saúde. Disponível em $<\underline{\text { http://www.sbis.org.br/codigo_etica imia.htm }}>$. Acessado em 10 de fevereiro de 2004.

ISO. ISO/IEC 10118-3:2004 Standard. Disponível em < http://www.iso.org/iso/en/CatalogueDetailPage.CatalogueDetail?CSNUMBER=3987 $\underline{6 \& \text { scopelist }}=>$, Acessado em 03 de março de 2006.

JAVA CRYPTOGRAPHIC ARCHITECTURE. Disponível em < http://java.sun.com/j2se/1.4.2/docs/guide/security/CryptoSpec.html >. Acessado em 18 de junho de 2004 .

JEPSEN, T. IT in healthcare: progress report. IT Pro January/February 2003, IEEE Computer Society, 8-14, 2003.

JURAMENTO DE HIPÓCRATES. Disponível em $<$ http://www.gineco.com.br/jura.htm $>$ acessado em 07/05/2004.

KROLL M., SCHÜTZE B., GEISBE T., LIPINSKI H.-G., GRÖNEMEYER D.H.W., FILLER T.J. Embedded systems for signing medical images using the DICOM standard. In: International Congress Series 1256, 849-854, 2003.

KUNDUR D., HATZINAKOS D. Digital Watermarking for Telltale tamper proofing and authentication. In: Proceedings of IEEE, 1999.

LIN, C.Y., CHANG, S.F. Semi-fragile watermarking for authenticating JPEG visual content. In: SPIE Security and watermarking of Multimedia Contents II, EI'00, 2000.

LIN, C.Y., CHANG, S.F. Generating robust digital signature for image/video authentication. In: Multimedia and Security Workshop at ACM Multimedia 1998, 1998. 
LIN, C.Y., CHANG, S.F. A robust image authentication method surviving JPEG lossy compression. In: SPIE Storage and retrieval of image/video database, 1998.

LIN, C.Y., CHANG, S.F. An image authenticator surviving DCT-based variable quantization table compressions. In: CU/CTR Technical Report, 1997.

LIN, E.T., PODILCHUCK C.I, DELP, E.J. Detection of Image Alterations using semi-fragile Watermarks. In: SPIE Security and Watermarking of Multimedia Contents II, Proceedings of, 2000.

LYNCH, C. Authenticity and integrity in the digital environment: an exploratory analysis of the central role of trust. Authenticity in a digital environment, Council on Library and Information Resources, Washington D.C., maio 2000.

MACQ B., DEWEY F. Trusted headers for medical images. DFG VIII-DII Watermarking Workshop, 1999.

MARGI C.B., Curso de Segurança em Sistemas e Redes de Computadores Conceitos Gerais, EPUSP, 2002.

MARVEL L.M., HARTWIG Jr., G.W., BONCELET Jr. C. Compression compatible fragile and semi-fragile tamper detection. In: SPIE Security and Watermarking of Multimedia Contents II, Proceedings of, 2000.

MCGREW D. A., VIEGA J. The Galois/Counter Mode of Operation (GCM). NIST Computer Security Division, Computer Security Resource Center, 2005.

MIAOU S., HSU C., TSAI Y., CHAO H. A secure data hiding technique with heterogeneous data-combining capability for electronic patient records. In: World Congress on Medical Physics and Biomedical Engineering, Proceedings of, Session Electronic Healthcare Records, IEEE-BEM, 2000. 
MOREIRA FILHO, J. R. Relação Médico - Paciente. Jus Navigandi, Teresina, a. 6, n. 55, 2002. Dar. Disponível em: < http://www1.jus.com.br/doutrina/texto.asp?id=2745 $>$. Acessado em 03 de junho de 2004.

MOTTA, G.H.M.B. Um modelo de autorização contextual para o controle de acesso ao Prontuário Eletrônico do Paciente em ambientes abertos e distribuídos. 2003. 213f. Tese (Doutorado em Engenharia) - Escola Politécnica, Universidade de São Paulo, São Paulo, 2003.

NATIONAL ELECTRICAL MANUFACTURERS ASSOCIATION (NEMA). The DICOM Standard, 2007. Disponível em < http://medical.nema.org/dicom/2007/ $>$. Acessado em 05 de junho de 2007.

NEUMANN, P. G. Risks to the Public. In: ACM SIGSOFT Software Engineering Notes, v. 30, n. 4, p. 19, 2005.

NIINIMAKI, J., SAVOLAINEN, M., FORSSTROM, J. J. Methodology for security development of an electronic prescription system. In: Proceedings of AMIA Symposium, p. 245-249, 1998.

ORGANIZAÇÃO DAS NAÇÕES UNIDAS. Escritório do Alto Comissariado para Direitos Humanos. Declaração Universal dos Direitos Humanos, 1948. Disponível em $<$ http://www.unhchr.ch/udhr/lang/por.htm $>$. Acessado em 07 de junho de 2004.

OSIRIX. DICOM Sample Image Sets. Disponível em < http://pubimage.hcuge.ch:8080/ > .Acessado em 17 de agosto de 2006.

PAMBOUKIAN S. V. D., KIM H. Y.. Marcas d'Água de Autenticação para Imagens Binárias: Marcas Reversíveis e Marcas para o Padrão JBIG2, Tese (Doutorado em Engenharia) - Escola Politécnica, USP, 2007. 
PFITZMANN A., PFITZMANN B. Technical Aspects of Data Protection in Health Care Informatics. Advances in Medical Informatics, 368-386, 1992.

QUELEZ, M.P., LAMY, P. Spacial watermark for image verification. In: SPIE Security and Watermarking of Multimedia Contents II, Proceedings of , 2000.

RAGHUPATHI, W., TAN, J. Strategic IT applications in health care. Communications of the ACM, 45(12): 56-61, 2002.

RECTOR A. L., NOLAN W.A., KAY S. Foundations for an electronic medical record. Methods of Information in Medicine 30:179-86, 1991.

SCHNEIER B. Description of a New Variable-Length Key, 64-bit Block Cipher (Blowfish), Fast Software Encryption 1993: 191-204, 1993.

SHORTLIFFE, E. H. The evolution of health-care records in the era of Internet. MEDINFO'98, 1-8, 1998.

SOCIEDADE BRASILEIRA DE INFORMÁTICA EM SAÚDE. GT Certificação de Software SBIS-CFM. Manual de Requisitos de Segurança, Conteúdo e Funcionalidades para Sistemas de Registro Eletrônico em Saúde (RES), versão 2.1, 2004. Disponível em < http://www.sbis.org.br/manual.htm $>$. Acessado em $27 \mathrm{de}$ fevereiro de 2004.

SOFTLINK JAVA DICOM TOOLKIT. Disponível em < http://www.softlink.be/jdt/features.htm >. Acessado em 18 de junho de 2004.

SOUZA, N. T. C. Responsabilidade civil do hospital. Jus Navigandi, Teresina, a. 6, n. 54, fev. 2002. Disponível em: < http://www1.jus.com.br/doutrina/texto.asp?id=2638 $>$. Acessado em 03 de junho de 2004. 
SOUZA, N. T. C. Responsabilidade civil do médico. Jus Navigandi, Teresina, a. 6, n. 54, fev. 2002. Disponível em: < http://www1.jus.com.br/doutrina/texto.asp?id=2582 >. Acessado em 03 de junho de 2004.

TEFAS A., PITAS I. Image Authentication using Chaotic mixing systems. In: ISCAS 2000, May 2000.

TRICHILI H., BOUHLEL M.-S., DERBEL N., KAMOUN L. In: 2002 IEEE International Conference on Systems, Man and Cybernetics. Session MP1B, 2002.

U. R. A., BHAT P. S., KUMAR S., MIN L.C. Transmission and storage of medical images with patient information. Computers in Biology and Medicine, 33:303-210, 2003.

WAKATANI A. Digital watermarking for ROI medical images by using compressed signature image. $35^{\text {th }}$ Hawaii International Conference on Systems Sciences, Proceedings of, $2043-2048,2002$

WHITING D., SCHNEIER B., LUCKS S., MULLER F. Phelix - Fast Encryption and Authentication in a Single Cryptographic Primitive. Disponível em < http://www.schneier.com/paper-phelix.pdf $>$. Acessado em 20 de fevereiro de 2006.

WONG P.W. A watermark for image integrity and ownership verification. In: IS\&T PIC Conference, Proceedings of, 1997.

WONG S.T.C., ABUNDO M., HUANG, H.K. Authenticity techniques for PACS images and records. SPIE 2435 (1995), 68-79, 1995.

YEUNG M., MINTZER C. An invisible watermarking technique for image verification. In: Proceedings of ICIP 1997.

YOUNG, R. R. Effective Requirements Practices. Addison-Wesley, 2001. 
ZHOU, X.Q., HUANG H.K. Authenticity and integrity of digital mammography images. Medical Imaging, IEEE Transactions on, 20(8):784 - 791, 2001. 


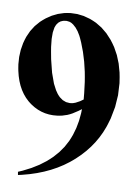

\section{Apêndice}

\subsection{Lista de publicações do doutorando}

KOBAYASHI, L.O.M, FURUIE, S.S, BARRETO, P.S.L.M. Providing Integrity and Authenticity in DICOM Images: a Novel Approach. Submetido para publicação à IEEE Transactions on Information Technology in Biomedicine, 2007.

KOBAYASHI, L.O.M, FURUIE, S.S. Proposal for DICOM Multiframe Medical Image Integrity and Authenticity. Aprovado para publicação à Journal of Digital Imaging, 2007.

KOBAYASHI, L.O.M, FURUIE, S.S. Segurança em informações médicas: visão introdutória e panorama atual. Revista Brasileira de Engenharia Biomédica, 23(1): 57-82, 2007.

KOBAYASHI, L.O.M, FURUIE, S.S. Abordagem Alternativa para Segurança em Imagens Médicas. In CBIS’2006, 2006.

KOBAYASHI, L.O.M, FURUIE, S.S. Segurança em Imagens Médicas: uma Revisão. In CBIS'2006, 2006.

KOBAYASHI, L.O.M., FURUIE, S.S. Implementation of integrity and authenticity oriented to information flow for radiological images. In: RSNA'2005, 2005. 
KOBAYASHI, L.O.M., MOTTA, G.H.M.B., FURUIE, S.S. Análise dos Requisitos Tecnológicos para Implementação de Segurança Fim-a-Fim em Imagens Médicas. In: CLAEB 2004, 2004.

KOBAYASHI, L.O.M., FURUIE, S.S. End-to-end security architecture for radiological images. In: RSNA'2004, 2004. 


\subsection{Glossário de termos relativos à segurança}

Os padrões ISO 7498-2 e ISO 8732 oferecem definições básicas para a maioria dos conceitos tratados dentro deste trabalho. Ao mesmo tempo, os padrões e grupos ISO/IEC 9594-8 / CCITT X.509, European ITSEC e SEISMED / CEN / TC251 / WG6 oferecem mais algumas definições complementares para alguns outros conceitos utilizados.

Assinatura Digital: dados anexos a, ou uma transformação criptografada de, uma unidade de dados que permite um recipiente da unidade a provar a fonte e a integridade dos dados e proteger contra falsificação, por exemplo, pelo recipiente.

Autenticação: estabelecimento da validade de uma identidade alegada. A informação de autenticação pode ser transferida a terceiros e prova a identidade do responsável a eles.

Autenticidade: a propriedade de um dado objeto de apresentar meios de verificar a sua procedência e a sua originalidade. É um serviço similar à Garantia de Autoria.

Chave Criptográfica: um parâmetro usado com um algoritmo para validar, autenticar, criptografar ou decriptografar uma mensagem (ISO 8732)

Controle de acesso: a prevenção do uso não autorizado de um recurso, incluindo as prevenções do uso de um recurso de maneira não autorizada.

Criptossistema ou sistema criptográfico: uma coleção de trasformações de texto simples para texto cifrado e vice-versa, as transformações particulares a serem usados sendo selecionadas por chaves. As transformações são normalmente definidas por um algoritmo matemático (ISO/IEC 9594-8 / CCITT X.509)

Disponibilidade: a propriedade de todas as entidades terem acesso à informação. 
Garantia de Autoria (ou Irretratabilidade): a propriedade de uma dada entidade ser incapaz de invalidar o reconhecimento correto sobre a origem da informação.

Gerenciamento de chaves: a geração, armazenamento, distribuição, remoção, arquivamento e aplicação de chaves (criptográficas) de acordo com uma política de segurança.

Identificação: estabelece a validade de uma identidade alegada. A informação de identificação não prova a identidade do reclamante a terceiros, já que o receptor da informação de identificação pode ter sido o autor da informação. (SEISMED / CEN / TC251 / WG6)

Integridade: a propriedade de que os dados não foram nem alterados nem destruídos de maneira não autorizada.

Masquerade: a pretensão de uma entidade de se passar por uma entidade diferente.

Privacidade: o direito de indivíduos de controlar ou influenciar quais informações relacionadas a eles podem ser coletadas e armazenadas e para quem tais informações podem ser reveladas.

Segurança: a combinação de confidencialidade, integridade e disponibilidade (European ITSEC). 
